\title{
Tables and Graphs of the Stable Probability Density Functions*
}

\author{
Donald R. Holt
}

Institute for Basic Standards, National Bureau of Standards, Boulder, Colorado 80302

and

\author{
Edwin L. Crow
}

Institute for Telecommunication Sciences, Office of Telecommunications, Boulder, Colorado 80302

(May 4, 1973)

\begin{abstract}
Four-decimal-place tables are presented of the probability density function $p(x ; \alpha, \beta)$ of the stable distribution for $\alpha=0.25(.25) 2.00, \beta=-1.00(.25) 1.00$, and nonnegative $x$ in steps varying by factors of 10 from 0.001 to 100 such that interpolation is possible, the tabulation being terminated where $p(x ; \alpha, \beta)$ falls to 0.0001 . The largest such value of $x$ is 338 , for $\alpha=0.25, \beta=-1.00$. Graphs of $p(x ; \alpha, \beta)$ are also provided for essentially the above values of $\alpha$ and $\beta$. The methods of calculation (from the characteristic function), checking, and interpolation with respect to $x, \beta$, and (to some extent) $\alpha$ are described. The most important properties of stable distributions are summarized. Some applications are cited. A selected bibliography with 91 items is included.
\end{abstract}

Key words: Accuracy; approximations; asymptotic expansion; Cauchy distribution; characteristic function; closed forms; contour; convergence; curves; distribution function; error; Fourier transform; infinite series; interpolation; limit distribution; normal distribution; polynomials; probability density function; quadrature; stable distribution; sums of independent random variables; tables; truncation.

\section{Contents}

1. Introduction'.....

2. Definition and properties of stable di

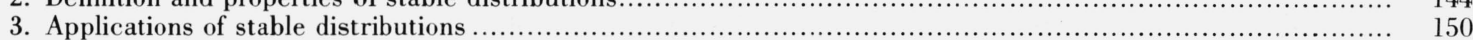



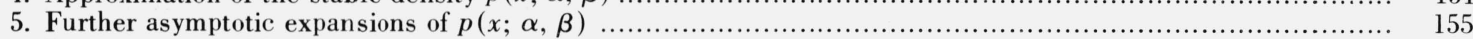

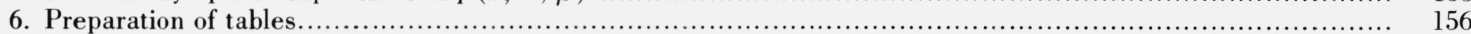

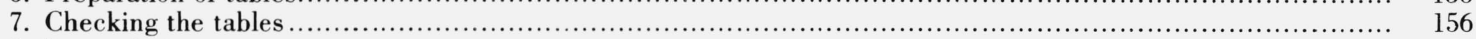

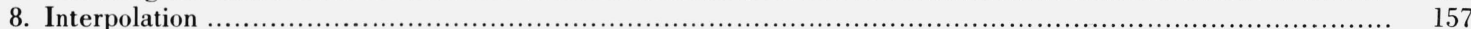

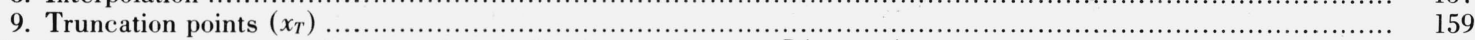

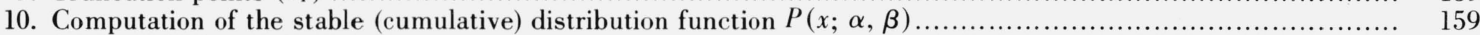

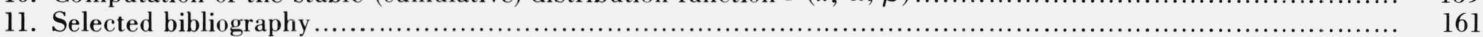

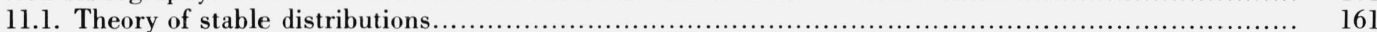

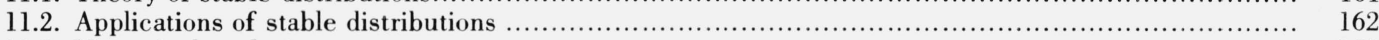

11.3. Numerical analysis . . . . .

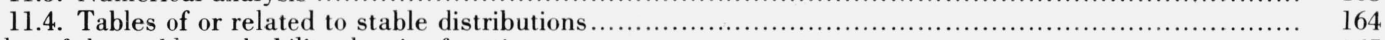

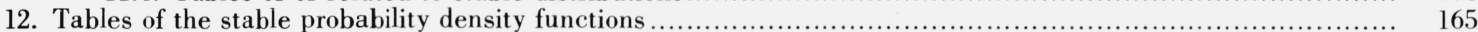

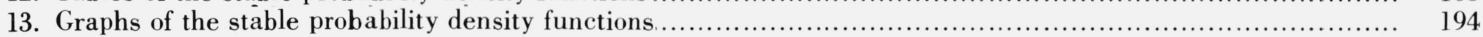

\footnotetext{
AMS Subject Classification: 60-00.

*The paper was begun when the second author was employed by the National Bureau of Standards, continued while he worked for the Environmental Science Services Administration (now National Oceanic and Atmospheric Administration), and completed under the Office of Telecommunications, all in Boulder, Colorado.
} 


\section{Introduction}

The stable distributions have provided a fascinating and fruitful area of research for probability theorists and models of value in physics, astronomy, economics, and communications theory. The symmetric stable distributions were introduced by Cauchy in 1853 [4], ${ }^{1}$ and one of them is well known by his name. The general class was studied systematically by Paul Lévy in the early 1920's $[18 \mathrm{a}, 19]$. If two independent real random variables with the same shape or type of distribution are combined linearly and the distribution of the resulting random variable has the same shape, the common distribution (or its type, more precisely) is said to be stable. The normal, or Gaussian, distribution is the best-known example.

The inspiration for systematic research on stable distributions was the desire to generalize the celebrated Central Limit Theorem, which states that under fairly general conditions, the distribution function $(d f)$ of the sum of $n$ independent random variables approaches (when standardized to constant median and scale) the normal $d f$ as $n$ becomes infinite. It was known that the mean of $n$ independent observations from a Cauchy distribution has the same distribution as a single observation, which is thus also the limit distribution as $n \rightarrow \infty$ and not covered by the Central Limit Theorem. It can be shown that all limit distributions of sums of independent random variables must be stable [Lévy, 19; Gnedenko and Kolmogorov, 11].

The restrictive condition of stability enabled A. Ya. Khintchine and Lévy in 1936 [see 11, p. 164] to derive the general form for the characteristic function ( $c f$, the Fourier transform of the probability density function $(p d f)$ ) of a stable distribution. However, the $p d f$ itself is not known in closed form except for the normal and Cauchy types and one other type (see sec. 2.13).

The considerable interest in stable distributions makes a general set of tables of the densities and distribution functions highly desirable. A table of $p d f^{\prime}$ 's for characteristic exponent $\alpha=1.1(.1) 1.9$, 1.95, 1.99 was given by Mandelbrot and Zarnfaller in 1961 [88]. Fama and Roll [85] published tables of the $d f$ 's and fractiles of standardized symmetric stable distributions for characteristic exponent $\alpha=1.0(.1) 1.9(.05) 2.0$ (as well as formulas and tables for estimating the parameters). Here we present four-decimal-place tables (sec. 12) of the standardized $p d f p(x ; \alpha, \beta)$ for $\alpha=$ $0.25(.25) 2.00, \beta=-1.00(.25) 1.00$, and nonnegative $x$ in steps varying by factors of 10 from 0.001 to 100 such that interpolation is possible. The tabulation is terminated where $p(x ; \alpha, \beta)$ first falls to 0.0001 , correct to the fourth decimal place. The largest such value of $x$ is 338 , for $\alpha=0.25$, $\beta=-1.00$. Graphs of $p(x ; \alpha, \beta)$ are also provided for the above values of $\alpha$ and $\beta$ (sec. 13). The methods of calculation, checking, and interpolation are described in detail (secs. 4-8). Probabilities may be calculated from the tables by Simpson's Rule (sec. 10).

The theory and properties of stable distributions have been systematically presented by Lukacs [23, 24], Gnedenko and Kolmogorov [11], and Feller [44], but a brief statement, without proofs, of the most important properties, taken from these sources, especially [24], is given in section 2 for convenience. Some applications are noted in section 3. An extensive selected bibliography is included (sec. 11).

\section{Definition and Properties of Stable Distributions}

\subsection{Definition.}

The (cumulative) distribution function $(d f), P(x)$, of a real random variable $X$ is the probability that $X$ is less than or equal to the real number $x$ :

$$
P(x) \equiv \operatorname{Prob}[X \leqslant x], \quad-\infty<x<+\infty .
$$

${ }^{1}$ Figures in brackets indicate the literature references on pages 161-164. 
(The definition of a random variable is omitted, being outside the scope of this paper.)

\subsection{Definition.}

The probability density function $(p d f)$, of $X$ is (when it exists or, equivalently, when $P(x)$ is absolutely continuous) the derivative of the $d f$ :

$$
p(x) \equiv P^{\prime}(x) \equiv d P / d x, \quad-\infty<x<+\infty .
$$

\subsection{Definition.}

The characteristic function $(c f)$ of $X$ is the Fourier-Stieltjes transform of the $d f$ :

$$
\begin{aligned}
\varphi(t) & \equiv \int_{-\infty}^{\infty} e^{i t x} d P(x), \quad-\infty<t<+\infty, \\
& =\int_{-\infty}^{\infty} e^{i t x} p(x) d x
\end{aligned}
$$

when $p(x)$ exists.

2.4. The $d f, p d f$ (when it exists), and $c f$ are alternative and equivalent ways of describing a probability distribution, and it is at times convenient and sufficient to say "distribution" rather than $d f, p d f$, or $c f$. When the $p d f p(x)$ exists,

$$
p(x)=\frac{1}{2 \pi} \int_{-\infty}^{\infty} e^{-i x t} \varphi(t) d t
$$

\subsection{Definition.}

If $X$, and $X_{2}$ are two independent random variables with $d f^{\prime}{ }_{s} P_{1}(x)$ and $P_{2}(x)$ and $c f^{\prime} \mathrm{s} \varphi_{1}(t)$ and $\varphi_{2}(t)$, then the $d f P(x)$ of the sum $X \equiv X_{1}+X_{2}$ is given by the convolution of $P_{1}(x)$ and $P_{2}(x)$ :

$$
P(x)=P_{1}(x) * P_{2}(x) \equiv \int_{-\infty}^{\infty} P_{1}(x-y) d P_{2}(y)
$$

The corresponding $c f$ is $\varphi(t)=\varphi_{1}(t) \varphi_{2}(t)$.

\subsection{Definition.}

Two $d f^{\prime}$ s $P(x)$ and $Q(x)$ are of the same type if there exist a postive $c$ and real $d$ such that the relation $Q(x)=P((x-d) / c)$ holds for all $x$.

\subsection{Definition.}

A $d f P(x)$ (or any $d f$ of the same type as $P(x))$ is stable if to every $c_{1}>0, c_{2}>0$ and real $d_{1}, d_{2}$ there correspond a positive $c$ and real $d$ such that

$$
P\left(\frac{x-d_{1}}{c_{1}}\right) * P\left(\frac{x-d_{2}}{c_{2}}\right) \equiv P\left(\frac{x-d}{c}\right)
$$


for all $x$. An equivalent condition for $P(x)$ to be stable is the following: If $X_{1}$ and $X_{2}$ are independent random variables with the $d f P(x)$, then the $d f$ of $c_{1} X_{1}+c_{2} X_{2}$ is of the same type as $P(x)$ for every $c_{1}>0, c_{2}>0$. Stability is really a property of the type of distribution rather than of any single distribution, but we may attribute it conveniently to a $d f$, a $p d f$, or a $c f$ also, just as we speak of the normal distribution when we mean the normal type.

2.8. A $c f \varphi(t)$ is stable if and only if it has the form

$$
\varphi(t)=\exp \left\{i d t-|c t|^{\alpha}[1+i \beta(t /|t|) \omega(|t|, \alpha)]\right\}
$$

where $-\infty<d<+\infty, c \geqslant 0,0<\alpha \leqslant 2,-1 \leqslant \beta \leqslant 1$, and

$$
\omega(|t|, \alpha)= \begin{cases}\tan (\pi \alpha / 2) & \text { for } \alpha \neq 1 \\ (2 / \pi) \log |t| & \text { for } \alpha=1 .\end{cases}
$$

(Here $c$ is the scale parameter as in Fama and Roll [85] but not as in Lukacs [23, 24]. If the $c$ of Lukacs is denoted by $c^{\prime}$, then $c^{\prime}=c^{\alpha}$.) The constant $\alpha$ is called the characteristic exponent. (Unfortunately the above definitions of $\omega$ produce the heavier tail of the $p d f$ in the positive $x$ direction for $\alpha=1$ and in the negative $x$ direction for $\alpha \neq 1$. Thus there is an apparent inconsistency in the tables and graphs.)

\subsection{Degenerate distribution.}

If $c=0$, the stable $c f$ reduces to that of the degenerate (improper) distribution with $d f$

$$
P(x)=\left\{\begin{array}{l}
0, x<d \\
1, x \geqslant d .
\end{array}\right.
$$

\subsection{Normal distribution.}

If $\alpha=2$, the stable $c f$ reduces to that of the normal distribution with mean $d$ and variance $2 c^{2}$ (independent of the value of $\beta$ ).

\subsection{Cauchy distribution.}

If $\alpha=1$ and $\beta=0$, the stable $c f$ reduces to that of the Cauchy distribution with median $d$, semi-interquartile range $c$, and $p d f$

$$
\frac{1}{\pi} \cdot \frac{c}{c^{2}+(x-d)^{2}}
$$

For $c=1$ and $d=0$ this reduces to the Student $t p d f$ with 1 degree of freedom.

2.12. The $c f$ of the standardized variable $(X-d) / c$ for $c>0$ is of the form in section 2.8 with $d=0$ and $c=1$. Hereafter (except in secs. 2.24 and 2.28) we therefore take $d=0$ and $c=1$ and write the $p d f$ of the standardized variable, by section 2.4 , as

$$
p(x ; \alpha, \beta)=\frac{1}{\pi} \int_{0}^{\infty} e^{-t^{\alpha}} \cos \left[x t+\beta t^{\alpha} \omega(t, \alpha)\right] d t .
$$


2.13. $\alpha=\frac{1}{2}, \beta=-1$.

Then the stable $c f$ corresponds to the $p d f$

$$
p\left(x ; \frac{1}{2},-1\right)=\left\{\begin{array}{cc}
(2 \pi)^{-1 / 2} x^{-3 / 2} e^{-1 /(2 x)} & \text { for } x>0 \\
0 & \text { for } x \leqslant 0 .
\end{array}\right.
$$

This is the $p d f$ of the reciprocal of a chi-square variable with 1 degree of freedom. It is also of Type $\mathrm{V}$ in the Pearson system of frequency curves. No stable distributions with $p d f$ 's that are elementary functions other than the four above are known.

\subsection{Higher transcendental functions.}

The stable densities for several rational values of $\alpha$ can be represented in terms of higher transcendental functions as follows:

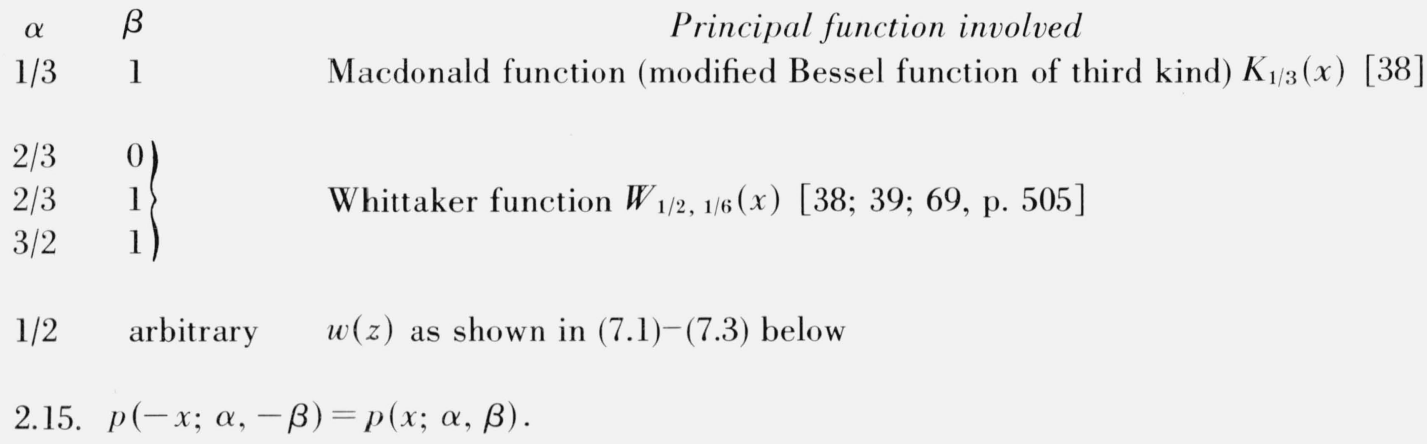

Hence we tabulate $p(x ; \alpha, \beta)$ only for nonnegative values of $x$.

\subsection{Continuity.}

All stable $d f$ 's are absolutely continuous. All stable $p d f$ 's are continuous.

\subsection{Regularity.}

The stable $p d f$ 's with $\alpha \geqq 1$ are regular (analytic) for all real $x$ and are entire functions except for the Cauchy distributions. The stable $p d f$ 's with $\alpha<1$ have the form

$$
p(x ; \alpha, \beta)= \begin{cases}(1 / x) \Phi_{1}\left(x^{-\alpha}\right) & \text { for } x>0 \\ (1 /|x|) \Phi_{2}\left(|x|^{-\alpha}\right) & \text { for } x<0\end{cases}
$$

where $\Phi_{1}(z)$ and $\Phi_{2}(z)$ are entire functions.

\subsection{Derivatives.}

Derivatives of the stable $p d f$ 's with respect to $x$ of all orders exist for all real $x$. They are bounded according to

$$
\left|\frac{\partial^{n} p(x ; \alpha, \beta)}{\partial x^{n}}\right| \leqslant \frac{1}{\pi \alpha} \Gamma\left(\frac{n+1}{\alpha}\right) .
$$


2.19. Unimodality.

All stable $p d f$ 's are unimodal.

2.20. Symmetry.

A stable $p d f$ is symmetrical if and only if $\beta=0$.

2.21. Convergent infinite series.

The stable $p d f$ 's have convergent infinite series representations. Let $x>0, \eta=\beta \tan (\pi \alpha / 2)$, $r=\left(1+\eta^{2}\right)^{-1 /(2 \alpha)}$, and $\gamma=-(2 / \pi)$ arctan $\eta$. Then the $p d f$ of the standardized variable evaluated at the abscissa $r x$ is, for $0<\alpha<1$,

$$
p(r x ; \alpha, \beta)=\frac{1}{\pi r x} \sum_{k=1}^{\infty} \frac{(-1)^{k-1}}{k !} \Gamma(\alpha k+1) x^{-\alpha k} \sin \left[\frac{k \pi}{2}(\alpha+\gamma)\right]
$$

and for $1<\alpha \leqslant 2$,

$$
p(r x ; \alpha, \beta)=\frac{1}{\pi r x} \sum_{k=1}^{\infty} \frac{(-1)^{k-1}}{k !} \Gamma\left(\frac{k}{\alpha}+1\right) x^{k} \sin \left[\frac{k \pi}{2 \alpha}(\alpha+\gamma)\right]
$$

A series in powers of $x$ exists for $\alpha=1$, but the coefficients are expressed only as complicated integrals.

\subsection{Asymptotic series.}

Asymptotic series are available for $x$ in the neighborhood of $0,+\infty$, or $-\infty$ and exhaustive ranges of values of $\alpha$ and $\beta$. In particular the first $n$ terms of the first series in section 2.21 is an asymptotic approximation for $x \rightarrow+\infty$ and $1<\alpha<2$. Likewise the first $n$ terms of the second series in section 2.21 is an asymptotic approximation for $x \downarrow 0$ and $0<\alpha<1$. (Note the interchange in the ranges of $\alpha$ from those for convergence in sec. 2.21.)

2.23. $x=0, \alpha \neq 1$.

By changes of variable in section 2.12 with $x=0$ and $\alpha \neq 1$ we obtain gamma functions and consequently

$$
p(0 ; \alpha, \beta)=\frac{1}{\pi \alpha} \Gamma\left(\frac{1}{\alpha}\right)\left(\cos \frac{\pi \gamma}{2}\right)^{1 / \alpha} \cos \frac{\pi \gamma}{2 \alpha},
$$

with $\gamma$ as in section 2.21.

In particular

$$
\begin{aligned}
& p(0 ; \alpha, 0)=\frac{1}{\pi \alpha} \Gamma\left(\frac{1}{\alpha}\right) ; \\
& p(0 ; \alpha, \pm 1)=0, \alpha<1 ; \\
& p\left(0 ; \frac{1}{2}, \beta\right)=\frac{2}{\pi} \frac{1-\beta^{2}}{\left(1+\beta^{2}\right)^{2}} \\
& p\left(0 ; \frac{1}{3}, \beta\right)=\frac{3 !}{\pi} \frac{1-\beta^{2}}{\left(1+\beta^{2} / 3\right)^{3}}
\end{aligned}
$$




$$
\begin{aligned}
& p\left(0 ; \frac{1}{4}, \beta\right)=\frac{4 !}{\pi} \frac{1-6 \eta^{2}+\eta^{4}}{\left(1+\eta^{2}\right)^{4}}, \quad \eta=\beta(\sqrt{2}-1) \\
& p\left(0 ; \frac{2}{3}, \beta\right)=\frac{3}{4 \sqrt{2 \pi}} \rho^{-3}(2-\rho)(1+\rho)^{1 / 2}, \quad \rho=\left(1+3 \beta^{2}\right)^{1 / 2} .
\end{aligned}
$$

2.24. Interrelation for $\alpha$ and $\alpha^{*}=1 / \alpha$.

It is convenient to consider a stable $p d f$ of the nonstandardized variable $Y=X / c$, where $c=[\cos (\pi \gamma / 2)]^{1 / \alpha}$ with $\gamma$ as in section 2.21. Let $1<\alpha \leqslant 2, \alpha^{*}=1 / \alpha, \gamma^{*}=(\gamma+\alpha-1) / \alpha$, and $p_{\alpha \gamma}(y)$ be the $p d f$ of $Y$. Then for $y>0$

$$
p_{\alpha} * \gamma *(y)=y^{-\alpha^{*}{ }_{-1}} p_{\alpha \gamma}\left(y^{-\alpha *}\right) .
$$

\subsection{Zero values of $p d f^{\prime}$ 's.}

If $0<\alpha<1$ and $\gamma=-\alpha$, then it follows from the first formula in section 2.21 that

$$
p(x ; \alpha, 1)=0 \text { for } x>0 .
$$

From section 2.15

$$
p(x ; \alpha,-1)=0 \text { for } x<0 \text { and } 0<\alpha<1 \text {. }
$$

\subsection{Infinite divisibility.}

A stable $c f$ is infinitely divisible; i.e., for every positive integer $n$ it can be expressed as the $n$th power of some $c f$. Equivalently we can say that for every positive integer $n$ a stable $d f$ can be expressed as the $n$-fold convolution of some $d f$.

\subsection{Moments.}

The absolute moment of order $\delta$ of a $d f P(x)$ is defined as

$$
\int_{-\infty}^{\infty}|x|^{\delta} d P(x) \text { or } \int_{-\infty}^{\infty}|x|^{\delta} p(x) d x
$$

when $p(x)$ exists. Every stable $d f$ with characteristic exponent $\alpha$ with $0<\alpha<2$ has finite absolute moments of all orders $\delta$ with $0<\delta<\alpha$, whereas all absolute moments of order $\delta \geqslant \alpha$ are infinite. Thus the normal $d f$ 's are the only stable $d f$ 's with finite variance. The mean exists for $1<\alpha \leqslant 2$, but neither the mean nor the variance exists for $0<\alpha \leqslant 1$.

\subsection{Location and scale parameters of a linear combination.}

If $X_{1}, X_{2}, \ldots, X_{n}$ are independent random variables with stable distributions of the same type (and therefore with the same $\alpha$ and $\beta$ ), location parameters $d_{1}, d_{2}, \ldots, d_{n}$, and scale parameters $c_{1}, c_{2}, \ldots, c_{n}$ respectively, then the linear combination

$$
Y=\sum_{i=1}^{n} a_{i} X_{i}, \quad a_{i} \geqslant 0
$$


has, from sections $2.3,2.5$, and 2.8 , the location parameter

$$
d=\sum_{i=1}^{n} a_{i} d_{i}
$$

and scale parameter $c$ given by

$$
c^{\alpha}=\sum_{i=1}^{n} a_{i}^{\alpha} c_{i}^{\alpha}
$$

The last equation is familiar for $\alpha=2$, the normal distribution, but is not so well known for other $\alpha$. In particular, if all $d_{i}=d_{1}, c_{i}=c_{1}$, and $a_{i}=1 / n$, so that $Y$ is the sample mean $\bar{X}$, then

$$
\begin{array}{ll}
c=\frac{c_{1}}{\sqrt{n}}, & \alpha=2(\text { normal }) \\
c=c_{1}, & \alpha=1(\text { Cauchy if } \beta=0) \\
c=n c_{1}, & \alpha=\frac{1}{2}(\text { Pearson Type } \mathrm{V} \text { if } \beta=-1)
\end{array}
$$

Thus the scale parameter (as well as the entire distribution) for $\alpha=1$ is the same for $\bar{X}$ as for $X_{1}$, but the scale parameter of $\bar{X}$ for $\alpha=\frac{1}{2}$ (and all other $\alpha<1$ ) increases without limit as $n \rightarrow \infty$.

\subsection{Importance in limit distributions.}

Let $Z_{1}, Z_{2}, \ldots, Z_{n}, \ldots$ be independent and identically distributed random variables. Let

$$
U_{n}=\frac{1}{B_{n}} \sum_{i=1}^{n} Z_{i}-A_{n}, \quad n=1,2, \ldots
$$

where $A_{1}, A_{2}, \ldots$ and $B_{1}, B_{2}, \ldots, B_{i}>0$, are sequences of constants. A well-known Central Limit Theorem states that if the $Z_{i}$ have a finite variance then the sequence of $d f$ 's of the $U_{n}$ converges to the standardized normal $d f$ for suitable choices of the $A_{i}$ and $B_{i}$. The normal $d f$ is not the only possible limit $d f$ for the $U_{n}$ in general, however: In order that a $d f$ be the limit $d f$ of a sequence of $d f$ 's of $U_{n}$ it is necessary and sufficient that it be a stable $d f$.

\section{Applications of Stable Distributions}

Beyond the pervasive occurrence of the normal distribution in practice as well as in theory, the primary interest in the stable distributions arises in probability theory as a result of their remarkable theoretical properties. However, they have also been applied in a wide variety of scientific fields, as indicated by the substantial but quite incomplete appended bibliography on applications. Feller's Volume II [44] discusses applications to the gravitational field of stars (Holtsmark distribution, $\alpha=3 / 2$; cf. Holtsmark, [48]), first-passage times in Brownian motion $(\alpha=1)$, diffusion theory, and economics.

Benoit Mandelbrot has discussed many applications in economics, including the distributions of income and of speculative prices and relating stable distributions to the well-known Pareto distributions [53-59, 61, 63]. He has also found stable distributions in biology [51, 62], psychology 
[52], and electrical engineering [60]. The occurrence in economics or business is also discussed by Press [66], Roll [67], Teichmoeller [68], Granger and Orr [47], and Fielitz and Smith [45].

The interest in economics led to the tabulation of the $c d f$ 's and fractiles of the symmetric stable distributions for $\alpha=1.0$ (.1) 2.0 by Fama and Roll [85] and to estimation of parameters and tests of hypotheses by them [86] and by Press [28]. A manuscript including the $c d f$ 's for certain asymmetric stable distributions $(\beta=-1(.25) 0)$ for $\alpha=1.1(.2) 1.9,2.0$, as well as graphs of the corresponding $p d f$ 's for $\alpha=1.1$ (.4) 1.9, has just been sent to us by M. J. Cross [84].

The infinite divisibility of the stable distributions accounts for their occurrence in the theory of stochastic processes with stationary independent increments; see Feller [44, Vol. II], Kolmogorov and Sevast'yanov [50], Kac [14], Berman [41], Getoor [10]; Greenwood [12], Kesten [15, 49], and Lukacs [25].

Other occurrences in electrical engineering are indicated by Dobrushin [42] and by Ovsevič and Yaglom [65].

\section{Approximation of the Stable Density $p(x ; \alpha, \beta)$}

The present tables of the stable $p d f p(x ; \alpha, \beta)$ were calculated primarily from four approximations:

$p_{1}$, the first $N$ terms of eq (4.1) below;

$p_{2},(4.12)$

$p_{3}$, Section 4.3;

$p_{4}$, Section 7.

The values of $\alpha$ and $\beta$ for which each of these is used are shown in table 1 .

TABLE 1. Approximations for the stable density $\mathrm{p}(\mathrm{x} ; \alpha, \beta)$

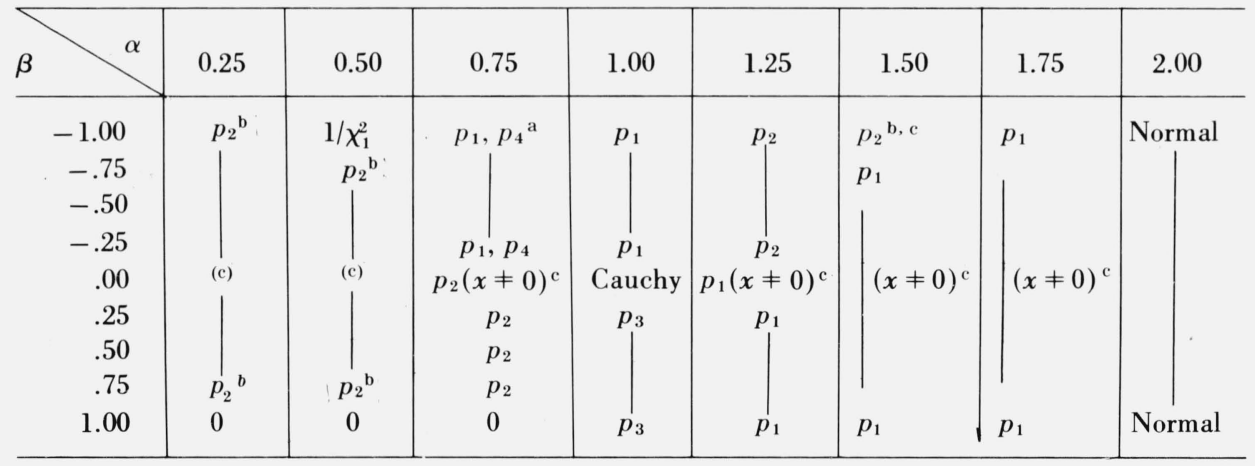

${ }^{\mathrm{a}} p_{1}$ for $0 \leqslant x \leqslant x_{N}, p_{4}$ for $x_{N} \leqslant x \leqslant x_{T}$

b $0<x_{0} \leqslant x \leqslant x_{T}$

${ }^{\mathrm{c}}$ See section 2.23

In all cases the $p d f$ is computed over the interval $0 \leqslant x \leqslant x_{T}$, where $x_{T}$ is such that $p\left(x_{T} ; \alpha, \beta\right)$ $=0.00010$ and $p\left(x_{T-1} ; \alpha, \beta\right)=0.00011$ with $x_{T}=x_{T-1}+0.1$. However, the tabulated $p d f$ values are rounded to 4 decimal places so that several values of $x$ usually exist for which $p(x ; \alpha, \beta)$ $=0.0001$. For $\alpha=0.75, \beta<0$, and $x$ large, say $x \geqslant x_{N}, p_{1}$ converges too slowly and $p_{4}$ is used for $x_{N} \leqslant x \leqslant x_{T}$. The approximation $p_{2}$ converges slowly for $x$ near 0 ; hence, it is used only for $x \geqslant x_{0}=10^{-n}, n=1,2,3$ with $n=3$ only where it is essential $(\alpha=0.25,0.50)$.

In sections $4.1-4.3$ we derive the approximations from the integral formula for $p(x ; \alpha, \beta)$ in section 2.12 . We assume $x \geqslant 0$ throughout the remaining sections. 
4.1. $p_{1}(x ; \alpha, \beta)$.

To obtain $p_{1}(x ; \alpha, \beta)$ we remove the branch point $t=0$ by setting $\alpha=p / q \neq 1(p, q$ positive integers) and $t=u^{q}$. Now consider the infinite series

$$
p(x ; \alpha, \beta)=\frac{q}{\pi} \sum_{k=0}^{\infty} \int_{u_{k}}^{u_{k+1}} e^{-u p} u^{q-1} \cos f_{1}(u ; \alpha, \beta, x) d u \quad\left(u_{0}=0\right)
$$

such that $u_{k}(k=0,1,2, \ldots)$ is the largest nonnegative real root of the function

$$
\left|f_{1}(u ; \alpha, \beta, x)\right|-k \pi \equiv\left|x u^{q}+\left(\beta \tan \frac{\pi \alpha}{2}\right) u^{p}\right|-k \pi
$$

To prove that the expansion (4.1) is an alternating series consider the proposition $u_{k+1}-u_{k \rightarrow 0}$ as $k \rightarrow \infty$. From (4.2) the difference equation for two successive extrema $u_{k}$ and $u_{k+1}$ yields

$$
x\left(u_{k+1}^{q}-u_{k}^{q}\right)+\eta\left(u_{k+1}^{p}-u_{k}^{p}\right)= \pm \pi
$$

where $\eta=\beta \tan (\pi \alpha / 2)$. Equation (4.3) can be written as

$$
u_{k+1}-u_{k}=\frac{ \pm \pi}{x g_{q-1}\left(u_{k}, u_{k+1}\right)+\eta g_{p-1}\left(u_{k}, u_{k+1}\right)}
$$

where $g_{n-1}\left(u_{k}, u_{k+1}\right)=u_{k+1}^{n-1}+u_{k+1}^{n-2} u_{k}+\ldots+u_{k}^{n-1}$. Since $u_{k} \rightarrow \infty$ as $k \rightarrow \infty$, it follows that $u_{k+1}$ $-u_{k} \rightarrow 0$.

We now show that for $k$ sufficiently large

$$
\begin{gathered}
\int_{u_{k}}^{u^{\prime}} e^{-u^{p}} u^{q-1}\left|\cos f_{1}(u ; \alpha, \beta, x)\right| d u \geqslant e^{-u^{\prime p}} u^{\prime q-1} \int_{u_{k}}^{u^{\prime}}\left|\cos f_{1}(u ; \alpha, \beta, x)\right| d u \\
\geqslant e^{-u^{\prime p}} u^{\prime q-1} \int_{u^{\prime}}^{u_{k+1}}\left|\cos f_{1}(u ; \alpha, \beta, x)\right| d u \\
\geqslant \int_{u^{\prime}}^{u_{k+1}} e^{-u^{p}} u^{q-1}\left|\cos f_{1}(u ; \alpha, \beta, x)\right| d u,
\end{gathered}
$$

where $\cos f_{1}\left(u_{k} ; \alpha, \beta, x\right)= \pm 1, \cos f_{1}\left(u^{\prime} ; \alpha, \beta, x\right)=0, \cos f_{1}\left(u_{k+1} ; \alpha, \beta, x\right)=\mp 1$, and $u_{k}<u^{\prime}$ $<u_{k+1}$. To demonstrate the middle inequality, let $v=x u^{q}+\eta u^{p}$. Then

$$
\int_{u_{k}}^{u^{\prime}}\left|\cos \left(x u^{q}+\eta u^{p}\right)\right| d u=\int_{v_{\max }}^{v_{0}}|\cos v| \frac{d v}{x q u^{q-1}+p \eta u^{p-1}},
$$

and, since $v_{\min }-v_{0}=v_{\max }-v_{0}=\pi / 2$, the inequality 


$$
\int_{v_{0}}^{v_{\min }}|\cos v| \frac{d v}{x q u^{q-1}+\eta p u^{p-1}} \leqslant \int_{v_{\max }}^{v_{0}} \frac{|\cos v|}{x q u^{q-1}+\eta p u^{p-1}} d v
$$

is true. Thus (4.4) is established. Since both the integrand and the interval $u_{k+1}-u_{k}$ approach zero as $k \rightarrow \infty$, so also does the $k$ th term of the series (4.1).

Similarly when $\alpha=1$ we have the infinite series

$$
p(x ; 1, \beta)=\frac{1}{\pi} \sum_{k=0}^{\infty} \int_{t_{k}}^{t_{k+1}} e^{-t} \cos f_{2}(t ; \beta, x) d t \quad\left(t_{0}=0\right)
$$

such that $t_{k}$ is the largest nonnegative real root of the equation

$$
\left|f_{2}(t ; \beta, x)-k \pi\right|=\left|x t+\frac{2 \beta}{\pi} t \ln \mathrm{t}\right|-k \pi \quad(k=0,1, \ldots) .
$$

It is easy to show that $t_{k+1}-t_{k} \rightarrow 0$ as $k \rightarrow \infty$ by substituting the expansion

$$
\begin{aligned}
\ln t_{k+1} & =\ln \left[t_{k}+t_{k+1}-t_{k}\right] \\
& =\ln t_{k}+2\left[\frac{t_{k+1}-t_{k}}{t_{k+1}+t_{k}}+\frac{1}{3}\left(\frac{t_{k+1}-t_{k}}{t_{k+1}+t_{k}}\right)^{3}+\ldots\right]
\end{aligned}
$$

into the difference equation

$$
x\left(t_{k+1}-t_{k}\right)+\frac{2 \beta}{\pi}\left(t_{k+1} \ln t_{k+1}-t_{k} \ln t_{k}\right)= \pm \pi .
$$

Hence we have

$$
t_{k+1}-t_{k}=\frac{ \pm \pi}{x+\frac{2 \beta}{\pi}\left[\ln t_{k}+2 \frac{t_{k+1}}{t_{k+1}+t_{k}}+\mathrm{O}\left(\frac{t_{k+1}-t_{k}}{t_{k}}\right)^{2}\right]}
$$

Since $t_{k} \rightarrow \infty$ as $k \rightarrow \infty$, it follows that $t_{k+1}-t_{k} \rightarrow 0$.

The fact that (4.5) is an alternating series follows in the same way as in establishing (4.4).

The approximation $p_{1}(x ; \alpha, \beta)$ is the truncation of (4.1) and (4.5) to $N$ terms with the $N$ th term the first term not greater than $10^{-5}$ in magnitude.

The zeros $u_{k}$ and $t_{k}$ are computed via the Newton-Raphson (NR) and False Position (FP) root-finding procedures. The NR procedure is used in the following cases, for which the necessary sign conditions certainly hold:

$$
\left.\begin{array}{l}
\alpha=\frac{3}{2},-1<\beta<0 \\
\alpha=\frac{7}{4}, \beta<0
\end{array}\right\} 0<x_{0}<x \leqslant x_{T} .
$$

In the remaining cases the $\mathrm{FP}$ procedure is applied. 
Determining the initial values, say $u_{k, 0}$ and $t_{k, 0}$, for the NR and FP procedures in the presence of arbitrary fixed $(x, \alpha, \beta)$ requires a little care. For the NR procedure the following initial values were used:

$$
\begin{gathered}
u_{0}\left(x_{i}\right)=0, u_{k, 0}\left(x_{0}\right)=1(k=1,2, \ldots), \quad u_{1,0}\left(x_{i}\right)=u_{1}\left(x_{i-1}\right), \\
u_{k, 0}\left(x_{i}\right)=u_{k-1}\left(x_{i}\right)(k=2,3, \ldots), \quad(i=0,1, \ldots)
\end{gathered}
$$

where $u_{k}\left(x_{i}\right)$ is the root of eq (4.2) with $x=x_{i}$.

A table of initial values for the FP procedure is available on request.

We denote the $k$ th integral of (4.1) (i.e., not including the factor $q / \pi$ ) by $T_{k}$, normalize the interval of integration to $[-1,1]$, and approximate $T_{k}$ by 48-point Legendre-Gaussian quadrature. Hence, the quadrature representation becomes

$$
\begin{gathered}
T_{k} \doteq A_{k} \sum_{j=1}^{48} H_{j} w_{j k}^{q-1} e^{-w_{j k}^{p}} \cos \left(x w_{j k}^{q}+\eta w_{j k}^{p}\right), \\
w_{j k}=A_{k} v_{j}+B_{k}, A_{k}=\frac{u_{k+1}-u_{k}}{2}, \text { and } B_{k}=\frac{u_{k+1}+u_{k}}{2},
\end{gathered}
$$

where $H_{j}$ and $v_{j}$ are Gaussian weights and abscissas respectively [79, p. 30].

The approximation for (4.5) parallels the approximation for (4.1); hence we omit that formulation.

Although the approximation $p_{1}(x ; \alpha, \beta)$ may be used for any given $(\alpha, \beta, x)$, experience showed that the other approximations below required less computer time for the desired accuracy over certain ranges of $\alpha, \beta, x$ as shown in table 1 .

$4.2 p_{2}(x ; \alpha, \beta)$

Consider the contour integral

$$
\frac{1}{\pi} \int_{C} \exp \left[-w^{\alpha}+i\left(x w+\eta w^{\alpha}\right)\right] d w \quad(\alpha \neq 1)
$$

taken on the path in figure 1.

Along the $t$ axis (4.9) reduces to $p(x ; \alpha, \beta)$ in the limit as $\epsilon \rightarrow 0$ and $R \rightarrow \infty$. The integral along $C_{1}$, say $I_{1}$, is bounded by

$$
\left|I_{1}\right| \leqslant R \int_{0}^{\pi / 2} \exp \left[-R^{\alpha}(\cos \alpha \theta+\eta \sin \alpha \theta)-x R \sin \theta\right] d \theta
$$

Hence, $I_{1} \rightarrow 0$ as $R \rightarrow \infty$. The contribution on $C_{2}$ goes to zero as the branch point is approached, and consequently, equating real parts yields

$$
\begin{gathered}
p(x ; \alpha, \beta)=\frac{1}{\pi} \int_{0}^{\infty} \exp \left(-x t-D_{1} t^{\alpha}\right) \sin D_{2} t^{\alpha} d t, \\
D_{1}=\cos \frac{\alpha \pi}{2}+\beta \tan \frac{\pi \alpha}{2} \sin \frac{\pi \alpha}{2}, D_{2}=(1-\beta) \sin \frac{\pi \alpha}{2},
\end{gathered}
$$

where $D_{1} \geqslant 0$ is sufficient for the integral to converge $\left(D_{1}>0\right.$ for $\left.x=0\right)$. 
Employing the transformation $t^{1 / q}=u$ in (4.11), applying 48-point Legendre-Gaussian quadrature between each extremum pair of the function $\sin D_{2} u^{P}$ and normalizing the $j$ th interval to $[-1,1]$ yields the approximation

$$
p_{2}(x ; \alpha, \beta)=\frac{q}{\pi}\left(\frac{\pi}{2 D_{2}}\right)^{q / p} \sum_{k=0}^{N} C_{1 k}\left\{\sum_{j=0}^{48} H_{j} z_{j k}^{q-1} \cdot \exp \left\{-\left[x\left(\frac{\pi}{2 D_{2}}\right)^{q / p} z_{j k}^{q}+\frac{D_{1} \pi}{2 D_{2}} z_{j k}^{p}\right]\right\} \sin \frac{\pi}{2} z_{j k}^{p}\right.
$$

where

$$
\begin{aligned}
z_{j k} & =C_{1 k} v_{j}+C_{2 k}, \\
C_{1 k} & =\frac{1}{2}\left[(2 k+1)^{1 / p}-(2 k-1)^{1 / p}\right], \\
C_{2 k} & =\frac{1}{2}\left[(2 k+1)^{1 / p}+(2 k-1)^{1 / p}\right], \quad k=1,2, \ldots, N, \\
C_{10} & =C_{20}=\frac{1}{2},
\end{aligned}
$$

$H_{j}$ and $v_{j}$ are Gaussian weights and abscissas respectively, and $N$ is determined so that the $N$ th term is the first term not greater than $10^{-5}$ in magnitude.

\section{$4.3 p_{3}(x ; 1, \beta)$.}

Using a different contour integration, Skorohod [32, p. 161] obtained a useful alternative integral formula for $\alpha=1$ :

$$
p(x ; 1, \beta)=\frac{1}{\pi} \int_{0}^{\infty} \exp [-x u-(2 / \pi) \beta u \ln u] \sin [(1+\beta) u] d u .
$$

The approximation $p_{3}(x ; 1, \beta)$ is obtained by applying the 48-point Legendre-Gaussian quadrature formula to each term of the convergent alternating series arising from (4.13) when it is divided at successive extrema of $\sin (1+\beta) u$.

\section{Further Asymptotic Expansions of $p(x ; \alpha, \beta)$}

A double series expansion of the product exp $\left(-D_{1} t^{\alpha}\right) \sin D_{2} t^{\alpha}$ in (4.11), an interchange of integration and summation, and the application of Watson's lemma yields

$$
p(x ; \alpha, \beta) \sim \frac{1}{\pi} \sum_{k=0}^{\infty} \sum_{l=0}^{\infty} \frac{(-1)^{k+l}}{k !(2 l+1) !} D_{1}^{k} D_{2}^{2 l+1} \frac{\Gamma[(k+2 l+1) \alpha+1]}{x^{(k+2 l+1) \alpha+1}}(\alpha \neq 1)
$$

as $x \rightarrow \infty$.

Expanding the integrand of (4.13) yields

$$
\begin{gathered}
p(x ; 1, \beta)=\frac{1}{\pi}\left[(1+\beta) \int_{0}^{\infty} e^{-x t} t d t-\frac{2 \beta}{\pi}(1+\beta) \int_{0}^{\infty} e^{-x t} t^{2} \ln d t\right. \\
-\frac{(1+\beta)}{3 !} \int_{0}^{\infty} e^{-x t} t^{3} d t+\left(\frac{2 \beta}{\pi}\right)^{2}(1+\beta) \int_{0}^{\infty} e^{-x t} t^{3} \ln ^{2} t d t+\frac{2 \beta}{\pi}(1+\beta)^{3} \\
\left.\times \int_{0}^{\infty} e^{-x t} t^{4} \ln t d t-\left(\frac{2 \beta}{\pi}\right)^{3}(1+\beta) \int_{0}^{\infty} e^{-x t} t^{4} \ln ^{3} t d t+\ldots\right]
\end{gathered}
$$


With the aid of integral tables [74, pp. 576-578] we obtain the incomplete asymptotic expansion

$$
\begin{gathered}
p(x ; 1, \beta) \sim \frac{1}{\pi} \frac{(1+\beta)}{x^{2}}-\frac{2^{2} \beta(1+\beta)}{\pi^{2} x^{3}}[\psi(3)-\ln x] \\
+\left[\frac{12 \beta^{2}}{\pi^{2}}(1+\beta)\left\{[\psi(4)-\ln x]^{2}+\zeta(2,3)\right\}-(1+\beta)^{3}\right] \frac{1}{x^{4}} \\
+\left[\frac{8(1+\beta)^{3} \beta}{\pi}[\psi(5)-\ln x]-\frac{2^{5} \beta^{3}}{\pi^{3}}(1+\beta)\left\{[\psi(5)-\ln x]^{3}\right.\right. \\
+[2 \psi(5)-3 \ln x] \zeta(2,4)-2 \zeta(3,4)\}] \frac{1}{x^{5}}, x \rightarrow \infty,
\end{gathered}
$$

which is valid for $\beta>0$. The symbols $\psi$ and $\zeta$ represent the digamma and generalized Riemann zeta functions

$$
\psi(z)=\frac{d \ln \Gamma(z)}{d z} \text { and } \zeta(z, q)=\sum_{n=0}^{\infty} \frac{1}{(q+n)^{z}}
$$

\section{Preparation of Tables}

To tabulate $p d f$ values computer programs were prepared from the various approximations. Since values of the $p d f$ were both printed and punched, the two sets of values were compared to safeguard against mechanical errors. In the vicinity of the maximum of each $p d f$ we employed a variable mesh size in the $x$ direction which depended on $|d p(x ; \alpha, \beta) / d x|$. Hence, for $\alpha \leqslant \frac{1}{2}$, $\Delta x=0.001,0.01$, or 0.1 ; for $\alpha=\frac{3}{4}, \Delta x=0.01$ or 0.1 ; and for $\alpha \geqslant 1, \Delta x=0.1$. On the $p d f$ tails most of the original values with a mesh size $\Delta x=0.1$ were discarded in favor of linear interpolation with steps $\Delta x=1,10$, or 100 . Consequently, after reading all $p d f$ values into the computer, we deleted unnecessary values, rounded the remaining ones to four decimal places, and punched the results on cards. After some trial and error the appended printout (reduced in size) was obtained from the punched cards.

\section{Checking the Tables}

In addition to the previous cross checking, the appropriate approximations, closed forms, and special values were compared. We also made spot checks by using

(a) $p_{1}(x ; 1, \beta)$ over $\beta>0$;

(b) $p_{5}(x ; 1, \beta)$ over $\beta>0$, for large values of $x$ near $x_{T}$;

(c) $p_{4}(x ; \alpha, \beta)$ over $\alpha \neq 1, \beta<1$ for large values of $x$ near $x_{T}$;

(d) $p_{6}(x ; \alpha, \beta)$ over $\alpha \neq 1$, for values of $x$ near 0 .

Approximation $p_{5}(x ; 1, \beta)$ is the truncation of the asymptotic expansion (5.3), two terms of which were generally required for agreement with the tabulated $p d f$ values. The approximations $p_{4}(x$; $\alpha, \beta)$ and $p_{6}(x ; \alpha, \beta)$ are the truncations of the first and second expansions of section 2.21 respectively. (See sec. 2.22 for asymptotic properties of the two expansions of sec. 2.21.) 
By use of the following equations of V. M. Zolotarev [38, p. 166], an additional check is available for $\alpha=\frac{1}{2}$. He showed that

where

$$
p\left(x ; \frac{1}{2}, \beta\right)=\operatorname{Re}\left\{\frac{z}{\pi x}\left[\pi^{1 / 2} e^{-z^{2}}-2 i w(z)\right]\right\}
$$

$$
w(z)=e^{-z^{2}} \int_{0}^{z} e^{t^{2}} d t, \quad z=\frac{1+\beta-i(1-\beta)}{2 \sqrt{2} x}
$$

By setting $w(z)=u(p,-q)+i v(p,-q)$ and $z=p-i q$ we obtain

$$
p\left(x ; \frac{1}{2}, \beta\right)=\frac{1}{\pi^{1 / 2}}(2 x)^{-3 / 2} e^{-\beta /(2 x)}\left[(1+\beta) \cos \frac{1-\beta^{2}}{4 x}+(1-\beta) \sin \frac{1-\beta^{2}}{4 x}-\frac{2}{\pi x}(q u-p v)\right] .
$$

Karpov [78] tabulates $u$ and $v$ from $w\left(\rho e^{i \theta}\right)$. Checking of several tabulated $p d f$ values corresponding to $\beta=0.25$ and $\beta=1$ reveals no error in our tables greater than $10^{-4}$.

Many of the tabulated values of $p(x ; 1.5, \pm 1)$ were checked with values found in a report by Mandelbrot and Zarnfaller [88]; no discrepancy was found. A check is also available from Fama and Roll's [85] 4-place table of $c d f$ 's for $\beta=0$ and $\alpha=1.0(0.1) 2.0$; see section 10 .

To detect blunders which escaped the preceding checks, $p d f$ values from the punched cards were subjected to differencing of orders 1 through 12. Miller [80] states that blunders may occur when sixth and tenth difference magnitudes greater than 22 and 300 respectively appear. Using this technique uncovered several entries which were obviously erroneous.

\section{Interpolation}

\subsection{Interpolation with respect to $\mathrm{x}$.}

To reduce the size of the table of $p d f$ values it is necessary to establish appropriate degree interpolation polynomials over certain intervals of $x$ for each $p(x ; \alpha, \beta)$. We justify this interpolation by noting the analytic properties of $p(x ; \alpha, \beta)$.

For $\alpha \geqslant 1$, (except $\alpha=1$ and $\beta=0), p(x ; \alpha, \beta)$ is an entire function of $x$ [sec. 2.17]. Hence, a sequence of interpolating polynomials $\left\{p_{n}(x)\right\}$ converges uniformly to $p(x ; \alpha, \beta)$ over a given closed interval [71]. For $\alpha<1,|d p(x ; \alpha, \beta) / d x|$ becomes large at or near $x=0$. Therefore, interpolation over $\left[0, x_{s}\right]$, for some small $x_{s}$ is difficult. However, away from $x=0, p(x ; \alpha, \beta)$ is an analytic function even for $\alpha<1$ [23], so that some $\left\{p_{n}(x)\right\}$ provides interpolation for $p(x ; \alpha, \beta)$ for $x>x_{s}$.

The Lagrange interpolation polynomial for $n$ equally spaced abscissas $x_{k}$ and corresponding ordinates $f_{k}$ is represented by

$$
f\left(x_{0}+p h\right)=\sum_{k} A_{k}^{n}(p) f_{k}+R_{n-1}
$$

where the index $k$ is defined via the inequalities

$$
\begin{gathered}
-\frac{1}{2}(n-2) \leqslant k \leqslant n / 2 \quad(n \text { even }), \\
-\frac{1}{2}(n-1) \leqslant k \leqslant \frac{1}{2}(n-1) \quad(n \text { odd }) .
\end{gathered}
$$

The coefficients $A_{k}^{n}(p)$ are defined in [69, p. 878] and tabulated in [69, pp. 900-913]. We computed a sample of $150-300 p d f$ values with $\Delta x=0.01$ (in contrast with $\Delta x=0.1$ for the tabulated $p d f$ values) around the maximum of each curve for $\alpha \geqslant 1$ and applied the Lagrange formula 
with $n=2(1) 8 ; p=0.1,0.5,0.9 ; h=0.1 ;$ and sliding intervals beginning with $0.00,0.01,0.02$, .... The interpolated points were compared with the computed points and all errors $(E)$ were tallied and classified according to the magnitudes:
(a) $|E| \geqslant 10^{-4}$,
(b) $10^{-4}>|E| \geqslant 0.5\left(10^{-4}\right)$,
(c) $0.5\left(10^{-4}\right)>|E|$.

An example below (table 2) illustrates this scheme:

$\alpha=1, \beta=-0.25,154$ points starting at $x=0.00$, i.e., $0.00 \leqslant x \leqslant 1.53$.

TABLE 2

\begin{tabular}{c|l|c|c|c|c}
\hline \hline$p$ & \multicolumn{1}{|c|}{$\begin{array}{c}\text { Degree of } \\
\text { interpolation }\end{array}$} & $\begin{array}{c}\text { Number of } \\
\text { errors in (a) }\end{array}$ & $\begin{array}{c}\text { Interval containing } \\
\text { errors in (a) }\end{array}$ & $\begin{array}{c}\text { Number of } \\
\text { errors in (b) }\end{array}$ & $\begin{array}{c}\text { Interval containing } \\
\text { errors in (b) }\end{array}$ \\
\hline 0.1 & 2 to $7^{\text {a }}$ & 0 & & 0 & \\
0.5 & 2 & 8 & {$[0.57,0.72]$} & 0 & {$[0.45,0.88]$} \\
0.5 & 3 to 7 & 0 & & 1 & \\
0.9 & 2 & 0 & & 0 & \\
0.9 & 3 to 7 & 0 & & & \\
\hline
\end{tabular}

a That is, each degree from 2 to 7 was used, and none of the formulas yielded any errors.

The interpolation results above illustrate that for $\alpha=1$ and $\beta=-0.25$ a third-degree polynomial succeeds over $[0.00,1.00]$. Furthermore, it appears that second-degree polynomial interpolation is successful for the tabulated $p d f$ values from $x=1.0$ to $x=10.0$. An additional examination of the $p d f$ values for $\alpha=1$ and $\beta=0.25$ reveals that linear interpolation is applicable beyond $x=10.0$ for $h=1$ and $0<p<1$; i.e., the next table entry corresponds to $x=11$ (instead of $x=10.1$ ). We summarize our results below in table 3 . Notice the range of application means, for instance, in the first line of table 3 that second-degree polynomial interpolation is valid for any three consecutive tabulated $p d f$ values from $x=2.0$ to $x=8.0$.

TABLE 3. Parameters for interpolation with respect to $\mathrm{x}$ for the tabulated values of $\mathrm{p}(\mathrm{x} ; \alpha, \beta)$ in section 13

\begin{tabular}{|c|c|c|c|c|}
\hline \multicolumn{5}{|c|}{ Error of interpolation $<5 \times 10^{-5}$} \\
\hline$\alpha$ & $\beta$ & $\begin{array}{c}\text { Degree of } \\
\text { interpolation }\end{array}$ & \multicolumn{2}{|c|}{$\begin{array}{l}\text { Range of } \\
\text { application }\end{array}$} \\
\hline 0.25 & $-1.00(0.25) 0.75$ & 2 & 2.0 & 8.0 \\
\hline \multirow[t]{2}{*}{0.50} & $-1.00(0.25)-0.25$ & $\begin{array}{l}3 \\
2\end{array}$ & $\begin{array}{l}2.0 \\
4.0\end{array}$ & $\begin{array}{r}4.0 \\
10.0\end{array}$ \\
\hline & $0.00(0.25) 0.75$ & 2 & 2.0 & 10.0 \\
\hline \multirow[t]{4}{*}{0.75} & -1.00 & $\begin{array}{l}5 \\
4 \\
3 \\
2\end{array}$ & $\begin{array}{l}2.0 \\
4.0 \\
6.0 \\
8.0\end{array}$ & $\begin{array}{r}4.0 \\
6.0 \\
8.0 \\
13.0\end{array}$ \\
\hline & -0.75 & $\begin{array}{l}4 \\
3 \\
2\end{array}$ & $\begin{array}{l}2.0 \\
5.0 \\
7.0\end{array}$ & $\begin{array}{r}5.0 \\
7.0 \\
13.0\end{array}$ \\
\hline & $-0.50,-0.25$ & $\begin{array}{l}3 \\
2\end{array}$ & $\begin{array}{l}2.0 \\
4.0\end{array}$ & $\begin{array}{r}4.0 \\
13.0\end{array}$ \\
\hline & $0.00(0.25) 0.75$ & 2 & 2.0 & 13.0 \\
\hline \multirow[t]{3}{*}{1.00} & -1.00 & 4 & 0.0 & 2.3 \\
\hline & $-0.75(0.25) 0.00$ & $\begin{array}{l}4 \\
3 \\
2\end{array}$ & $\begin{array}{l}0.0 \\
2.0 \\
4.0\end{array}$ & $\begin{array}{r}2.0 \\
4.0 \\
10.0\end{array}$ \\
\hline & $0.25(0.25) 1.00$ & $\begin{array}{l}3 \\
2\end{array}$ & $\begin{array}{l}0.0 \\
2.0\end{array}$ & $\begin{array}{r}2.0 \\
10.0\end{array}$ \\
\hline $1.25,1.50,1.75$ & All $\beta$ & 2 & 0.0 & 8.0 \\
\hline
\end{tabular}




\subsection{Interpolation with respect to $\beta$.}

The accuracy of polynomial interpolation with respect to $\beta$ was estimated from the remainder formulas for Lagrangian interpolation in the Handbook of Mathematical Functions [69, sec. 25.2, pp. 878-879]. The accuracy was also tested by extensive application of Lagrangian interpolation to the tabulated $p d f$ values using the interval on $\beta$ of 0.50 to interpolate the $p d f$ values at the midpoints of intervals and comparing with the corresponding tabulated values. We conclude that:

(a) $p(x ; \alpha, \beta)$ can be obtained accurate to 3 or 4 decimal places (DP) by at least one of 2-, 3-, or 4-point Lagrangian interpolation with respect to $\beta$ (using coefficients given in the Handbook $[69$, table 25.1, pp. 900-903]) for all $\beta$ for the tabulated $\alpha$ 's and any $x$ not too near to 0.0 .

(b) Higher than 4-point interpolation may not necessarily improve the accuracy since higherorder differences often do not decrease in magnitude.

(c) $p(0 ; \alpha, \beta)$ for $(\alpha, \beta)$ not in the table should always be calculated from the closed formula, section 2.23 (not applicable for $\alpha=1$ ).

Rule (a) cannot be easily stated more quantitatively. For sufficiently large $x$ linear interpolation with respect to $\beta$ yields $4 D P$ accuracy (i.e., within 1 unit in the 4th $D P$ ). As $x$ decreases, higherdegree interpolation is required for the same accuracy. For example, for $\alpha=0.25$ linear interpolation yields $4 D P$ accuracy for $x \geqslant 1.00$ but cubic is in general needed (and is sufficient) for $x=0.10$. For $\alpha=1$ quadratic interpolation yields $4 D P$ accuracy for $x \geqslant 2.0$, but only $3 D P$ can be attained for $x=0.5$, even if cubic or quartic interpolation is used.

\subsection{Interpolation with respect to $\alpha$.}

Interpolation with respect to $\alpha$ was investigated in the same way as that with respect to $\beta$. Unfortunately the results are mostly negative because there are as many as three local maxima with respect to $\alpha$ for tabulated values of $\beta \neq 0$ and $x$. We conclude that:

(a) For $\beta=0$, linear quadratic, or cubic interpolation with respect to $\alpha$ yields $3 D P$ accuracy for $x \geqslant 1.0$.

(b) For $\beta \neq 0$ quadratic interpolation may yield $2 D P$ or $3 D P$ accuracy for $\alpha>1.50$, but interpolation is unreliable for $\alpha<1.50$.

\section{Truncation Points $\left(x_{T}\right)$}

In section 4 we defined $x_{T}$ such that $p\left(x_{T} ; \alpha, \beta\right)=0.00010$ and $p\left(x_{T-1} ; \alpha, \beta\right)=0.00011$ with $x_{T}=x_{T-1}+0.1$. The last tabulated $p d f$ value is rounded to 0.0001 , and the tabulated $x$ is usually an integer, not the actual truncation point $x_{T}$. We show in table 4 the computed truncation points $x_{T}$ for every $(\alpha, \beta)$.

TABLE 4. Truncation points of $\mathrm{p}(\mathrm{x}: \alpha, \beta)$

\begin{tabular}{|c|c|c|c|c|c|c|c|c|c|c|}
\hline$\alpha \quad \beta$ & -1.00 & -0.75 & -0.50 & -0.25 & 0.00 & 0.25 & 0.50 & 0.75 & 1.00 & \\
\hline 0.25 & 413.2 & 367.6 & 321.2 & 274.0 & 225.6 & 175.8 & 123.6 & 68.7 & & .25 \\
\hline 0.50 & 251.2 & 227.8 & 203.6 & 178.3 & 151.7 & 123.2 & 91.9 & 55.6 & & .50 \\
\hline 0.75 & 140.9 & 129.3 & 117.1 & 104.2 & 90.4 & 75.2 & 58.0 & 37.1 & & .75 \\
\hline 1.00 & 2.3 & 26.8 & 39.2 & 48.4 & 56.5 & 63.5 & 70.1 & 76.2 & 81.9 & 1.00 \\
\hline 1.25 & 49.1 & 46.5 & 43.6 & 40.5 & 36.9 & 33.0 & 28.0 & 21.2 & 5.5 & 1.25 \\
\hline 1.50 & 32.4 & 30.6 & 28.8 & 26.9 & 24.1 & 22.3 & 19.6 & 14.6 & 4.8 & 1.50 \\
\hline 1.75 & 20.3 & 19.5 & 18.4 & 17.4 & 16.0 & 14.4 & 12.6 & 10.0 & 5.1 & 1.75 \\
\hline
\end{tabular}

\section{Computation of the Stable (Cumulative) Distribution Function $P(x ; \alpha, \beta)$}

In a very direct way it is possible to calculate the (cumulative) distribution function $P(x ; \alpha, \beta)$ of a stable distribution for the values of $\alpha$ and $\beta$ in table 1 except for the cases $(\alpha=1,|\beta| \leqslant 1)$, 
$(\alpha=0.75,|\beta| \leqslant 1),(\alpha>1,|\beta|=1)$. Assuming $\alpha \leqslant \frac{1}{2},|\beta| \leqslant 1$, we obtain a representation of $P(x ; \alpha, \beta)$ from (4.11) by an interchange of the order of integration:

$$
\begin{aligned}
P(x ; \alpha, \beta) & =\int_{-\infty}^{x} p\left(x^{\prime} ; \alpha, \beta\right) d x^{\prime}, \\
& =1-\frac{1}{\pi} \int_{0}^{\infty}\left[\frac{1}{t} e^{-x t-D_{1} t^{\alpha}}\right] \sin D_{2} t^{\alpha} d t(x>0) .
\end{aligned}
$$

Via the identity $p(-x ; \alpha, \beta)=p(x ; \alpha, \beta)$ we have from (10.1) the representation

$$
P(-x ; \alpha, \beta)=\frac{1}{\pi} \int_{0}^{\infty} \frac{1}{t} e^{-x t-D_{1}(\alpha, \beta) t^{\alpha}} \sin \left[D_{2}(\alpha,-\beta) t^{\alpha}\right] d t(x>0) .
$$

Hence, an approximation paralleling (4.12) requires only several terms for convergence in the $t$ direction.

To compute $P(x ; \alpha, \beta)$ for the category $(\alpha>1,|\beta|<1)$ we break up the interval of integrational $(-\infty, x)$ into two subintervals $(-\infty,-10)$ and $(-10, x)$. The contribution to $P(x ; \alpha, \beta)$ over the subinterval $(-\infty,-10)$ may be found from the approximation

$$
P_{4}(-10 ; \alpha, \beta)=\int_{10}^{\infty} p_{4}(x ; \alpha,-\beta) d x=\frac{1}{\pi} \sum_{n=0}^{N} \frac{A_{n}(\alpha,-\beta)}{\alpha n} 10^{-\alpha n}
$$

where $N=4$ usually suffices. Over the second subinterval $(-10, x)$ Simpson's rule is applied to the tabulated $p d f$ values by assuming the rounding error $\left( \pm 5 \times 10^{-5}\right)$ is uncorrelated from ordinate to ordinate. To carry this further, let $n / 2=100, x=10$, and $h=1$ in Simpson's rule,

$$
\begin{array}{r}
\int_{x_{0}}^{x_{n}} p(x ; \alpha, \beta) d x=\frac{h}{3}\left[p\left(x_{0} ; \alpha, \beta\right)+4 p\left(x_{0}+h, \alpha, \beta\right)+2 p\left(x_{0}+2 h ; \alpha, \beta\right)\right. \\
\left.+\ldots+p\left(x_{n}, \alpha, \beta\right)\right]-\left.\frac{n h^{5}}{180} \frac{d^{4}}{d x^{4}} p(x ; \alpha, \beta)\right|_{x=\xi},
\end{array}
$$

$x_{0}<\xi<x_{n}$. In view of the form of $(10.4)$ the total rounding error is less than $\frac{1}{3} \cdot \frac{1}{2}\left(10^{-4}\right)\left(2+100 \cdot 4^{2}\right.$ $\left.+99 \cdot 2^{2}\right) \frac{3}{\sqrt{3}} \doteq 1.3 \times 10^{-4}$. The factor $1 / \sqrt{3}$ results from the assumption of uniform distribution for individual ordinate rounding errors, and the factor 3 results from defining the "maximum" total rounding error as 3 times the standard deviation.

The integration error term of (10.4) has the bound (sec. 2.18)

$$
\left|\frac{n h^{5}}{180} \frac{d^{4}}{d x^{4}} p(\cdot x ; \alpha, \beta)\right| \leqslant \frac{n h^{5}}{180} \frac{1}{\pi \alpha} \Gamma\left(\frac{5}{\alpha}\right) .
$$

When $\alpha \geqslant 1$, the error bound (10.5) is not more than $2 \times 10^{-4}$ for $h=0.1$ and not more than $2 \times 10^{-9}$ for $h=0.01$.

Application of Simpson's rule (plus linear interpolation for intermediate $x$ ) to the three cases of explicit $p d f^{\prime}$ 's (normal, Cauchy, $1 / \chi_{1}^{2}$ ) indicates that the above bounds are conservative: (1) The maximum error of 7 normal probabilities calculated was $3 \times 10^{-7}$, attributable to rounding. (2) The maximum error of 59 Cauchy probabilities calculated was $8 \times 10^{-5}$ except in the tail where 
the steps in $x$ become 10, and then the maximum error was $3 \times 10^{-4}$. (3) The maximum error of twelve $1 / \chi_{1}^{2}(\alpha=0.5, \beta=-1)$ probabilities was $1.3 \times 10^{-5}$ for $x$ in steps of 0.01 and $3.6 \times 10^{-5}$ for $x$ in steps of 0.1 .

Values of $c d f$ for $\alpha=1.5, \beta=0$, as well as the above ones for $\alpha=1, \beta=0$ and $\alpha=2$, were derived for comparison with Fama and Roll's [85] 4-place table for $c d f$ 's for $\beta=0$ and $\alpha=1.0(0.1) 2.0$. In 39 comparisons there was only one difference (3) greater than 1 in the 4 th place.

The rather dense grid of values of $x$, as fine as 0.001 for the largest $p d f$ values, is an important contributor to the accuracy of calculation of probabilities. We conclude from the above that probabilities can be calculated by Simpson's rule plus linear interpolation with maximum error of $3 \times 10^{-4}$ for $\alpha \geqslant 1$. For $\alpha<1$ we have no rigorous error bound and the errors tend to be larger than for $\alpha \geqslant 1$, but calculated probabilities may well have satisfactory accuracies comparable to those above.

The authors thank Garney Hardy ${ }^{2}$ and Matthew Lojko ${ }^{3}$ of NBS for computer programming support. Stephen Jarvis, Jr., and John Sopka of NBS were especially helpful in their encouragement of this project.

\section{Selected Bibliography}

A few listed works, Feller's books in particular, may have material in more than one of the following four categories, but each is listed only once. Several Russian papers have English translations in "Selected Translations in Mathematical Statistics and Probability", published for the Institute of Mathematical Statistics by the American Mathematical Society, Providence, Rhode Island. These are identified below as AMS-IMS.

\subsection{Theory of Stable Distributions}

[1] Bergström, H., On some expansions of stable distribution functions, Ark. Mat. 2, 375-378 (1952).

[2] Bergström, H., On distribution functions with a limiting stable distribution function, Ark. Mat. 2, $463-474$ (1953).

[3] Bergström, H., Eine Theorie der stabilen Verteilungsfunktionen, Arch. Math., Karlsruhe 4, 380-391 (1953).

[4] Cauchy, A. Oeuvres Complètes, 1st ser., 12, Sur les résultats moyens d'observations de même nature, et sur les résultats les probables, 94-104; Sur la probabilité des erreurs qui affectent des résultats moyens d'observations de même nature, 104-114, Gauthier-Villars, Paris (1900). (Originals in C. R. Acad. Sci. Paris 37, 198 (Aug. 8, 1853) and 264 (Aug. 15, 1853)).

[5] Chao, C. J., Explicit formula for the stable law of distribution (Chinese. English summary), Acta Math. Sinica 7, 63-78 (1953). English version in Sci. Sinica 7, 565-581.

[6] Cramér, H., On the approximation to a stable probability distribution, pp. 70-76 in Studies in Mathematical Analysis and Related Topics: Essays in Honor of George Polya, ed. G. Szegö et al. (Stanford University Press, 1962).

[7] Darling, D. A., The maximum of sums of stable random variables, Trans. Amer. Math. Soc. 83, 164-169 (1956).

[8] Ferguson, T. S., A representation of the symmetric bivariate Cauchy distribution, Ann. Math. Statis. 33, 1256-1266 (1962).

[9] Fisz, M., Infinitely divisible distributions: Recent results and applications, Ann. Math. Statis. 33, 68-84 (1962).

[10] Getoor, R. K., The asymptotic distribution of the number of zero free intervals of a stable process, Trans. Amer. Math. Soc. 106, 127-138 (1963).

[11] Gnedenko, B. V., and Kolmogorov, A. N., Limit Distributions for Sums of Independent Random Variables, Chap. 7, English translation with notes by K. L. Chung (Addison-Wesley Publishing Co., Reading, Mass., 1954, revised 1968).

[12] Greenwood, P. E., The variation of a stable path is stable, Z. Wahrscheinlichkeitstheorie verw. Geb. 14, 140-148 (1969).

[13] Ibragimov, I. A., and Chernin, K. E., On the unimodality of stable laws, Theor. Probability Appl. 4, 417-419 (1959).

[14] Kac, M., Some remarks on stable processes with independent increments, pp. 130-138 in Probability and Statistics, The Harald Cramér Volume, ed. U. Grenander (John Wiley \& Sons, New York, 1959).

[15] Kesten, H., A convolution equation and hitting probabilities of single points for processes with stationary independent increments, Bull. Amer. Math. Soc. 75, 573-578 (1969).

[16] Kimbleton, S. R., A simple proof of a random stable limit theorem, J. Appl. Prob. 7, 502-504 (1970).

[17] Laha, R. G., On a characterization of the stable law with finite expectation, Ann. Math. Statist. 27, 187-195 (1956).

[18] Lamperti, J., Probability, A Survey of the Mathematical Theory, Secs. 16-17 (W. A. Benjamin, Inc. New York, 1966).

${ }^{2}$ Now with Office of Telecommunications, Boulder, Colorado.

${ }^{3}$ Now with National Oceanic and Atmospheric Administration, Boulder, Colorado. 
[18a] Lévy, P., Théorie des erreurs. La loi de Gauss et les lois exceptionelles, Bull. Société Math. France 52, 49-85 (1924). See also C. R. Acad. Sci. Paris 174, 855-857 (1922) and 176, 1118-1120 (1923).

[19] Lévy, P., Calcul des probabilités, Part II, Chap. 6 (Gauthier-Villars, Paris, 1925).

[20] Lévy, P., Théorie de l'addition des variables aléatoires, Secs. 30, 57-63 (Gauthiers-Villars, Paris, 1937; 2nd rev. ed., 1954).

[21] Linnik, Yu. V., On stable probability laws with exponent less than one (Russian), Dokl. Akad. Nauk SSSR 94, 619-621 (1954).

[22] Loéve, M., Probability Theory (D. Van Nostrand Co., Princeton, N.J., 3rd ed., 1963).

[23] Lukacs, E., Characteristic Functions, Chapter 5 (Hafner Publishing Co., New York, 1960; 2nd rev. ed., 1970).

[24] Lukacs, E., Stable distributions and their characteristic functions, Jahresbericht der Deutschen Math.-Vereinigung 71, 84-114 (1969).

[25] Lukacs, E., A characterization of stable processes, J. Appl. Prob. 6, 409-418 (1969).

[26] Menon, M. V., A characterization of the Cauchy distribution, Ann. Math. Statist. 33, 1267-1271 (1962).

[27] Pitman, E. J. G., and Williams, E. J., Cauchy-distributed functions of Cauchy variates, Ann. Math. Statist. 38, 916-918 (1967).

[28] Press, S. J., Estimation in univariate and multivariate stable distributions, J. Amer. Statist. Assoc. 67, 842-846 (1972).

[29] Prohorov, Yu. V., and Rozanov, Yu. A., Probability Theory, 186-189 (Springer-Verlag, New York, 1969).

[30] Sakovich, G. N., A single form for the conditions for attraction to stable laws, Theor. Probability Appl. 1, 322-325 (1956).

[31] Shimizu, R., Certain class of infinitely divisible characteristic functions, Ann. Inst. Statist. Math. 17, 115-132 (1965).

[32] Skorohod, A. V., Asymptotic formulas for stable distribution laws (Russian), Dokl. Akad. Nauk SSSR 98, 731-734 (1954). English translation, AMS-IMS 1, 157-161 (1961).

[33] Skorohod, A. V., On a theorem concerning stable distributions (Russian), Uspehi Mat. Nauk (N.S.) 9, 189-190 (1954). English translation, AMS-IMS 1, 169-170 (1969).

[34] Tucker, H. G., Convolutions of distributions attracted to stable laws, Ann. Math. Statist. 39, 1381-1390 (1968).

[35] Wintner, A., On the stable distribution laws, Amer. J. Math. 55, 335-339 (1933).

[36] Wintner, A., The singularities of Cauchy's distributions, Duke Math. J. 8, 678-681 (1941).

[37] Wintner, A., Cauchy's stable distributions and an "explicit formula” of Mellin, Amer. J. Math. 78, 819-861 (1956).

[38] Zolotarev, V. M., Expression of the density of a stable distribution with exponent $\alpha$ greater than one by means of a frequency with exponent $1 / \alpha$ (Russian), Dokl. Akad. Nauk SSSR 98, 735-738 (1954). English translation, AMSIMS 1, 163-167 (1961).

[39] Zolotarev, V. M., On analytic properties of stable probability laws (Russian), Vestnik Leningrad. Univ. 11, 49-52 (1956). English translation, AMS-IMS 1, 207-211 (1961).

[40] Zolotarev, V. M., Mellin-Stieltjes transforms in probability theory, Theor. Probability Appl. 2, $433-460$ (1957).

\subsection{Applications of Stable Distributions}

[41] Berman, S. M., A general arc sine law and its application to diffusion processes (Abstract), Notices of Amer. Math. Soc. 10, 567 (1963).

[42] Dobrushin, R. L., A statistical problem arising in the theory of detection of signals in the presence of noise in a multichannel system and leading to stable distribution laws, Theor. Probability Appl. 3, 161-173 (1958).

[43] DuMouchel, W. H., Stable distributions in statistical inference, Ph. D. dissertation, Dept. of Statistics, Univ. of Connecticut (1971).

[44] Feller, W., An Introduction to Probability Theory and Its Applications, Vol I: Sec. III.7 (3rd ed., 1968); Vol. II: Secs. II.4e-h; III. le-f; VI. 1-2, 10, 13; IX. 8; X. 7; XI. 5; XIII. 6-7; XVII. 4-6, 11, 12 (1966, 2nd ed., 1971) (John Wiley \& Sons, Inc., New York).

[45] Fielitz, B. D., and Smith, E. W., Asymmetric stable distributions of stock price changes, J. Amer. Statist. Assoc. 67, 813-814 (1972).

[46] Good, I. J., The real stable characteristic functions and chaotic acceleration, J. Roy. Statist. Soc. Ser. B 23, 180-183 (1961).

[47] Granger, C. W. J., and Orr, D., "Infinite variance" and research strategy in time series analysis, J. Amer. Statist. Assoc. 67, 275-285 (1972).

[48] Holtsmark, J., Über die Verbreiterung von Spektrallinien, Annalen der Physik 58, 577-630 (1919).

[49] Kesten, H., On a theorem of Spitzer and Stone and random walks with absorbing barriers, Ill. J. Math. 5, 246-266 (1961).

[50] Kolmogorov, A. N., and Sevast'yanov, B. A., The calculation of final probabilities for branching random processes, Dokl. Akad. Nauk SSSR 56, 783-786 (Russian) (1947).

[51] Mandelbrot, B., La distribution de Willis-Yule, relative au nombre d'espèces dans les genres taxonomiqùes, C. R. Acad. Sci. Paris 242, 2223-2226 (1956).

[52] Mandelbrot, B., Les lois statistiques macroscopiques du comportement (rôle de la loi de Gauss et des lois de Paul Lévy), Psychologie Francaise 3, 237-249 (1958). 
[53] Mandelbrot, B., Variables et processus stochastiques de Pareto-Lévy et la repartition des revenus, I \& II, C. R. Acad. Sci. Paris 249, 613-615 and 2153-2155 (1959).

[54] Mandelbrot, B., The Pareto-Lévy law and the distribution of income, Internat. Econ. Rev. 1, $79-106$ (1960).

[55] Mandelbrot, B., Stable Paretian random functions and the multiplicative variation of income, Econometrica 29, 517-543 (1961).

[56] Mandrelbrot, B., Sur certains prix spéculatifs: faits empiriques et modèle base sur les processus stables additifs de Paul Lévy, C. R. Acad. Sci. Paris 254, 3968-3970 (1962).

[57] Mandelbrot, B., The stable Paretian income distribution, when the apparent exponent is near two, Internat. Econ. Rev. 4, 111-115 (1963).

[58] Mandelbrot, B., New methods in statistical economics, J. Political Economy 71, 421-440 (1963).

[59] Mandelbrot, B., The variation of certain speculative prices, J. Business Univ. Chicago 36, 394-419 (1963).

[60] Mandelbrot, B., Some noises with $1 / \mathrm{f}$ spectrum, a bridge between direct current and white noise, IEEE Trans. Info. Th. IT-13, 289-298 (1967).

[61] Mandelbrot, B., The variation of some other speculative prices, J. Business Univ. Chicago 40, 393-413 (1967).

[62] Mandelbrot, B., and Gerstein, G. L., Random walk models for the spike activity of a single neuron, Biophysical J. 4, 41-68 (1964).

[63] Mandelbrot, B., and Taylor, H. M., On the distribution of stock price differences, Operations Res. 15, 1057-1062 (1967).

[64] Nahman, N. S., A discussion on the transient analysis of coaxial cables considering high-frequency losses, IRE Trans. Circuit Th. CT-9, 144-152 (1962). (See p. 148, eq. 19).)

[65] Ovsevič, I. A., and Yaglom, A. M., Monotonic transfer processes in homogeneous long lines, Izv. Akad. Nauk SSSR Otd. Tehn. Nauk, No. 7, 13-20 (Russian) (1954).

[66] Press, S. J., A compound events model for security prices, J. Business 40, 317-335 (1968).

[67] Roll, R., The efficient market model applied to U.S. Treasury bill rates, Doctoral dissertation, Graduate School of Business, Univ. of Chicago (1968).

[68] Teichmoeller, J., A note on the distribution of stock price changes, J. Amer. Statist. Assoc. 66, 282-284 (1971).

\subsection{Numerical Analysis}

[69] Abramowitz, M., and Stegun, I. A., Handbook of Mathematical Functions, Nat. Bur. Stand. (U.S.), Appl. Math. Ser. 55 (1964); 9th printing, 1970.

[70] Berezin, I. S., and Zhidkov, N. P., Computing Methods (Pergamon Press, Addison Wesley Pub. Co., Reading, Mass., 1965). Chap. 1, Errors; Chap. 2, Sec. 14, The Use of Interpolation in Computing Tables.

[71] Davis, P. J., Interpolation and Approximation, pp. 81-82, (Blaisdell Pub. Co., New York, 1963).

[72] de Balbine, G., and Franklin, J. N., The calculation of Fourier integrals, Math. of Computation 20,570-589 (1966).

[73] Fox. L., The Use and Construction of Mathematical Tables, Nat. Physical Lab. Mathematical Tables, Vol. 1 (H. M. Stationery Office, London, 1956).

[74] Gradshteyn, I. S., and Ryzhik, I. M., Tables of Integrals, Series, and Products (Academic Press, New York, 1965).

[75] Hildebrand, F. B., Introduction to Numerical Analysis (McGraw-Hill Book Co., Inc., New York, 1956), p. 449.

[76] Hurwitz, H., Jr., and Zweifel, P. F., Numerical quadrature of Fourier transform integrals, Math. Tables and Other Aids to Comp. 10, 140-149 (1956).

[77] Hurwitz, H., Jr., Pfeiffer, R. A., and Zweifel, P. F., Numerical quadrature of Fourier transform integrals, II, Math. Tables and Other Aids to Comp. 13, 87-90 (1959).

[78] Karpov, K. A., Tables of the Function $w=e^{-z^{2}} \int_{0}^{z} e^{x^{2}} d x$ in the Complex Domain (Pergamon Press, Macmillan, New York, 1965).

[79] Love, C. H., Abscissas and Weights for Gaussian Quadrature for $N=2$ to 100 and $N=125,150,175,200$, Nat. Bur. Stand. Monograph 98 (U.S. Government Printing Office, Washington, 1966).

[80] Miller, J. C. P., Checking by differences - I, Math. Tables and Other Aids to Comp. 4, 3-11 (1950).

[81] Nuttall, A. H., Numerical Evaluation of Cumulative Probability Distribution Functions Directly From Characteristic Functions (Navy Underwater Sound Lab., New London, Conn., Aug. 11, 1969).

[82] Ralston, A., A First Course in Numerical Analysis (McGraw-Hill Book Co., New York, 1965). Table checking by differences, pp. 50-52 and Exs. 12, 13, pp. 69-70.

\subsection{Tables of or Related to Stable Distributions}

[83] Bol'shev, L. N., Zolotarev, V. M., Kedrova, E. S., and Rybinskaya, M. A., Tables of cumulative functions of one-sided stable distributions, Theor. Probability Appl. 15, 299-309 (1968). Cdf's for $\beta= \pm 1, \alpha=0.1$ (0.1) 1.0, but with scale factors different from ours that make comparison difficult. We did not achieve a check in fact.

[84] Cross, M. J., Tables of the finite-mean nonsymmetric stable distributions as computed from their convergent and asymptotic series. Unpublished manuscript, 39 pp. (1973). $C d f$ for $\alpha=1.1(.2) 1.9,2.0 ; \beta=-1(.25) 0$. Graphs of $p d f$ for $\alpha=1.1(.4) 1.9 ; \beta=-1(.25) 0$. 
[85] Fama, E. F., and Roll, R., Some properties of symmetric stable distributions, J. Amer. Statist. Assoc. 63, 817-836 (1968). Includes $c d f$ 's and fractiles, $\alpha=1.0(0.1) 2.0$.

[86] Fama, E. F., and Roll, R., Parameter estimates for symmetric stable distributions, J. Amer. Statist. Assoc. 66, 331-338 (1971). Includes tables of distributions of estimators.

[87] Harter, H. L., New Tables of the Incomplete Gamma-Function Ratio and of Percentage Points of the Chi-Square and Beta Distributions, Aerospace Research Labs., USAF (U.S. Government Printing Office, Washington, 1964). For $c d f$ for $\alpha=0.5, \beta=-1$.

[88] Mandelbrot, B., and Zarnfaller, F., Five Place Tables of Certain Stable Distributions, IBM Research Report RC-421 (IBM Research Center, Yorktown, N.Y., Dec. 31, 1959). $P d f$ for $\beta=1$ and $\alpha=1.01,1.05,1.1(0.1) 1.9,1.95,1.99$.

[89] Nationsl Bureau of Standards, Table of Arctan $x$, Applied Math. Series 26 (U.S. Government Printing Office, Washington, 1953). $C d f$ for $\alpha=1, \beta=0$.

[90] National Bureau of Standards, Tables of Normal Probability Functions, Applied Math. Series 23, (U.S. Government Printing Office, Washington, 1953). 


\begin{tabular}{|c|c|c|c|c|c|c|c|c|c|}
\hline BETA & .00 & -.25 & .25 & -.50 & .50 & -.75 & .75 & -1.00 & $x$ \\
\hline $\begin{array}{l}0.000 \\
0.001 \\
0.002 \\
0.002 \\
0.003 \\
0.004\end{array}$ & $\begin{array}{l}7.6394 \\
5.6948 \\
4.6299 \\
3.9662 \\
3.5002\end{array}$ & $\begin{array}{l}6.8502 \\
6.3547 \\
5.3938 \\
4.7186 \\
4.2182\end{array}$ & $\begin{array}{l}6.8502 \\
4.4417 \\
3.5237 \\
2.9832 \\
2.6138\end{array}$ & $\begin{array}{l}4.8079 \\
6.1773 \\
5.6279 \\
5.0931 \\
4.6482\end{array}$ & $\begin{array}{l}4.8079 \\
2.8977 \\
2.2742 \\
1.9162 \\
1.6743\end{array}$ & $\begin{array}{l}2.2737 \\
5.0616 \\
5.1996 \\
4.9694 \\
4.6848\end{array}$ & $\begin{array}{l}2.2737 \\
1.3461 \\
1.0566 \\
0.8910 \\
0.7793\end{array}$ & $\begin{array}{l}0.0000 \\
3.1154 \\
4.0753 \\
4.2832 \\
4.2581\end{array}$ & $\begin{array}{l}0.000 \\
0.001 \\
0.002 \\
0.003 \\
0.004\end{array}$ \\
\hline $\begin{array}{l}0.005 \\
0.006 \\
0.006 \\
0.007 \\
0.008 \\
0.009\end{array}$ & $\begin{array}{l}3.1493 \\
2.8730 \\
2.6483 \\
2.4609 \\
2.3018\end{array}$ & $\begin{array}{l}3.8294 \\
3.5165 \\
3.2580 \\
3.0400 \\
2.8531\end{array}$ & $\begin{array}{l}2.3403 \\
2.1273 \\
1.9555 \\
1.8132 \\
1.6930\end{array}$ & $\begin{array}{l}4.2802 \\
3.9721 \\
3.7103 \\
3.4848 \\
3.2882\end{array}$ & $\begin{array}{l}1.4966 \\
1.3588 \\
1.2480 \\
1.1565 \\
1.0794\end{array}$ & $\begin{array}{l}4.4098 \\
4.1586 \\
3.9328 \\
3.7304 \\
3.5486\end{array}$ & $\begin{array}{l}0.6972 \\
0.6336 \\
0.5824 \\
0.5401 \\
0.5044\end{array}$ & $\begin{array}{l}4.1495 \\
4.0112 \\
3.8651 \\
3.7207 \\
3.5821\end{array}$ & $\begin{array}{l}0.005 \\
0.006 \\
0.007 \\
0.008 \\
0.009\end{array}$ \\
\hline $\begin{array}{l}0.01 \\
0.01 \\
0.02 \\
0.03 \\
0.004 \\
0.005\end{array}$ & $\begin{array}{l}2.1646 \\
1.3915 \\
1.0443 \\
0.8419 \\
0.7078\end{array}$ & $\begin{array}{l}2.6907 \\
1.7553 \\
1.3252 \\
1.0718 \\
0.9029\end{array}$ & $\begin{array}{l}1.5897 \\
1.0146 \\
0.7595 \\
0.6116 \\
0.5139\end{array}$ & $\begin{array}{l}3.1152 \\
2.0814 \\
1.5870 \\
1.2907 \\
1.0912\end{array}$ & $\begin{array}{l}1.0132 \\
0.6461 \\
0.4839 \\
0.3899 \\
0.3278\end{array}$ & $\begin{array}{l}3.3847 \\
2.3431 \\
1.8131 \\
1.4869 \\
1.2640\end{array}$ & $\begin{array}{l}0.4738 \\
0.3036 \\
0.2281 \\
0.1842 \\
0.1551\end{array}$ & $\begin{array}{l}3.4510 \\
2.5142 \\
1.9863 \\
1.6482 \\
1.4118\end{array}$ & $\begin{array}{l}0.01 \\
0.02 \\
0.03 \\
0.04 \\
0.05\end{array}$ \\
\hline $\begin{array}{l}0.06 \\
0.067 \\
0.07 \\
0.08 \\
0.09 \\
0.10\end{array}$ & $\begin{array}{l}0.6118 \\
0.5394 \\
0.4828 \\
0.4371 \\
0.3995\end{array}$ & $\begin{array}{l}0.7815 \\
0.6897 \\
0.6177 \\
0.5596 \\
0.5117\end{array}$ & $\begin{array}{l}0.4440 \\
0.3914 \\
0.3503 \\
0.3172 \\
0.2899\end{array}$ & $\begin{array}{l}0.9469 \\
0.8373 \\
0.7509 \\
0.6811 \\
0.6233\end{array}$ & $\begin{array}{l}0.2834 \\
0.2500 \\
0.2238 \\
0.2028 \\
0.1854\end{array}$ & $\begin{array}{l}1.1011 \\
0.9764 \\
0.8777 \\
0.7975 \\
0.7310\end{array}$ & $\begin{array}{l}0.1343 \\
0.1186 \\
0.1063 \\
0.0964 \\
0.0882\end{array}$ & $\begin{array}{l}1.2366 \\
1.1011 \\
0.9930 \\
0.9046 \\
0.8309\end{array}$ & $\begin{array}{l}0.06 \\
0.07 \\
0.08 \\
0.09 \\
0.10\end{array}$ \\
\hline $\begin{array}{l}0.11 \\
0.112 \\
0.12 \\
0.13 \\
0.114 \\
0.15\end{array}$ & $\begin{array}{l}0.3680 \\
0.3411 \\
0.3179 \\
0.2977 \\
0.2800\end{array}$ & $\begin{array}{l}0.4714 \\
0.4371 \\
0.4075 \\
0.3817 \\
0.3590\end{array}$ & $\begin{array}{l}0.2670 \\
0.2475 \\
0.2307 \\
0.2161 \\
0.2032\end{array}$ & $\begin{array}{l}0.5747 \\
0.5332 \\
0.4974 \\
0.4661 \\
0.4385\end{array}$ & $\begin{array}{l}0.1709 \\
0.1585 \\
0.1478 \\
0.1384 \\
0.1302\end{array}$ & $\begin{array}{l}0.6749 \\
0.6268 \\
0.5852 \\
0.5488 \\
0.5167\end{array}$ & $\begin{array}{l}0.0814 \\
0.0755 \\
0.0705 \\
0.0661 \\
0.0622\end{array}$ & $\begin{array}{l}0.7685 \\
0.7149 \\
0.6683 \\
0.6275 \\
0.5914\end{array}$ & $\begin{array}{l}0.11 \\
0.12 \\
0.13 \\
0.14 \\
0.15\end{array}$ \\
\hline $\begin{array}{l}0.16 \\
0.16 \\
0.17 \\
0.18 \\
0.19 \\
0.20\end{array}$ & $\begin{array}{l}0.2642 \\
0.2501 \\
0.2375 \\
0.2261 \\
0.2157\end{array}$ & $\begin{array}{l}0.3388 \\
0.3208 \\
0.3046 \\
0.2899 \\
0.2766\end{array}$ & $\begin{array}{l}0.1918 \\
0.1816 \\
0.1724 \\
0.1642 \\
0.1567\end{array}$ & $\begin{array}{l}0.4140 \\
0.3921 \\
0.3724 \\
0.3546 \\
0.3384\end{array}$ & $\begin{array}{l}0.1230 \\
0.1165 \\
0.1106 \\
0.1053 \\
0.1005\end{array}$ & $\begin{array}{l}0.4881 \\
0.4626 \\
0.4396 \\
0.4187 \\
0.3997\end{array}$ & $\begin{array}{l}0.0587 \\
0.0557 \\
0.0529 \\
0.0504 \\
0.0481\end{array}$ & $\begin{array}{l}0.5592 \\
0.5304 \\
0.5043 \\
0.4807 \\
0.4592\end{array}$ & $\begin{array}{l}0.16 \\
0.17 \\
0.18 \\
0.19 \\
0.20\end{array}$ \\
\hline $\begin{array}{l}0.21 \\
0.21 \\
0.22 \\
0.223 \\
0.224 \\
0.25\end{array}$ & $\begin{array}{l}0.2062 \\
0.1975 \\
0.1895 \\
0.1822 \\
0.1754\end{array}$ & $\begin{array}{l}0.2645 \\
0.2534 \\
0.2431 \\
0.2337 \\
0.2249\end{array}$ & $\begin{array}{l}0.1498 \\
0.1435 \\
0.1377 \\
0.1324 \\
0.1274\end{array}$ & $\begin{array}{l}0.3236 \\
0.3101 \\
0.2976 \\
0.2861 \\
0.2754\end{array}$ & $\begin{array}{l}0.0961 \\
0.0921 \\
0.0884 \\
0.0850 \\
0.0819\end{array}$ & $\begin{array}{l}0.3824 \\
0.3665 \\
0.3519 \\
0.3383 \\
0.3258\end{array}$ & $\begin{array}{l}0.0460 \\
0.0441 \\
0.0424 \\
0.0408 \\
0.0392\end{array}$ & $\begin{array}{l}0.4396 \\
0.4215 \\
0.4048 \\
0.3895 \\
0.3752\end{array}$ & $\begin{array}{l}0.21 \\
0.22 \\
0.23 \\
0.24 \\
0.25\end{array}$ \\
\hline $\begin{array}{l}0.26 \\
0.26 \\
0.27 \\
0.28 \\
0.29 \\
0.30\end{array}$ & $\begin{array}{l}0.1690 \\
0.1631 \\
0.1576 \\
0.1525 \\
0.1477\end{array}$ & $\begin{array}{l}0.2168 \\
0.2093 \\
0.2022 \\
0.1956 \\
0.1894\end{array}$ & $\begin{array}{l}0.1228 \\
0.1186 \\
0.1146 \\
0.11109 \\
0.1074\end{array}$ & $\begin{array}{l}0.2655 \\
0.2562 \\
0.2476 \\
0.2396 \\
0.2320\end{array}$ & $\begin{array}{l}0.0789 \\
0.0762 \\
0.0737 \\
0.0713 \\
0.0691\end{array}$ & $\begin{array}{l}0.3142 \\
0.3033 \\
0.2932 \\
0.2837 \\
0.2747\end{array}$ & $\begin{array}{l}0.0379 \\
0.0366 \\
0.0353 \\
0.0342 \\
0.0331\end{array}$ & $\begin{array}{l}0.3619 \\
0.3495 \\
0.3379 \\
0.3271 \\
0.3169\end{array}$ & $\begin{array}{l}0.26 \\
0.27 \\
0.28 \\
0.29 \\
0.30\end{array}$ \\
\hline $\begin{array}{l}0.31 \\
0.31 \\
0.32 \\
0.33 \\
0.34 \\
0.34\end{array}$ & $\begin{array}{l}0.1431 \\
0.1389 \\
0.1348 \\
0.11310 \\
0.1274\end{array}$ & $\begin{array}{l}0.1836 \\
0.1781 \\
0.1730 \\
0.1681 \\
0.1635\end{array}$ & $\begin{array}{l}0.1041 \\
0.1010 \\
0.0981 \\
0.0953 \\
0.0927\end{array}$ & $\begin{array}{l}0.2249 \\
0.2182 \\
0.2119 \\
0.2059 \\
0.2003\end{array}$ & $\begin{array}{l}0.0670 \\
0.0650 \\
0.0631 \\
0.0613 \\
0.0597\end{array}$ & $\begin{array}{l}0.2664 \\
0.2585 \\
0.2510 \\
0.2440 \\
0.2374\end{array}$ & $\begin{array}{l}0.0321 \\
0.0312 \\
0.0303 \\
0.0295 \\
0.0287\end{array}$ & $\begin{array}{l}0.3073 \\
0.2983 \\
0.2898 \\
0.2817 \\
0.2741\end{array}$ & $\begin{array}{l}0.31 \\
0.32 \\
0.33 \\
0.34 \\
0.35\end{array}$ \\
\hline $\begin{array}{l}0.36 \\
0.36 \\
0.37 \\
0.38 \\
0.39 \\
0.40\end{array}$ & $\begin{array}{l}0.1240 \\
0.1208 \\
0.11177 \\
0.1148 \\
0.11120\end{array}$ & $\begin{array}{l}0.1591 \\
0.1549 \\
0.1510 \\
0.1473 \\
0.1437\end{array}$ & $\begin{array}{l}0.0902 \\
0.0879 \\
0.0857 \\
0.0835 \\
0.0815\end{array}$ & $\begin{array}{l}0.1949 \\
0.1899 \\
0.1850 \\
0.1804 \\
0.1761\end{array}$ & $\begin{array}{l}0.0581 \\
0.0566 \\
0.0552 \\
0.0538 \\
0.0525\end{array}$ & $\begin{array}{l}0.2310 \\
0.2251 \\
0.2194 \\
0.2139 \\
0.2088\end{array}$ & $\begin{array}{l}0.0279 \\
0.0272 \\
0.0265 \\
0.0259 \\
0.0253\end{array}$ & $\begin{array}{l}0.2668 \\
0.2600 \\
0.2534 \\
0.2472 \\
0.2413\end{array}$ & $\begin{array}{l}0.36 \\
0.37 \\
0.38 \\
0.39 \\
0.40\end{array}$ \\
\hline
\end{tabular}




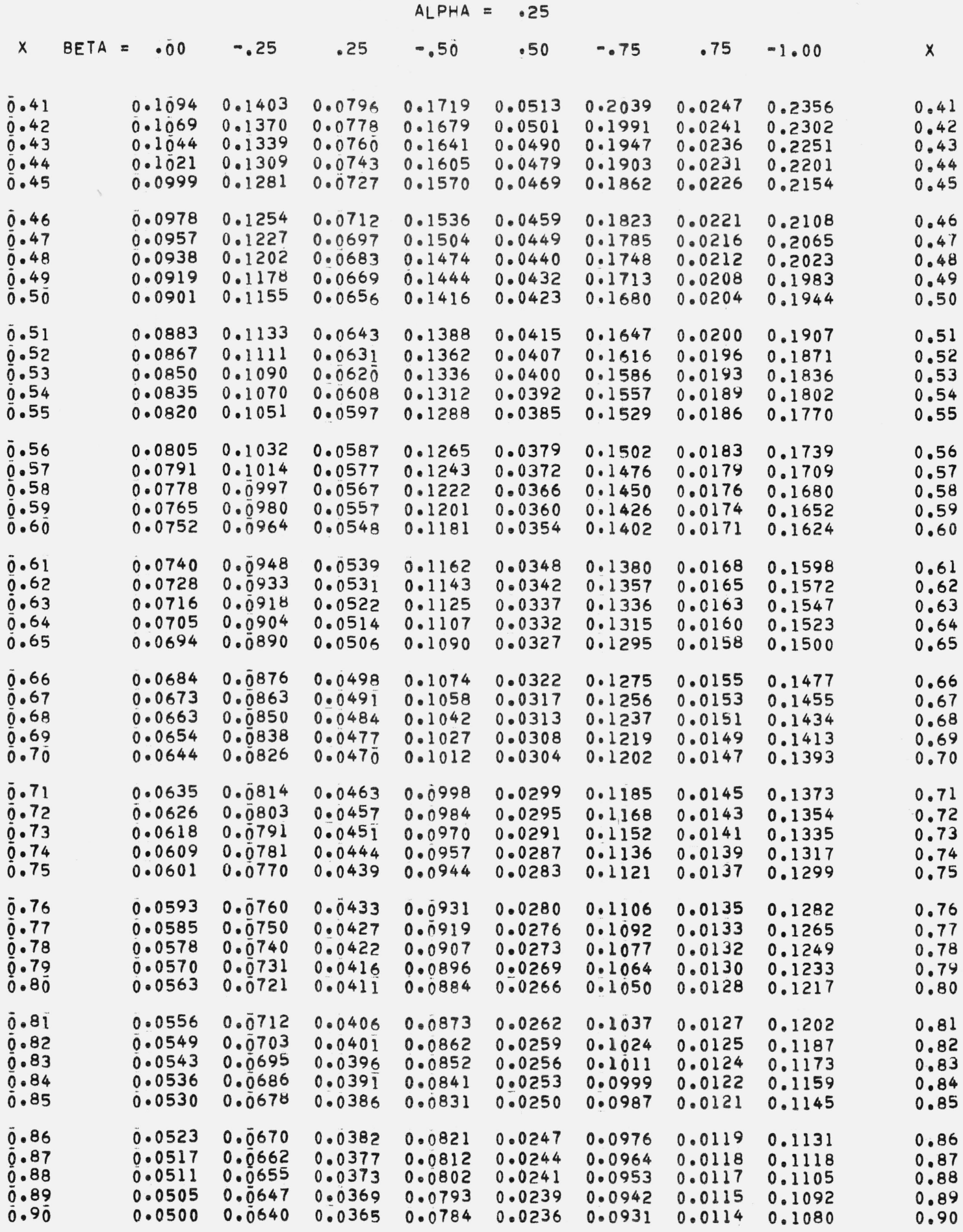




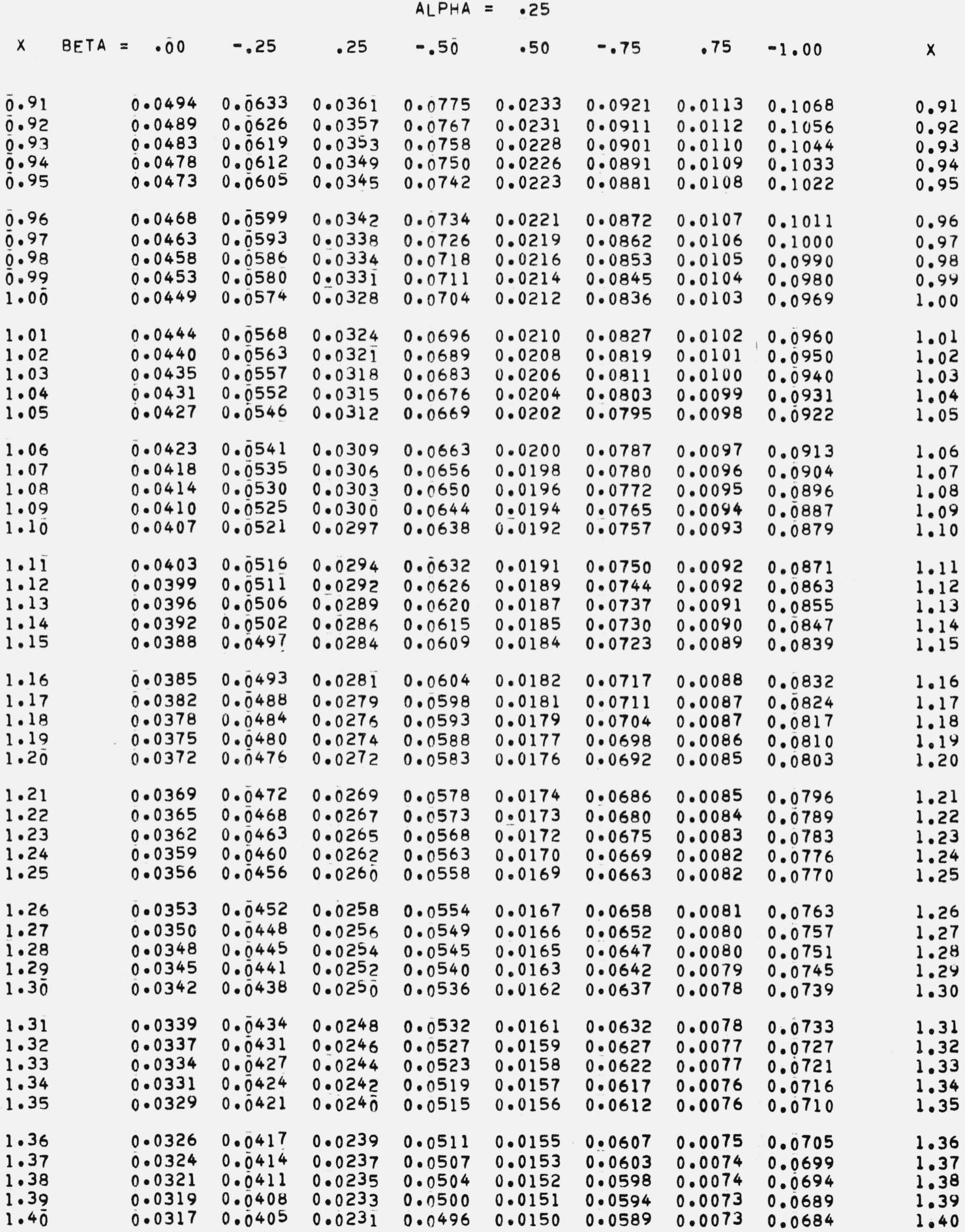




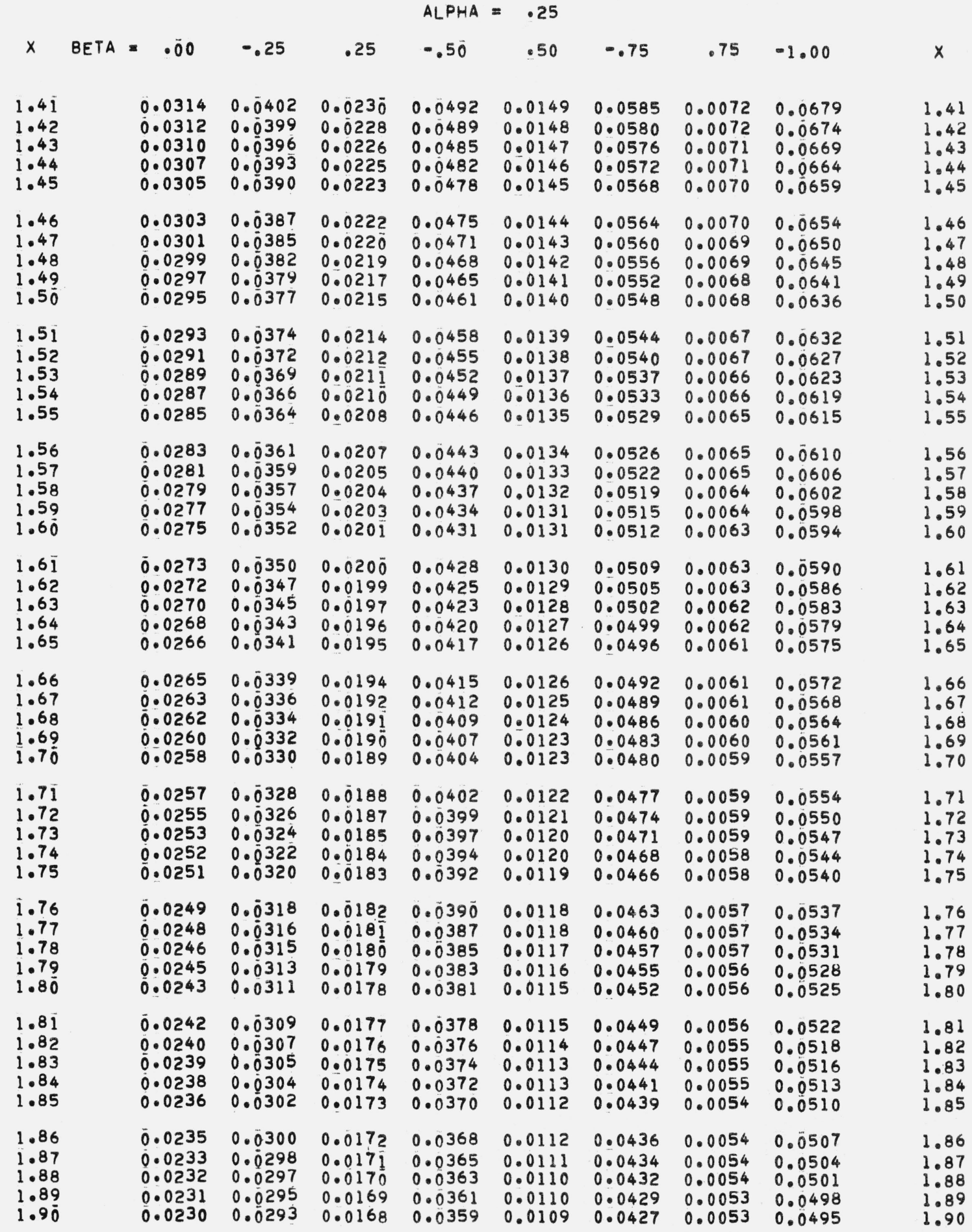




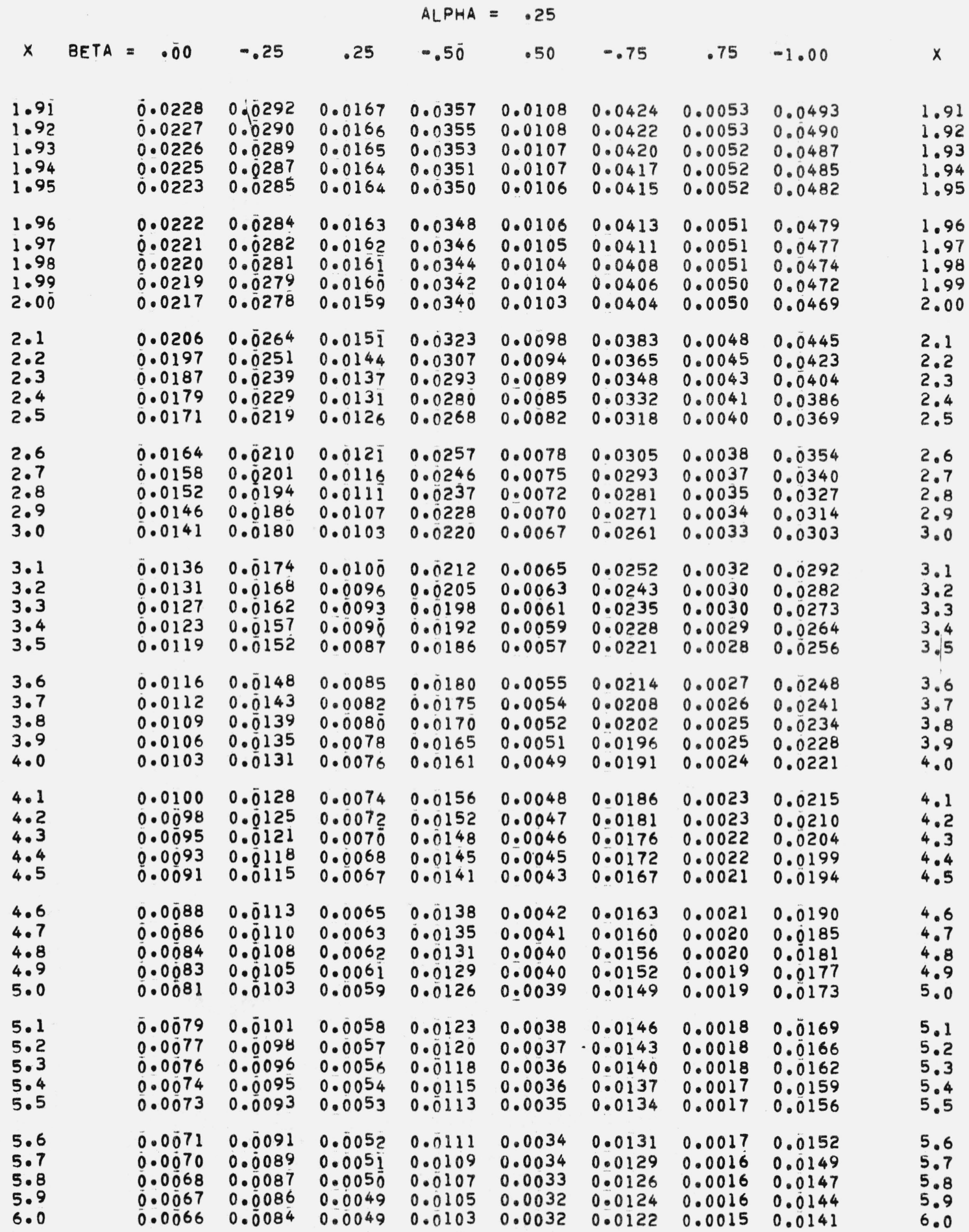




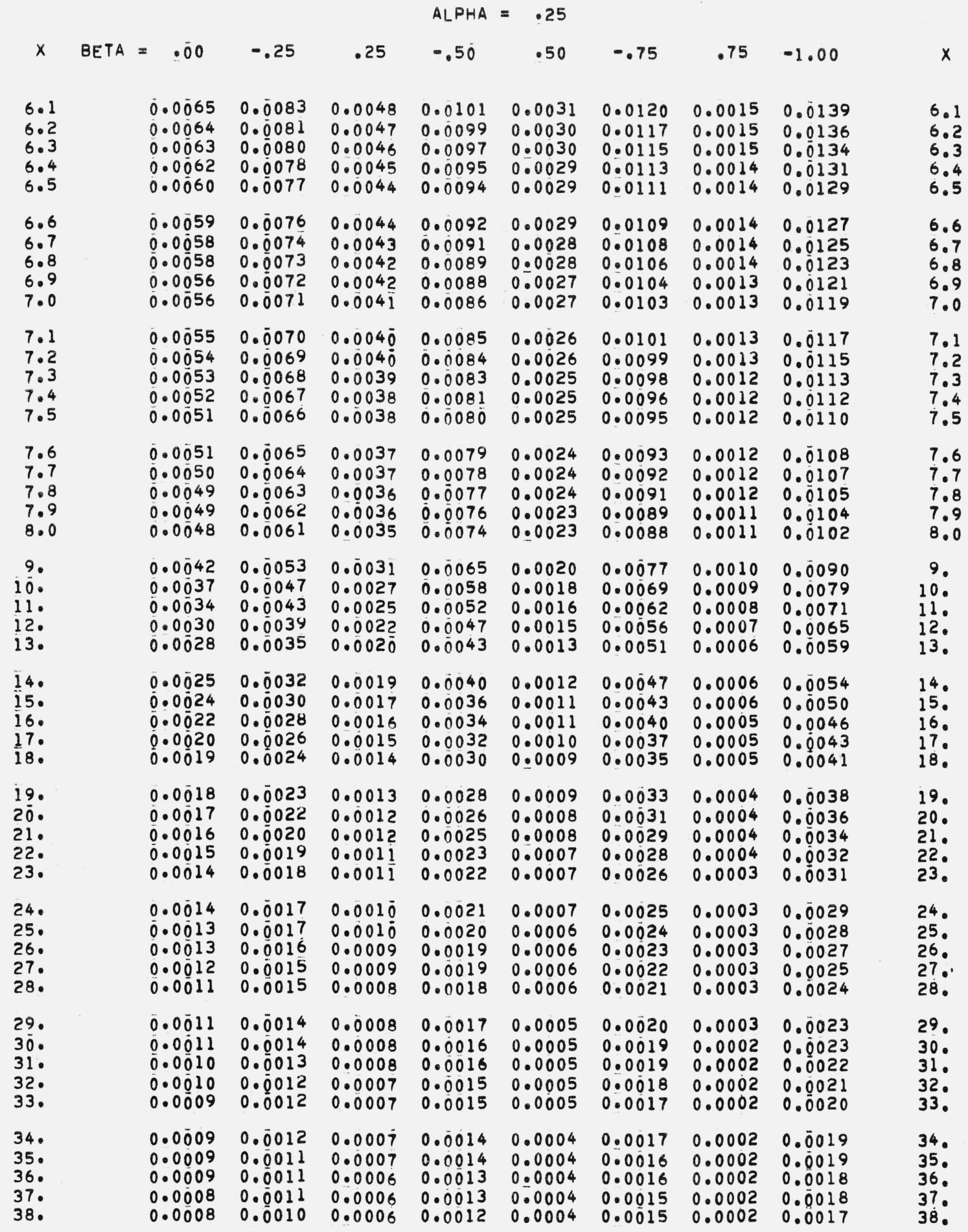




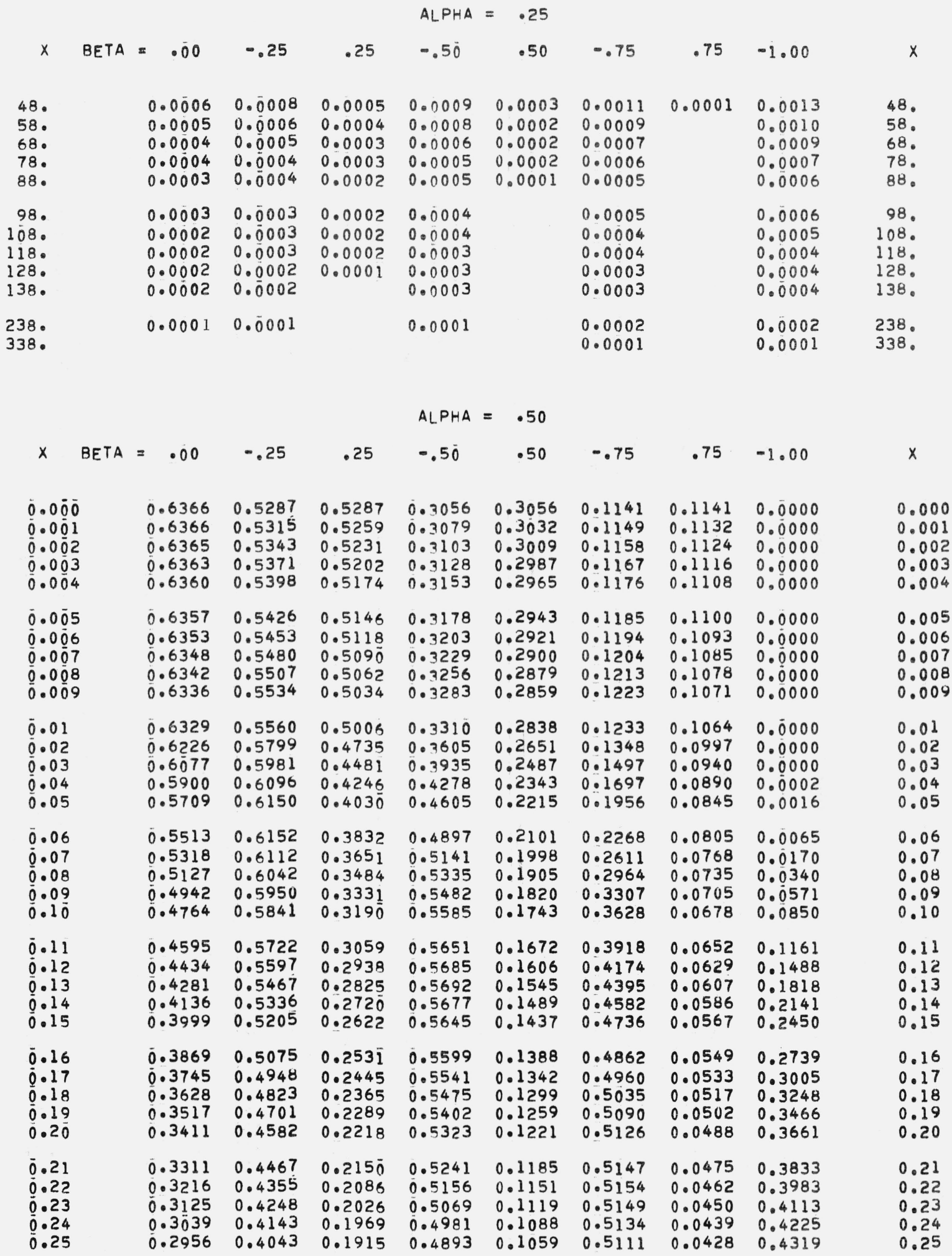




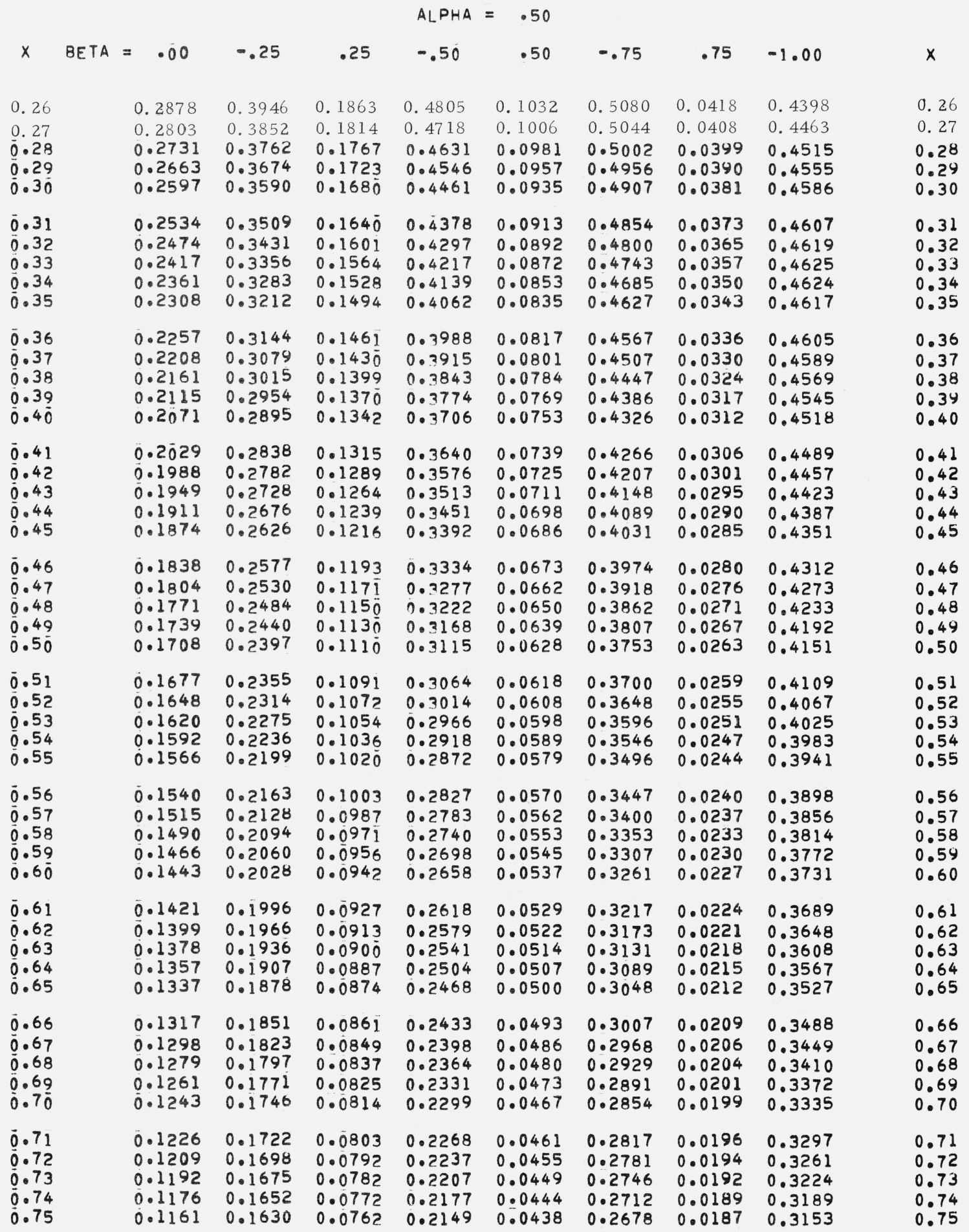




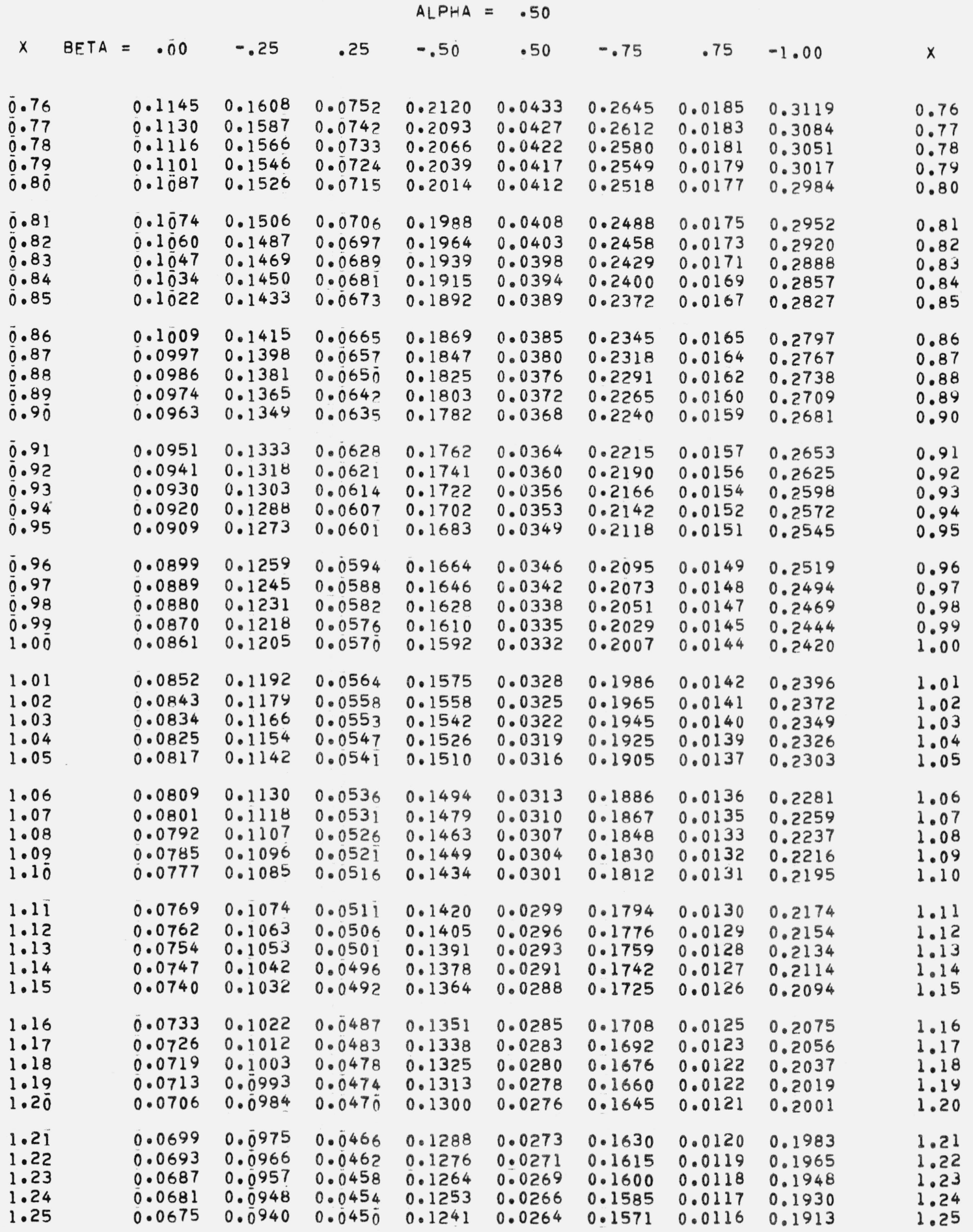




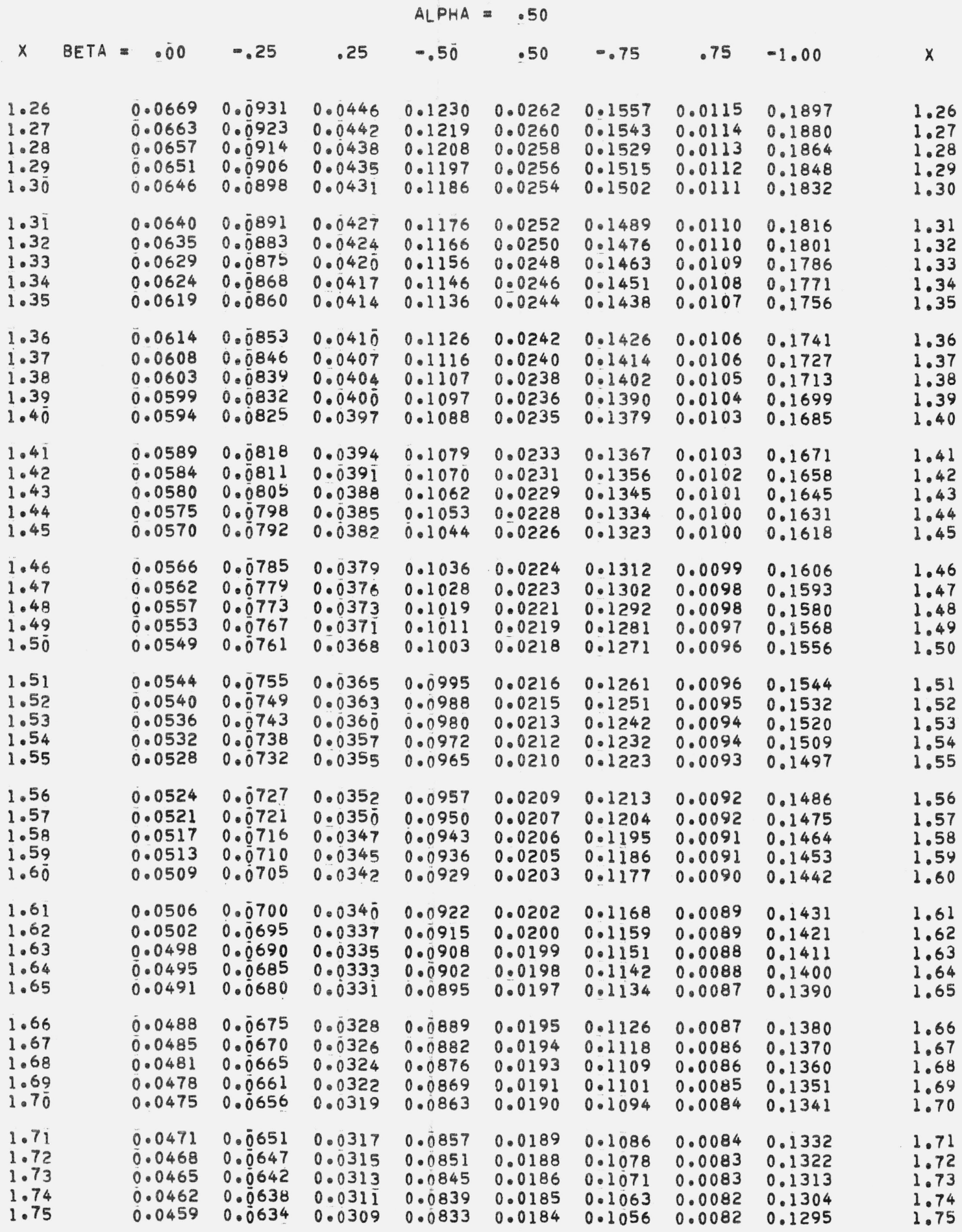




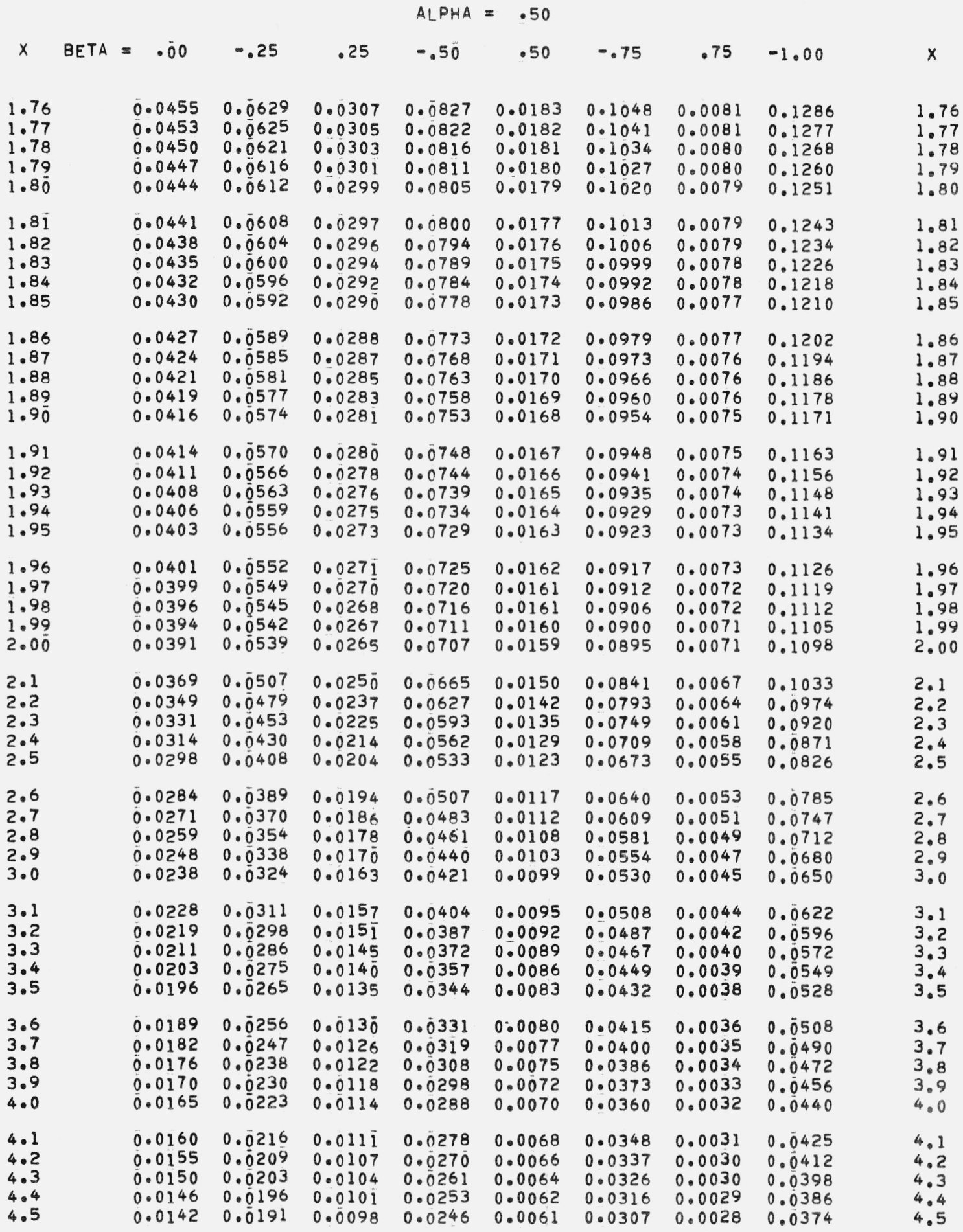




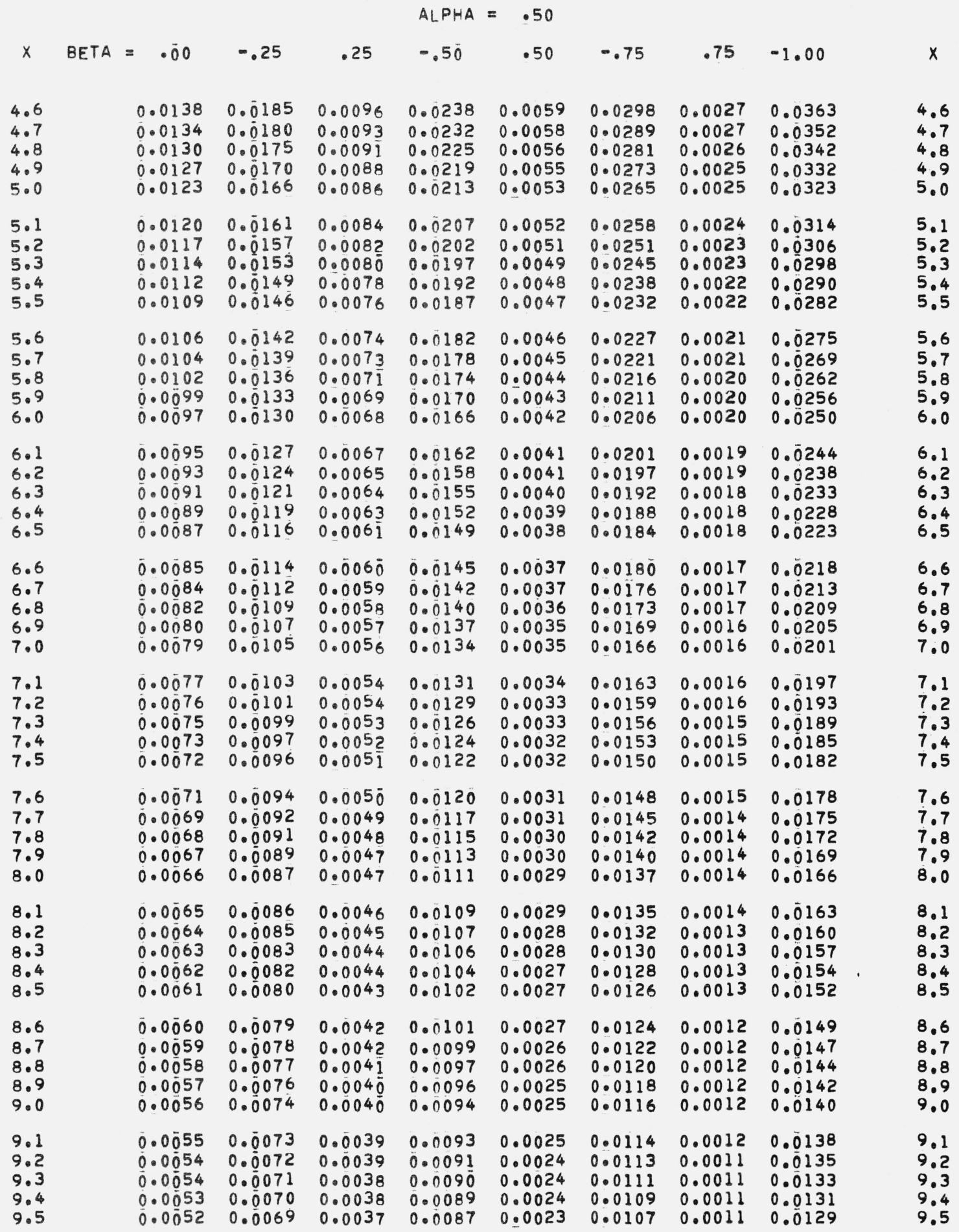




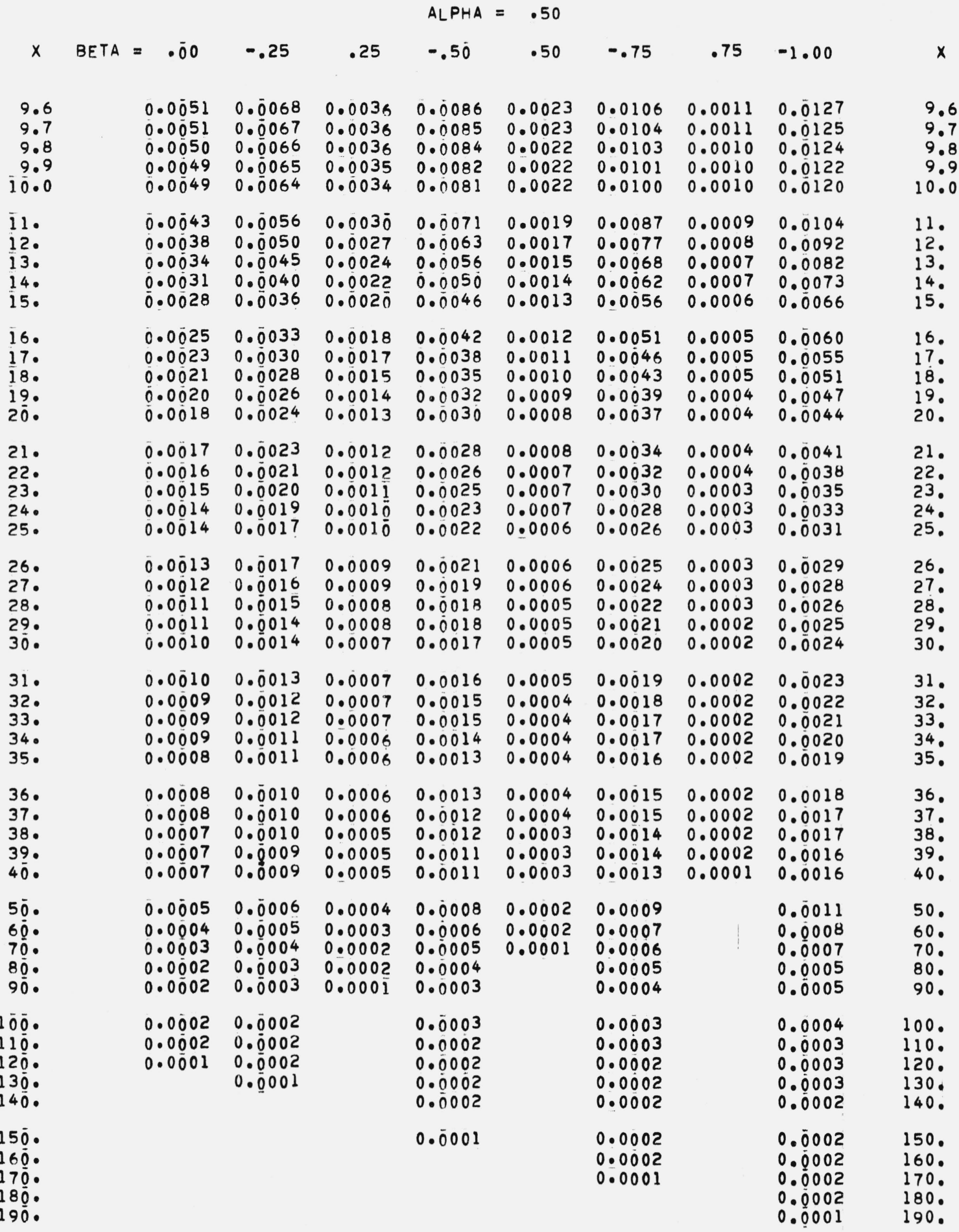




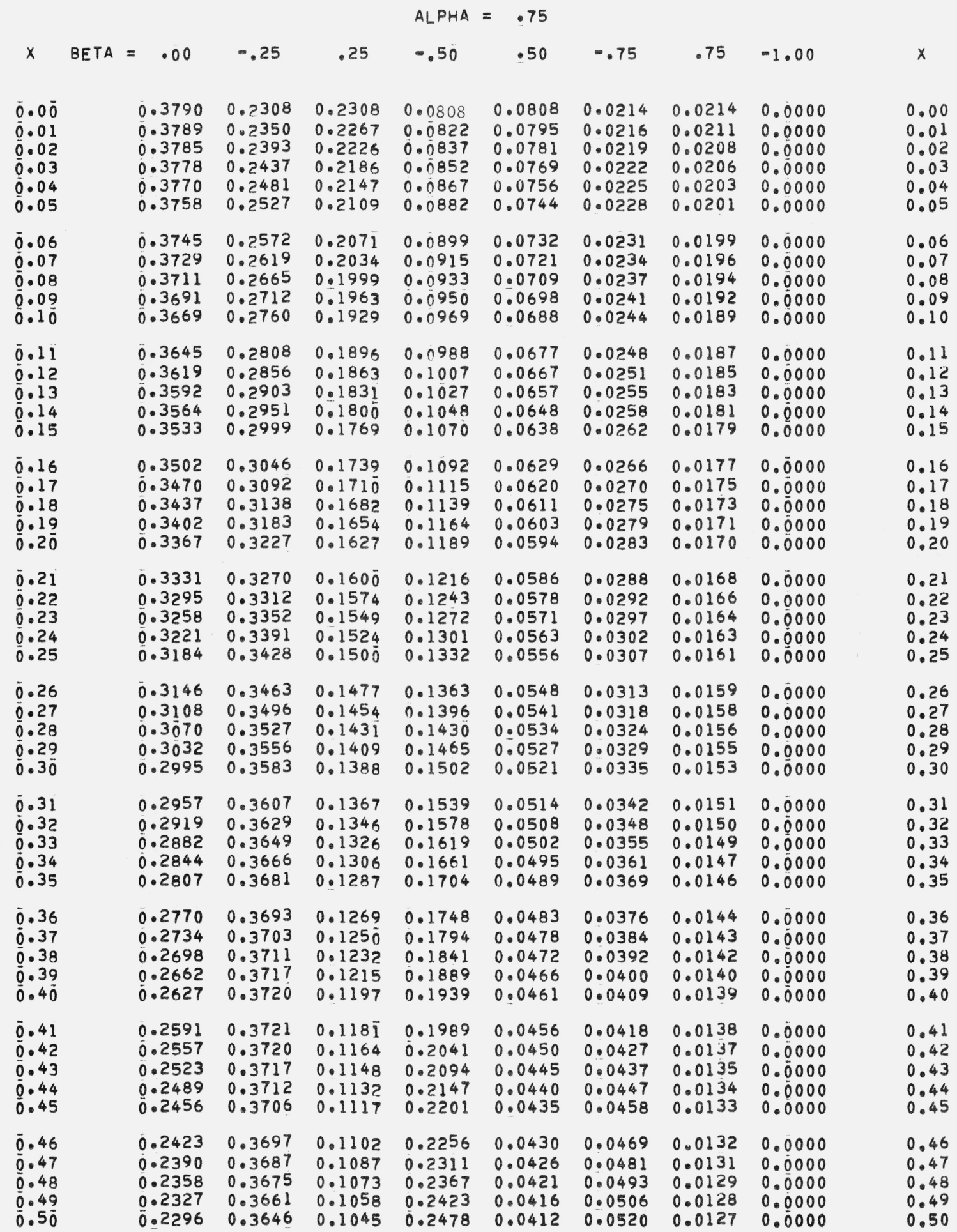









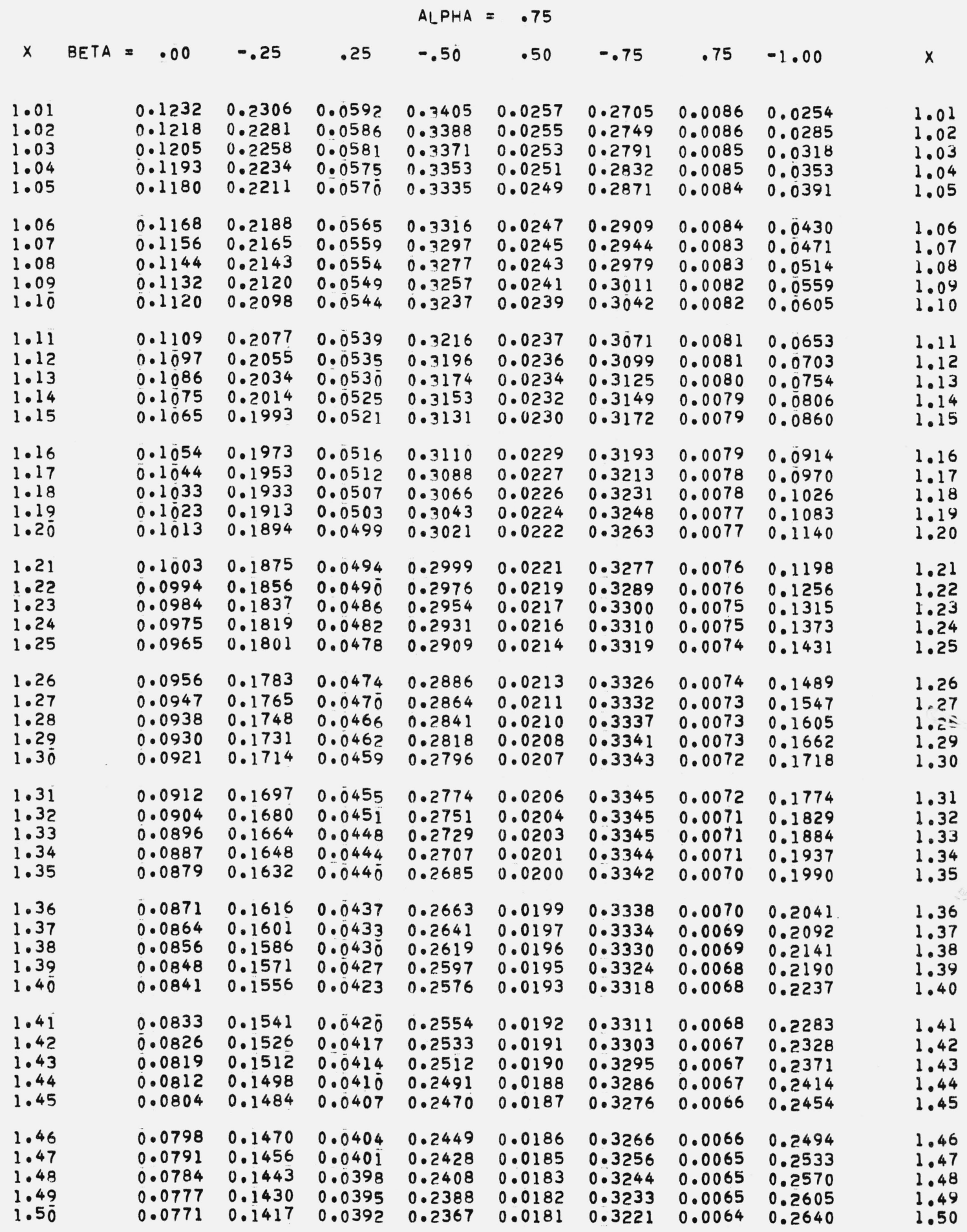




\begin{tabular}{|c|c|c|c|c|c|c|c|c|c|}
\hline$x$ & BETA $=$ & -.25 & .25 & -.50 & .50 & -.75 & .75 & -1.00 & $x$ \\
\hline $\begin{array}{l}1.51 \\
1.52 \\
1.53 \\
1.54 \\
1.55\end{array}$ & $\begin{array}{l}0.0764 \\
0.0758 \\
0.0752 \\
0.0745 \\
0.0739\end{array}$ & $\begin{array}{l}0.1404 \\
0.1391 \\
0.1378 \\
0.1366 \\
0.1354\end{array}$ & $\begin{array}{l}0.0390 \\
0.0387 \\
0.0384 \\
0.0381 \\
0.0378\end{array}$ & $\begin{array}{l}0.2347 \\
0.2327 \\
0.2308 \\
0.2288 \\
0.2269\end{array}$ & $\begin{array}{l}0.0180 \\
0.0179 \\
0.0178 \\
0.0177 \\
0.0176\end{array}$ & $\begin{array}{l}0.3208 \\
0.3195 \\
0.3182 \\
0.3168 \\
0.3154\end{array}$ & $\begin{array}{l}0.0064 \\
0.0064 \\
0.0063 \\
0.0063 \\
0.0063\end{array}$ & $\begin{array}{l}0.2673 \\
0.2705 \\
0.2735 \\
0.2764 \\
0.2792\end{array}$ & $\begin{array}{l}1.51 \\
1.52 \\
1.53 \\
1.54 \\
1.55\end{array}$ \\
\hline $\begin{array}{l}1.56 \\
1.57 \\
1.58 \\
1.59 \\
1.60\end{array}$ & $\begin{array}{l}0.0733 \\
0.0727 \\
0.0721 \\
0.0715 \\
0.0709\end{array}$ & $\begin{array}{l}0.1342 \\
0.1330 \\
0.1318 \\
0.11306 \\
0.1295\end{array}$ & $\begin{array}{l}0.0376 \\
0.0373 \\
0.0370 \\
0.0368 \\
0.0365\end{array}$ & $\begin{array}{l}0.2250 \\
0.2231 \\
0.2212 \\
0.2193 \\
0.2175\end{array}$ & $\begin{array}{l}0.0174 \\
0.0173 \\
0.0172 \\
0.0171 \\
0.0170\end{array}$ & $\begin{array}{l}0.3140 \\
0.3125 \\
0.3110 \\
0.3095 \\
0.3080\end{array}$ & $\begin{array}{l}0.0062 \\
0.0062 \\
0.0062 \\
0.0061 \\
0.0061\end{array}$ & $\begin{array}{l}0.2819 \\
0.2844 \\
0.2868 \\
0.2891 \\
0.2913\end{array}$ & $\begin{array}{l}1.56 \\
1.57 \\
1.58 \\
1.59 \\
1.60\end{array}$ \\
\hline $\begin{array}{l}1.61 \\
1.62 \\
1.63 \\
1.64 \\
1.65\end{array}$ & $\begin{array}{l}0.0704 \\
0.0698 \\
0.0692 \\
0.0687 \\
0.0681\end{array}$ & $\begin{array}{l}0.1283 \\
0.1272 \\
0.1261 \\
0.1250 \\
0.1239\end{array}$ & $\begin{array}{l}0.0362 \\
0.0360 \\
0.0357 \\
0.0355 \\
0.0352\end{array}$ & $\begin{array}{l}0.2156 \\
0.2138 \\
0.2120 \\
0.2102 \\
0.2084\end{array}$ & $\begin{array}{l}0.0169 \\
0.0168 \\
0.0167 \\
0.0166 \\
0.0165\end{array}$ & $\begin{array}{l}0.3064 \\
0.3048 \\
0.3032 \\
0.3016 \\
0.2999\end{array}$ & $\begin{array}{l}0.0061 \\
0.0060 \\
0.0060 \\
0.0060 \\
0.0059\end{array}$ & $\begin{array}{l}0.2933 \\
0.2953 \\
0.2971 \\
0.2988 \\
0.3004\end{array}$ & $\begin{array}{l}1.61 \\
1.62 \\
1.63 \\
1.64 \\
1.65\end{array}$ \\
\hline $\begin{array}{l}1.66 \\
1.67 \\
1.68 \\
1.69 \\
1.70\end{array}$ & $\begin{array}{l}0.0676 \\
0.0671 \\
0.0665 \\
0.0660 \\
0.0655\end{array}$ & $\begin{array}{l}0.1228 \\
0.1218 \\
0.1207 \\
0.1197 \\
0.1187\end{array}$ & $\begin{array}{l}0.0350 \\
0.0347 \\
0.0345 \\
0.0343 \\
0.0340\end{array}$ & $\begin{array}{l}0.2067 \\
0.2049 \\
0.2032 \\
0.2015 \\
0.1998\end{array}$ & $\begin{array}{l}0.0164 \\
0.0163 \\
0.0162 \\
0.0161 \\
0.0160\end{array}$ & $\begin{array}{l}0.2983 \\
0.2966 \\
0.2949 \\
0.2932 \\
0.2915\end{array}$ & $\begin{array}{l}0.0059 \\
0.0059 \\
0.0059 \\
0.0058 \\
0.0058\end{array}$ & $\begin{array}{l}0.3019 \\
0.3032 \\
0.3045 \\
0.3057 \\
0.3067\end{array}$ & $\begin{array}{l}1.66 \\
1.67 \\
1.68 \\
1.69 \\
1.70\end{array}$ \\
\hline $\begin{array}{l}1.71 \\
1.72 \\
1.73 \\
1.74 \\
1.75\end{array}$ & $\begin{array}{l}0.0650 \\
0.0645 \\
0.0640 \\
0.0635 \\
0.0630\end{array}$ & $\begin{array}{l}0.1177 \\
0.1167 \\
0.1157 \\
0.11148 \\
0.1138\end{array}$ & $\begin{array}{l}0.0338 \\
0.0336 \\
0.0333 \\
0.0331 \\
0.0329\end{array}$ & $\begin{array}{l}0.1981 \\
0.1965 \\
0.1948 \\
0.1932 \\
0.1916\end{array}$ & $\begin{array}{l}0.0159 \\
0.0158 \\
0.0157 \\
0.0156 \\
0.0156\end{array}$ & $\begin{array}{l}0.2898 \\
0.2880 \\
0.2863 \\
0.2845 \\
0.2828\end{array}$ & $\begin{array}{l}0.0058 \\
0.0057 \\
0.0057 \\
0.0057 \\
0.0056\end{array}$ & $\begin{array}{l}0.3077 \\
0.3086 \\
0.3094 \\
0.3101 \\
0.3107\end{array}$ & $\begin{array}{l}1.71 \\
1.72 \\
1.73 \\
1.74 \\
1.75\end{array}$ \\
\hline $\begin{array}{l}1.76 \\
1.77 \\
1.78 \\
1.79 \\
1.80\end{array}$ & $\begin{array}{l}0.0626 \\
0.0621 \\
0.0616 \\
0.0612 \\
0.0607\end{array}$ & $\begin{array}{l}0.1128 \\
0.1119 \\
0.11110 \\
0.11101 \\
0.11092\end{array}$ & $\begin{array}{l}0.0327 \\
0.0325 \\
0.0323 \\
0.0320 \\
0.0318\end{array}$ & $\begin{array}{l}0.1900 \\
0.1884 \\
0.1869 \\
0.1853 \\
0.1838\end{array}$ & $\begin{array}{l}0.0155 \\
0.0154 \\
0.0153 \\
0.0152 \\
0.0151\end{array}$ & $\begin{array}{l}0.2810 \\
0.2793 \\
0.2775 \\
0.2758 \\
0.2740\end{array}$ & $\begin{array}{l}0.0056 \\
0.0056 \\
0.0056 \\
0.0055 \\
0.0055\end{array}$ & $\begin{array}{l}0.3112 \\
0.3116 \\
0.3120 \\
0.3123 \\
0.3125\end{array}$ & $\begin{array}{l}1.76 \\
1.77 \\
1.78 \\
1.79 \\
1.80\end{array}$ \\
\hline $\begin{array}{l}1.81 \\
1.82 \\
1.83 \\
1.84 \\
1.85\end{array}$ & $\begin{array}{l}0.0603 \\
0.0598 \\
0.0594 \\
0.0589 \\
0.0585\end{array}$ & $\begin{array}{l}0.1083 \\
0.1074 \\
0.1065 \\
0.11057 \\
0.1048\end{array}$ & $\begin{array}{l}0.0316 \\
0.0314 \\
0.0312 \\
0.0310 \\
0.0308\end{array}$ & $\begin{array}{l}0.1823 \\
0.1808 \\
0.1793 \\
0.1779 \\
0.1764\end{array}$ & $\begin{array}{l}0.0150 \\
0.0149 \\
0.0149 \\
0.0148 \\
0.0147\end{array}$ & $\begin{array}{l}0.2723 \\
0.2705 \\
0.2687 \\
0.2670 \\
0.2652\end{array}$ & $\begin{array}{l}0.0055 \\
0.0055 \\
0.0054 \\
0.0054 \\
0.0054\end{array}$ & $\begin{array}{l}0.3126 \\
0.3127 \\
0.3127 \\
0.3126 \\
0.3125\end{array}$ & $\begin{array}{l}1.81 \\
1.82 \\
1.83 \\
1.84 \\
1.85\end{array}$ \\
\hline $\begin{array}{l}1.86 \\
1.87 \\
1.88 \\
1.89 \\
1.90\end{array}$ & $\begin{array}{l}0.0581 \\
0.0576 \\
0.0572 \\
0.0568 \\
0.0564\end{array}$ & $\begin{array}{l}0.1040 \\
0.11032 \\
0.1023 \\
0.1015 \\
0.11007\end{array}$ & $\begin{array}{l}0.0306 \\
0.0304 \\
0.0302 \\
0.0300 \\
0.0298\end{array}$ & $\begin{array}{l}0.1750 \\
0.1735 \\
0.1721 \\
0.1707 \\
0.1694\end{array}$ & $\begin{array}{l}0.0146 \\
0.0145 \\
0.01145 \\
0.01144 \\
0.0143\end{array}$ & $\begin{array}{l}0.2635 \\
0.2617 \\
0.2600 \\
0.2582 \\
0.2565\end{array}$ & $\begin{array}{l}0.0054 \\
0.0053 \\
0.0053 \\
0.0053 \\
0.0053\end{array}$ & $\begin{array}{l}0.3123 \\
0.3120 \\
0.3117 \\
0.3114 \\
0.3109\end{array}$ & $\begin{array}{l}1.86 \\
1.87 \\
1.88 \\
1.89 \\
1.90\end{array}$ \\
\hline $\begin{array}{l}1.91 \\
1.92 \\
1.93 \\
1.94 \\
1.95\end{array}$ & $\begin{array}{l}0.0560 \\
0.0556 \\
0.0552 \\
0.0548 \\
0.0544\end{array}$ & $\begin{array}{l}0.0999 \\
0.0991 \\
0.0984 \\
0.0976 \\
0.0968\end{array}$ & $\begin{array}{l}0.0297 \\
0.0295 \\
0.0293 \\
0.0291 \\
0.0289\end{array}$ & $\begin{array}{l}0.1680 \\
0.1666 \\
0.1653 \\
0.1640 \\
0.1627\end{array}$ & $\begin{array}{l}0.0142 \\
0.01141 \\
0.01141 \\
0.0140 \\
0.0139\end{array}$ & $\begin{array}{l}0.2548 \\
0.2530 \\
0.2513 \\
0.2496 \\
0.2479\end{array}$ & $\begin{array}{l}0.0052 \\
0.0052 \\
0.0052 \\
0.0052 \\
0.0051\end{array}$ & $\begin{array}{l}0.3105 \\
0.3100 \\
0.3094 \\
0.3088 \\
0.3081\end{array}$ & $\begin{array}{l}1.91 \\
1.92 \\
1.93 \\
1.94 \\
1.95\end{array}$ \\
\hline $\begin{array}{l}1.96 \\
1.97 \\
1.98 \\
1.99 \\
2.00\end{array}$ & $\begin{array}{l}0.0541 \\
0.0537 \\
0.0533 \\
0.0530 \\
0.0526\end{array}$ & $\begin{array}{l}0.0961 \\
0.0954 \\
0.0946 \\
0.0939 \\
0.0932\end{array}$ & $\begin{array}{l}0.0287 \\
0.0286 \\
0.0284 \\
0.0282 \\
0.0280\end{array}$ & $\begin{array}{l}0.1614 \\
0.1601 \\
0.1588 \\
0.1576 \\
0.1563\end{array}$ & $\begin{array}{l}0.0138 \\
0.0138 \\
0.0137 \\
0.0136 \\
0.0135\end{array}$ & $\begin{array}{l}0.2462 \\
0.2445 \\
0.2428 \\
0.2411 \\
0.2394\end{array}$ & $\begin{array}{l}0.0051 \\
0.0051 \\
0.0051 \\
0.0050 \\
0.0050\end{array}$ & $\begin{array}{l}0.3074 \\
0.3068 \\
0.3059 \\
0.3051 \\
0.3042\end{array}$ & $\begin{array}{l}1.96 \\
1.97 \\
1.98 \\
1.99 \\
2.00\end{array}$ \\
\hline
\end{tabular}




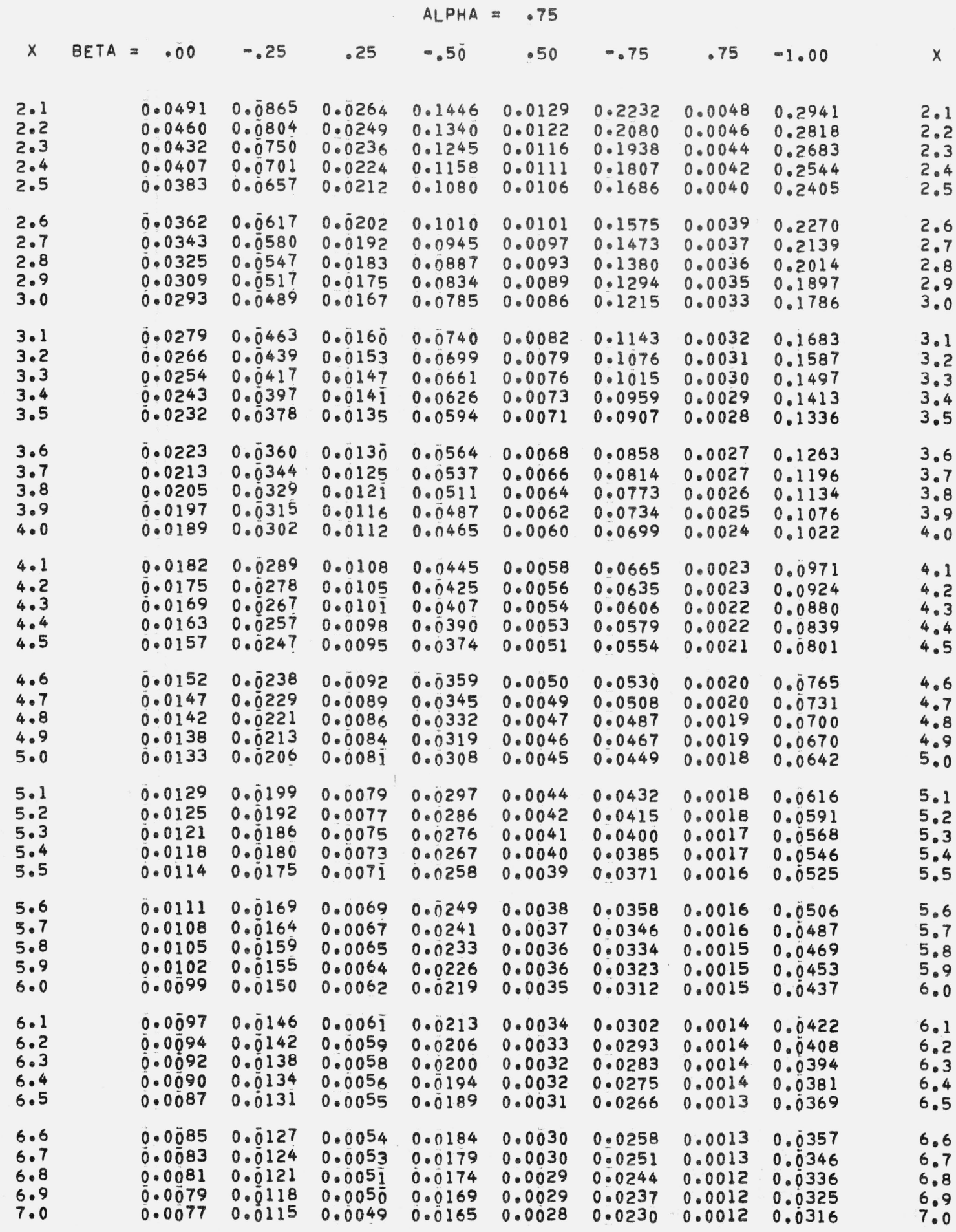




\begin{tabular}{|c|c|c|c|c|c|c|c|c|c|}
\hline$x$ & BETA $=$ & -.25 & .25 & -.50 & .50 &. .75 & .75 & -1.00 & $x$ \\
\hline $\begin{array}{l}7.1 \\
7.2 \\
7.3 \\
7.4 \\
7.5\end{array}$ & $\begin{array}{l}0.0076 \\
0.0074 \\
0.0072 \\
0.0071 \\
0.0069\end{array}$ & $\begin{array}{l}0.01112 \\
0.0109 \\
0.0107 \\
0.0104 \\
0.0102\end{array}$ & $\begin{array}{l}0.0048 \\
0.0047 \\
0.0046 \\
0.0045 \\
0.0044\end{array}$ & $\begin{array}{l}0.0160 \\
0.0156 \\
0.0152 \\
0.0148 \\
0.0145\end{array}$ & $\begin{array}{l}0.0027 \\
0.0027 \\
0.0026 \\
0.0026 \\
0.0025\end{array}$ & $\begin{array}{l}0.0224 \\
0.0217 \\
0.0212 \\
0.0206 \\
0.0201\end{array}$ & $\begin{array}{l}0.0012 \\
0.0011 \\
0.0011 \\
0.0011 \\
0.0011\end{array}$ & $\begin{array}{l}0.0307 \\
0.0298 \\
0.0289 \\
0.0281 \\
0.0273\end{array}$ & $\begin{array}{l}7.1 \\
7.2 \\
7.3 \\
7.4 \\
7.5\end{array}$ \\
\hline $\begin{array}{l}7.6 \\
7.7 \\
7.8 \\
7.9 \\
8.0\end{array}$ & $\begin{array}{l}0.00688 \\
0.0066 \\
0.0065 \\
0.0064 \\
0.0062\end{array}$ & $\begin{array}{l}0.0100 \\
0.0097 \\
0.0095 \\
0.0093 \\
0.0091\end{array}$ & $\begin{array}{l}0.0044 \\
0.0043 \\
0.0042 \\
0.0041 \\
0.0040\end{array}$ & $\begin{array}{l}0.0141 \\
0.0138 \\
0.0134 \\
0.0131 \\
0.0128\end{array}$ & $\begin{array}{l}0.0025 \\
0.0024 \\
0.0024 \\
0.0023 \\
0.0023\end{array}$ & $\begin{array}{l}0.0195 \\
0.0190 \\
0.0186 \\
0.0181 \\
0.0177\end{array}$ & $\begin{array}{l}0.0011 \\
0.0010 \\
0.0010 \\
0.0010 \\
0.0010\end{array}$ & $\begin{array}{l}0.0266 \\
0.0259 \\
0.0252 \\
0.0245 \\
0.0239\end{array}$ & $\begin{array}{l}7.6 \\
7.7 \\
7.8 \\
7.9 \\
8.0\end{array}$ \\
\hline $\begin{array}{l}8.1 \\
8.2 \\
8.3 \\
8.4 \\
8.5\end{array}$ & $\begin{array}{l}0.0061 \\
0.0060 \\
0.0059 \\
0.0058 \\
0.0056\end{array}$ & $\begin{array}{l}0.00089 \\
0.00087 \\
0.00085 \\
0.00084 \\
0.00082\end{array}$ & $\begin{array}{l}0.0039 \\
0.0039 \\
0.0038 \\
0.0037 \\
0.0036\end{array}$ & $\begin{array}{l}0.0125 \\
0.0123 \\
0.0120 \\
0.0117 \\
0.0115\end{array}$ & $\begin{array}{l}0.0023 \\
0.0022 \\
0.0022 \\
0.0021 \\
0.0021\end{array}$ & $\begin{array}{l}0.0172 \\
0.0168 \\
0.0164 \\
0.0160 \\
0.0157\end{array}$ & $\begin{array}{l}0.0010 \\
0.0010 \\
0.0009 \\
0.0009 \\
0.0009\end{array}$ & $\begin{array}{l}0.0233 \\
0.0227 \\
0.0221 \\
0.0216 \\
0.0210\end{array}$ & $\begin{array}{l}8.1 \\
8.2 \\
8.3 \\
8.4 \\
8.5\end{array}$ \\
\hline $\begin{array}{l}8.6 \\
8.7 \\
8.8 \\
8.9 \\
9.0\end{array}$ & $\begin{array}{l}0.0055 \\
0.0054 \\
0.0053 \\
0.0052 \\
0.0051\end{array}$ & $\begin{array}{l}0.0080 \\
0.0079 \\
0.0077 \\
0.0076 \\
0.0074\end{array}$ & $\begin{array}{l}0.0036 \\
0.0035 \\
0.0035 \\
0.0034 \\
0.0033\end{array}$ & $\begin{array}{l}0.0112 \\
0.0110 \\
0.0107 \\
0.0105 \\
0.0103\end{array}$ & $\begin{array}{l}0.0021 \\
0.0020 \\
0.0020 \\
0.0020 \\
0.0019\end{array}$ & $\begin{array}{l}0.0153 \\
0.0150 \\
0.0146 \\
0.0143 \\
0.0140\end{array}$ & $\begin{array}{l}0.0009 \\
0.0009 \\
0.0009 \\
0.0009 \\
0.0008\end{array}$ & $\begin{array}{l}0.0205 \\
0.0201 \\
0.0196 \\
0.0191 \\
0.0187\end{array}$ & $\begin{array}{l}8.6 \\
8.7 \\
8.8 \\
8.9 \\
9.0\end{array}$ \\
\hline $\begin{array}{l}9.1 \\
9.2 \\
9.3 \\
9.4 \\
9.5\end{array}$ & $\begin{array}{l}0.0050 \\
0.0050 \\
0.0049 \\
0.0048 \\
0.0047\end{array}$ & $\begin{array}{l}0.0073 \\
0.0071 \\
0.00070 \\
0.0069 \\
0.0067\end{array}$ & $\begin{array}{l}0.0033 \\
0.0032 \\
0.0032 \\
0.0031 \\
0.0031\end{array}$ & $\begin{array}{l}0.0101 \\
0.0099 \\
0.0097 \\
0.0095 \\
0.0093\end{array}$ & $\begin{array}{l}0.0019 \\
0.0019 \\
0.0018 \\
0.0018 \\
0.0018\end{array}$ & $\begin{array}{l}0.0137 \\
0.0134 \\
0.0131 \\
0.0129 \\
0.0126\end{array}$ & $\begin{array}{l}0.0008 \\
0.0008 \\
0.0008 \\
0.0008 \\
0.0008\end{array}$ & $\begin{array}{l}0.0183 \\
0.0179 \\
0.0175 \\
0.0171 \\
0.0167\end{array}$ & $\begin{array}{l}9.1 \\
9.2 \\
9.3 \\
9.4 \\
9.5\end{array}$ \\
\hline $\begin{array}{l}9.6 \\
9.7 \\
9.8 \\
9.9 \\
0.0\end{array}$ & $\begin{array}{l}0.0046 \\
0.0045 \\
0.0045 \\
0.0044 \\
0.0043\end{array}$ & $\begin{array}{l}0.00066 \\
0.0065 \\
0.0064 \\
0.00633 \\
0.0062\end{array}$ & $\begin{array}{l}0.0030 \\
0.0030 \\
0.0029 \\
0.0029 \\
0.0028\end{array}$ & $\begin{array}{l}0.0092 \\
0.0090 \\
0.0088 \\
0.0086 \\
0.0085\end{array}$ & $\begin{array}{l}0.0018 \\
0.0017 \\
0.0017 \\
0.0017 \\
0.0017\end{array}$ & $\begin{array}{l}0.0123 \\
0.0121 \\
0.0119 \\
0.0116 \\
0.0114\end{array}$ & $\begin{array}{l}0.0008 \\
0.0008 \\
0.0007 \\
0.0007 \\
0.0007\end{array}$ & $\begin{array}{l}0.0164 \\
0.0160 \\
0.0157 \\
0.0154 \\
0.0150\end{array}$ & $\begin{array}{r}9.6 \\
9.7 \\
9.8 \\
9.9 \\
10.0\end{array}$ \\
\hline $\begin{array}{l}0.1 \\
0.02 \\
0.02 \\
0.03 \\
0.04 \\
0.5\end{array}$ & $\begin{array}{l}0.0042 \\
0.0042 \\
0.0041 \\
0.0040 \\
0.0040\end{array}$ & $\begin{array}{l}0.0060 \\
0.0059 \\
0.0059 \\
0.0058 \\
0.0056\end{array}$ & $\begin{array}{l}0.0028 \\
0.0027 \\
0.0027 \\
0.0027 \\
0.0026\end{array}$ & $\begin{array}{l}0.0083 \\
0.0082 \\
0.0080 \\
0.0079 \\
0.0077\end{array}$ & $\begin{array}{l}0.0016 \\
0.0016 \\
0.0016 \\
0.0016 \\
0.0015\end{array}$ & $\begin{array}{l}0.0112 \\
0.0110 \\
0.0108 \\
0.0106 \\
0.0104\end{array}$ & $\begin{array}{l}0.0007 \\
0.0007 \\
0.0007 \\
0.0007 \\
0.0007\end{array}$ & $\begin{array}{l}0.0147 \\
0.0144 \\
0.0142 \\
0.0139 \\
0.0136\end{array}$ & $\begin{array}{l}10.1 \\
10.2 \\
10.3 \\
10.4 \\
10.5\end{array}$ \\
\hline $\begin{array}{l}10.6 \\
0.7 \\
0.7 \\
0.8 \\
0.9 \\
1.0\end{array}$ & $\begin{array}{l}0.0039 \\
0.0038 \\
0.0038 \\
0.0037 \\
0.0037\end{array}$ & $\begin{array}{l}0.0056 \\
0.0055 \\
0.0054 \\
0.0053 \\
0.0052\end{array}$ & $\begin{array}{l}0.0026 \\
0.0025 \\
0.0025 \\
0.0025 \\
0.0024\end{array}$ & $\begin{array}{l}0.0076 \\
0.0075 \\
0.0074 \\
0.0072 \\
0.0071\end{array}$ & $\begin{array}{l}0.0015 \\
0.0015 \\
0.0015 \\
0.0015 \\
0.0014\end{array}$ & $\begin{array}{l}0.0102 \\
0.0100 \\
0.0098 \\
0.0096 \\
0.0095\end{array}$ & $\begin{array}{l}0.0007 \\
0.0007 \\
0.0007 \\
0.0006 \\
0.0006\end{array}$ & $\begin{array}{l}0.0133 \\
0.0131 \\
0.0129 \\
0.0126 \\
0.0124\end{array}$ & $\begin{array}{l}10.6 \\
10.7 \\
10.8 \\
10.9 \\
11.0\end{array}$ \\
\hline 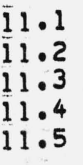 & $\begin{array}{l}0.0036 \\
0.0036 \\
0.0035 \\
0.0035 \\
0.0034\end{array}$ & $\begin{array}{l}0.0051 \\
0.0050 \\
0.0050 \\
0.0049 \\
0.0048\end{array}$ & $\begin{array}{l}0.0024 \\
0.0024 \\
0.0023 \\
0.0023 \\
0.0023\end{array}$ & $\begin{array}{l}0.0070 \\
0.0069 \\
0.0068 \\
0.0067 \\
0.0065\end{array}$ & $\begin{array}{l}0.0014 \\
0.0014 \\
0.0014 \\
0.0014 \\
0.0014\end{array}$ & $\begin{array}{l}0.0093 \\
0.0091 \\
0.0090 \\
0.0088 \\
0.0087\end{array}$ & $\begin{array}{l}0.0006 \\
0.0006 \\
0.0006 \\
0.0006 \\
0.0006\end{array}$ & $\begin{array}{l}0.0122 \\
0.0119 \\
0.0117 \\
0.0115 \\
0.0113\end{array}$ & $\begin{array}{l}11.1 \\
11.2 \\
11.3 \\
11.4 \\
11.5\end{array}$ \\
\hline $\begin{array}{l}1.7 \\
1.8 \\
1.9 \\
2.0\end{array}$ & $\begin{array}{l}0.0034 \\
0.0033 \\
0.0033 \\
0.0032 \\
0.0032\end{array}$ & $\begin{array}{l}0.00047 \\
0.0047 \\
0.00046 \\
0.0045 \\
0.0045\end{array}$ & $\begin{array}{l}0.0022 \\
0.0022 \\
0.0022 \\
0.0021 \\
0.0021\end{array}$ & $\begin{array}{l}0.0064 \\
0.0063 \\
0.0063 \\
0.0062 \\
0.0061\end{array}$ & $\begin{array}{l}0.0013 \\
0.0013 \\
0.0013 \\
0.0013 \\
0.0013\end{array}$ & $\begin{array}{l}0.0085 \\
0.0084 \\
0.0083 \\
0.0081 \\
0.0080\end{array}$ & $\begin{array}{l}0.0006 \\
0.0006 \\
0.0006 \\
0.0006 \\
0.0006\end{array}$ & $\begin{array}{l}0.01111 \\
0.0109 \\
0.0107 \\
0.00105 \\
0.0104\end{array}$ & $\begin{array}{l}11.6 \\
11.7 \\
11.8 \\
11.9 \\
12.0\end{array}$ \\
\hline
\end{tabular}




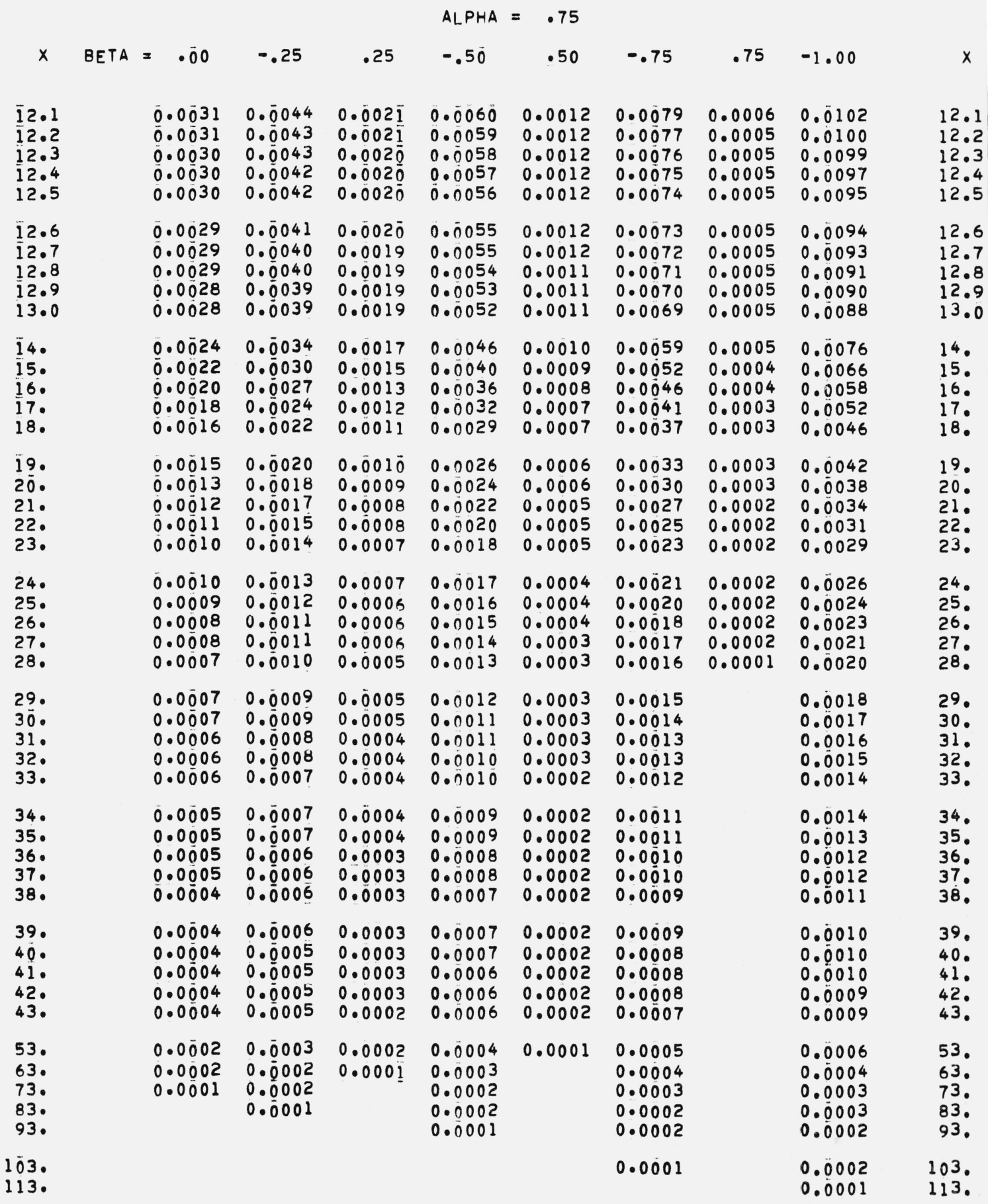


$A L P H A=1.00$

\begin{tabular}{|c|c|c|c|c|c|c|c|c|c|c|c|}
\hline$x$ & BETA & .00 & -.25 & .25 & -.50 & .50 & -.75 & .75 & -1.00 & 1.00 & $x$ \\
\hline $\begin{array}{l}0.0 \\
0.1 \\
0.2 \\
0.3 \\
0.4 \\
0.5\end{array}$ & & $\begin{array}{l}0.3183 \\
0.3152 \\
0.3061 \\
0.2920 \\
0.2744 \\
0.2547\end{array}$ & $\begin{array}{l}0.3096 \\
0.3147 \\
0.3143 \\
0.3077 \\
0.2953 \\
0.2776\end{array}$ & $\begin{array}{l}0.3096 \\
0.2999 \\
0.2867 \\
0.2711 \\
0.2543 \\
0.2369\end{array}$ & $\begin{array}{l}0.2925 \\
0.3011 \\
0.3061 \\
0.3069 \\
0.3025 \\
0.2926\end{array}$ & $\begin{array}{l}0.2925 \\
0.2814 \\
0.2685 \\
0.2545 \\
0.2400 \\
0.2254\end{array}$ & $\begin{array}{l}0.2761 \\
0.2849 \\
0.2915 \\
0.2954 \\
0.2958 \\
0.2921\end{array}$ & $\begin{array}{l}0.2761 \\
0.2657 \\
0.2543 \\
0.2423 \\
0.2301 \\
0.2178\end{array}$ & $\begin{array}{l}0.2622 \\
0.2702 \\
0.2768 \\
0.2814 \\
0.2836 \\
0.2830\end{array}$ & $\begin{array}{l}0.2622 \\
0.2532 \\
0.2434 \\
0.2332 \\
0.2228 \\
0.2123\end{array}$ & $\begin{array}{l}0.0 \\
0.1 \\
0.2 \\
0.3 \\
0.4 \\
0.5\end{array}$ \\
\hline $\begin{array}{l}0.6 \\
0.7 \\
0.8 \\
0.9 \\
1.0\end{array}$ & & $\begin{array}{l}0.2340 \\
0.2136 \\
0.1941 \\
0.1759 \\
0.1591\end{array}$ & $\begin{array}{l}0.2562 \\
0.2327 \\
0.2087 \\
0.1855 \\
0.1640\end{array}$ & $\begin{array}{l}0.2197 \\
0.2030 \\
0.1872 \\
0.1724 \\
0.1587\end{array}$ & $\begin{array}{l}0.2772 \\
0.2568 \\
0.2325 \\
0.2061 \\
0.1793\end{array}$ & $\begin{array}{l}0.2111 \\
0.1973 \\
0.1841 \\
0.1716 \\
0.1599\end{array}$ & $\begin{array}{l}0.2838 \\
0.2705 \\
0.2523 \\
0.2297 \\
0.2036\end{array}$ & $\begin{array}{l}0.2057 \\
0.1940 \\
0.1827 \\
0.1719 \\
0.1617\end{array}$ & $\begin{array}{l}0.2789 \\
0.2710 \\
0.2588 \\
0.2424 \\
0.2218\end{array}$ & $\begin{array}{l}0.2020 \\
0.1919 \\
0.1820 \\
0.1726 \\
0.1635\end{array}$ & $\begin{array}{l}0.6 \\
0.7 \\
0.8 \\
0.9 \\
1.0\end{array}$ \\
\hline $\begin{array}{l}1.1 \\
1.2 \\
1.3 \\
1.4 \\
1.5\end{array}$ & & $\begin{array}{l}0.1440 \\
0.1305 \\
0.1183 \\
0.1075 \\
0.01079\end{array}$ & $\begin{array}{l}0.1447 \\
0.1277 \\
0.1130 \\
0.1002 \\
0.0892\end{array}$ & $\begin{array}{l}0.1461 \\
0.1346 \\
0.1241 \\
0.1145 \\
0.1058\end{array}$ & $\begin{array}{l}0.1537 \\
0.1306 \\
0.1107 \\
0.0939 \\
0.0801\end{array}$ & $\begin{array}{l}0.1490 \\
0.1389 \\
0.1295 \\
0.1208 \\
0.1128\end{array}$ & $\begin{array}{l}0.1754 \\
0.1469 \\
0.1197 \\
0.0955 \\
0.0751\end{array}$ & $\begin{array}{l}0.1520 \\
0.1430 \\
0.1344 \\
0.1265 \\
0.1190\end{array}$ & $\begin{array}{l}0.1974 \\
0.1701 \\
0.1411 \\
0.1120 \\
0.0845\end{array}$ & $\begin{array}{l}0.1549 \\
0.1467 \\
0.1389 \\
0.1315 \\
0.1246\end{array}$ & $\begin{array}{l}1.1 \\
1.2 \\
1.3 \\
1.4 \\
1.5\end{array}$ \\
\hline $\begin{array}{l}1.6 \\
1.7 \\
1.8 \\
1.9 \\
2.0\end{array}$ & & $\begin{array}{l}0.0894 \\
0.0818 \\
0.0751 \\
0.0691 \\
0.0637\end{array}$ & $\begin{array}{l}0.0798 \\
0.0716 \\
0.0646 \\
0.0585 \\
0.0531\end{array}$ & $\begin{array}{l}0.0979 \\
0.0907 \\
0.0842 \\
0.0783 \\
0.0729\end{array}$ & $\begin{array}{l}0.0689 \\
0.0597 \\
0.0522 \\
0.0460 \\
0.0409\end{array}$ & $\begin{array}{l}0.1054 \\
0.0986 \\
0.0923 \\
0.0865 \\
0.0812\end{array}$ & $\begin{array}{l}0.0589 \\
0.0465 \\
0.0374 \\
0.0307 \\
0.0258\end{array}$ & $\begin{array}{l}0.1121 \\
0.1056 \\
0.0996 \\
0.0940 \\
0.0887\end{array}$ & $\begin{array}{l}0.0599 \\
0.0396 \\
0.0240 \\
0.0132 \\
0.0065\end{array}$ & $\begin{array}{l}0.1180 \\
0.1119 \\
0.1061 \\
0.1006 \\
0.0955\end{array}$ & $\begin{array}{l}1.6 \\
1.7 \\
1.8 \\
1.9 \\
2.0\end{array}$ \\
\hline $\begin{array}{l}2.1 \\
2.2 \\
2.3 \\
2.4 \\
2.5\end{array}$ & & $\begin{array}{l}0.0588 \\
0.0545 \\
0.0506 \\
0.0471 \\
0.0439\end{array}$ & $\begin{array}{l}0.0485 \\
0.0444 \\
0.0408 \\
0.0376 \\
0.0348\end{array}$ & $\begin{array}{l}0.0680 \\
0.0636 \\
0.0595 \\
0.0557 \\
0.0523\end{array}$ & $\begin{array}{l}0.0365 \\
0.0329 \\
0.0298 \\
0.0271 \\
0.0247\end{array}$ & $\begin{array}{l}0.0763 \\
0.0718 \\
0.0676 \\
0.0637 \\
0.0602\end{array}$ & $\begin{array}{l}0.0220 \\
0.0191 \\
0.0168 \\
0.0150 \\
0.0134\end{array}$ & $\begin{array}{l}0.0838 \\
0.0793 \\
0.0751 \\
0.0711 \\
0.0674\end{array}$ & $\begin{array}{l}0.0028 \\
0.0010 \\
0.0003\end{array}$ & $\begin{array}{l}0.0907 \\
0.0862 \\
0.0820 \\
0.0780 \\
0.0742\end{array}$ & $\begin{array}{l}2.1 \\
2.2 \\
2.3 \\
2.4 \\
2.5\end{array}$ \\
\hline $\begin{array}{l}2.6 \\
2.7 \\
2.8 \\
2.9 \\
3.0\end{array}$ & & $\begin{array}{l}0.0410 \\
0.0384 \\
0.0360 \\
0.0338 \\
0.0318\end{array}$ & $\begin{array}{l}0.0322 \\
0.0300 \\
0.0279 \\
0.0261 \\
0.0244\end{array}$ & $\begin{array}{l}0.0492 \\
0.0463 \\
0.0437 \\
0.0412 \\
0.0390\end{array}$ & $\begin{array}{l}0.0227 \\
0.0209 \\
0.0193 \\
0.0179 \\
0.0166\end{array}$ & $\begin{array}{l}0.0568 \\
0.0538 \\
0.0509 \\
0.0483 \\
0.0458\end{array}$ & $\begin{array}{l}0.0121 \\
0.0110 \\
0.0101 \\
0.0092 \\
0.0085\end{array}$ & $\begin{array}{l}0.0640 \\
0.0608 \\
0.0578 \\
0.0550 \\
0.0523\end{array}$ & & $\begin{array}{l}0.0707 \\
0.0674 \\
0.0643 \\
0.0614 \\
0.0586\end{array}$ & $\begin{array}{l}2.6 \\
2.7 \\
2.8 \\
2.9 \\
3.0\end{array}$ \\
\hline $\begin{array}{l}3.1 \\
3.2 \\
3.3 \\
3.4 \\
3.5\end{array}$ & & $\begin{array}{l}0.0300 \\
0.0283 \\
0.0268 \\
0.0253 \\
0.02240\end{array}$ & $\begin{array}{l}0.0229 \\
0.0215 \\
0.0202 \\
0.0191 \\
0.0180\end{array}$ & $\begin{array}{l}0.0369 \\
0.0349 \\
0.0331 \\
0.0315 \\
0.0299\end{array}$ & $\begin{array}{l}0.0155 \\
0.0145 \\
0.0136 \\
0.0128 \\
0.0120\end{array}$ & $\begin{array}{l}0.0435 \\
0.0414 \\
0.0394 \\
0.0375 \\
0.0358\end{array}$ & $\begin{array}{l}0.0079 \\
0.0073 \\
0.0068 \\
0.0064 \\
0.0060\end{array}$ & $\begin{array}{l}0.0499 \\
0.0476 \\
0.0454 \\
0.0434 \\
0.0415\end{array}$ & & $\begin{array}{l}0.0560 \\
0.0536 \\
0.0513 \\
0.0491 \\
0.0471\end{array}$ & $\begin{array}{l}3.1 \\
3.2 \\
3.3 \\
3.4 \\
3.5\end{array}$ \\
\hline $\begin{array}{l}3.6 \\
3.7 \\
3.8 \\
3.9 \\
4.0\end{array}$ & & $\begin{array}{l}0.0228 \\
0.0217 \\
0.0206 \\
0.0196 \\
0.0187\end{array}$ & $\begin{array}{l}0.0171 \\
0.0162 \\
0.0153 \\
0.0146 \\
0.0139\end{array}$ & $\begin{array}{l}0.0285 \\
0.0271 \\
0.0259 \\
0.0247 \\
0.0236\end{array}$ & $\begin{array}{l}0.0113 \\
0.0107 \\
0.0101 \\
0.0096 \\
0.0091\end{array}$ & $\begin{array}{l}0.0341 \\
0.0326 \\
0.0312 \\
0.0298 \\
0.0285\end{array}$ & $\begin{array}{l}0.0056 \\
0.0053 \\
0.0050 \\
0.0047 \\
0.0045\end{array}$ & $\begin{array}{l}0.0397 \\
0.0380 \\
0.0364 \\
0.0349 \\
0.0335\end{array}$ & & $\begin{array}{l}0.0451 \\
0.0433 \\
0.0416 \\
0.0399 \\
0.0384\end{array}$ & $\begin{array}{l}3.6 \\
3.7 \\
3.8 \\
3.9 \\
4.0\end{array}$ \\
\hline $\begin{array}{l}4.1 \\
4.2 \\
4.3 \\
4.4 \\
4.5\end{array}$ & & $\begin{array}{l}0.0179 \\
0.00171 \\
0.0163 \\
0.0156 \\
0.00150\end{array}$ & $\begin{array}{l}0.0132 \\
0.0126 \\
0.0120 \\
0.0115 \\
0.0110\end{array}$ & $\begin{array}{l}0.0226 \\
0.0216 \\
0.0207 \\
0.0199 \\
0.0191\end{array}$ & $\begin{array}{l}0.0086 \\
0.0032 \\
0.0078 \\
0.0075 \\
0.0072\end{array}$ & $\begin{array}{l}0.0273 \\
0.0262 \\
0.0252 \\
0.0242 \\
0.0232\end{array}$ & $\begin{array}{l}0.0042 \\
0.0040 \\
0.0038 \\
0.0036 \\
0.0035\end{array}$ & $\begin{array}{l}0.0321 \\
0.0309 \\
0.0297 \\
0.0285 \\
0.0275\end{array}$ & & $\begin{array}{l}0.0369 \\
0.0355 \\
0.0342 \\
0.0329 \\
0.0317\end{array}$ & $\begin{array}{l}4.1 \\
4.2 \\
4.3 \\
4.4 \\
4.5\end{array}$ \\
\hline $\begin{array}{l}4.6 \\
4.7 \\
4.8 \\
4.9 \\
5.0\end{array}$ & & $\begin{array}{l}0.01144 \\
0.01138 \\
0.00132 \\
0.00127 \\
0.01122\end{array}$ & $\begin{array}{l}0.0105 \\
0.0101 \\
0.0097 \\
0.0093 \\
0.0089\end{array}$ & $\begin{array}{l}0.0183 \\
0.0176 \\
0.0169 \\
0.0163 \\
0.0157\end{array}$ & $\begin{array}{l}0.0068 \\
0.0065 \\
0.0063 \\
0.0060 \\
0.0058\end{array}$ & $\begin{array}{l}0.0223 \\
0.0215 \\
0.0207 \\
0.0199 \\
0.0192\end{array}$ & $\begin{array}{l}0.0033 \\
0.0032 \\
0.0030 \\
0.0029 \\
0.0028\end{array}$ & $\begin{array}{l}0.0264 \\
0.0255 \\
0.0246 \\
0.0237 \\
0.0228\end{array}$ & & $\begin{array}{l}0.0306 \\
0.0295 \\
0.0285 \\
0.0275 \\
0.0266\end{array}$ & $\begin{array}{l}4.6 \\
4.7 \\
4.8 \\
4.9 \\
5.0\end{array}$ \\
\hline
\end{tabular}


ALPHA $=1.00$

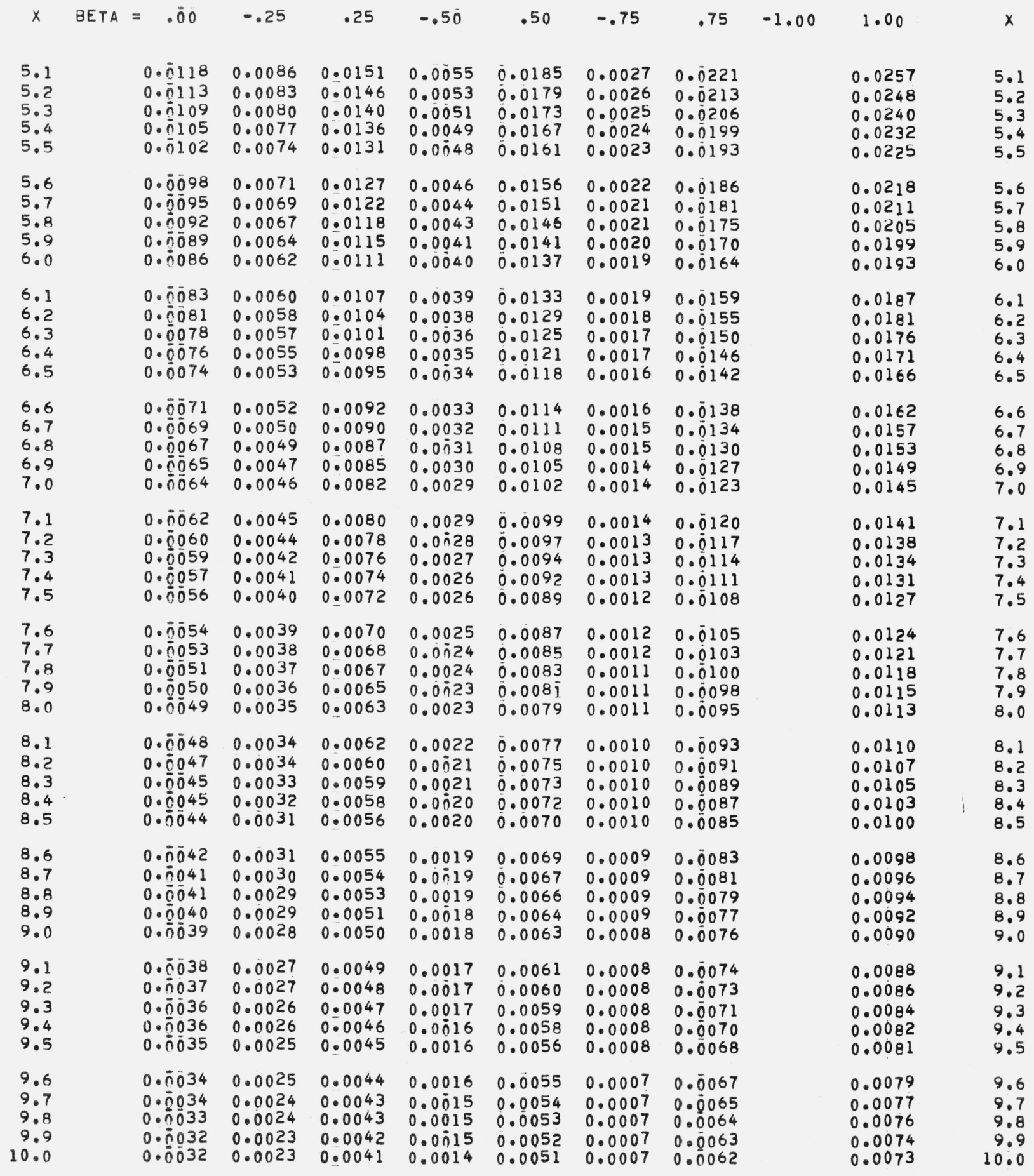


$A L P H A=1.00$

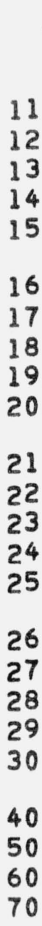

BETA $=.00$

$-.25$

.25

$-.50$

.50

$-.75$

.75

$-1.00$

1.00

$x$

11.

0.00026

0.00022

0.0019

$0 \cdot 0016$

0.00019

0.0034

0.0012

0.0042

0.0006

$\begin{array}{lll}0.0016 & 0.0028 & 0.0010\end{array}$

0.0014

0.00240 .0009

0.0012

0.00210 .0007

0.0035

0.0030

0.0026

0.0005

0.0004

$\begin{array}{ll}0.0018 & 0.0006\end{array}$

0.0023

0.0004

0.00012

0.0009

$0.0016 \quad 0.0006$

$0 \cdot 0011$

0.0010

0.0009

0.0008

0.0008

0.0014

0.0020

0.0003

0.0007

0.0006

0.0013

0.0005

0.0005

0.0011

0.0004

0.0018

0.0003

0.0016

0.0002

0.0002

0.0006

0.0010

0.0014

0.0002

0.00007

0.0007

0.0006

0.0005

0.0005

0.0009

0.0004

0.0013

0.0002

0.0005

0.0004

0.0008

0.0003

0.0011

0.0002

0.0004

0.0008

0.0003

0.0003

0.0010

0.0001

0.0004

0.0006

0.0003

0.0009

0.0009

0.0008

0.00005

0.0004

0.0004

0.0004

0.00003

0.0006

0.0002

0.0007

0.0003

0.0003

0.0006

0.0005

0.0002

0.0002

0.0002

0.0007

0.0003

0.0005

0.0005

0.0002

0.0006

0.0003

0.07002

0.0001

0.0001

0.0002
0.0002
0.0001

0.000

0.0005

0.0003

0.0002

0.0001

0.0051

0.0043

0.0036

0.0031

0.0027

0.0024

0.0021

0.0019

0.0017

0.0015

0.0014

0.0012

0.0011

0.0010

0.0010

0.0009

0.0008

0.0008

0.0007

0.0007

0.00004

0.0002

0.0002

0.0001

ALPHA $=1.25$

BETA $=.0 \overline{0}$

. .25

.25

$-.50$

.50

. .75

.75

0.2985

0.2901

0.2827

0.2727

0.2606

0.2375

0.2375

0.2507

\subsection{8}

0.1578

0.1090

0.1090

0.1472

0.1690

0.2097

0.2629

0.2738

0.1371

0.1807

0.1022

0.1957

0.2828

0.1277

0.1928

0.2052

0.1689

0.2896

0.1105

0.2177

0.0958

0.0899

0.0843

0.1163

0.1241

0.1323

0.1410

0.2469

0.1563

0.2937

0.1029

0.230

0.0791

0.1502

0.2320

0.2166

0.1444

0.2950

0.0957

0.2422

0.0743

0.1599

0.2933

0.0891

0.2537

0.0699

0.1229

0.2884

0.0830

0.2643

0.0657

0.1854

0.1133

0.2806

0.0774

0.2736

0.0618

0.1703

0.1044

0.2700

0.0722

0.2813

0.0582

0.1560

0.1424

0.1298

0.0962

0.2570

0.0674

0.2869

0.0549

0.2421

0.0630

0.2903

0.0887

0.2259

0.0589

0.2910

0.0517

0.0488

0.0461

0.0757

0.2089

0.0552

0.2889

0.0436

0.1075

0.0979

0.0699

0.1915

0.0517

$0.2838 \quad 0.0412$

0.1744

0.0485

$0.2758 \quad 0.0391$

0.0600

0.1579

0.0455

0.265

0.0370

0.0811

0.0740

0.0517

1422

0.0351

$\begin{array}{llll}0.0403 & 0.2361 & 0.0333\end{array}$

$0 . \overline{0} 676$

0.0618

0.0566

0.0519

0.0477

0.0481

0.037

$0.2189 \quad 0.0316$

$\begin{array}{lll}0.0357 & 0.2007 & 0.0301\end{array}$

0.0337

0.1820

0.0418

0.0912

0.0815

0.0319

0.0301

0.0286

0.0272

0.1452

0.0260

0.1700

0.1805 
ALPHA $=1.25$

2.

2.7

2.8

2.9

3.0

3.1

3.2

3.3

3.4

3.5

3.6

3.7

3.8

3.9

4.0

4.1

4.2

4.3

4.4

4.5

4.6

4.7

4.8

4.9

5.0

5.1

5.2

5.3

5.4

5.5

5.6

5.7

5.8

5.9

6.0

6.1

6.2

6.3

6.4

6.5

6.6

6.7

6.8

6.9

7.0

7.1

7.2

7.3

$7 \cdot 4$

7.5

\begin{tabular}{|c|c|c|c|}
\hline $\begin{array}{l}.0440 \\
.0406 \\
.0375 \\
.0348 \\
.03323\end{array}$ & $\begin{array}{l}0.0342 \\
0.0321 \\
0.0301 \\
0.0283 \\
0.0267\end{array}$ & $\begin{array}{l}0.0653 \\
0.0587 \\
0.0528 \\
0.0476 \\
0.0431\end{array}$ & $\begin{array}{l}0.0285 \\
0.0270 \\
0.0256 \\
0.0243 \\
0.0231\end{array}$ \\
\hline$\frac{1}{4}$ & $\begin{array}{l}0.0251 \\
0.0237 \\
0.0224 \\
0.0212 \\
0.0201\end{array}$ & & $\begin{array}{l}0.0220 \\
0.0209 \\
0.0199 \\
0.01190 \\
0.0181\end{array}$ \\
\hline $\begin{array}{l}.020 \\
-018 \\
-017\end{array}$ & $\begin{array}{l}0.0190 \\
0.0180 \\
0.0171 \\
0.0163 \\
0.0155\end{array}$ & $\begin{array}{l}0.0 \\
0.0 \\
0.0 \\
0.0 \\
0.0\end{array}$ & $\begin{array}{l}0.0 \\
0.0 \\
0.0 \\
0.0 \\
0.0\end{array}$ \\
\hline $\begin{array}{l}0 \\
0 \\
0 \\
0 \\
0 \\
0 \\
0\end{array}$ & $\begin{array}{l}0.0148 \\
0.0141 \\
0.0134 \\
0.0128 \\
0.0123\end{array}$ & & \\
\hline $\begin{array}{l}0.0 \\
0.0 \\
0.0 \\
0.0\end{array}$ & $\begin{array}{l}0.0117 \\
0.0112 \\
0.0108 \\
0.0103 \\
0.0099\end{array}$ & & \\
\hline $\begin{array}{l}\cdot 0 \\
\cdot 0 \\
\cdot 0 \\
0 \\
0\end{array}$ & $\begin{array}{l}0.0095 \\
0.0091 \\
0.0088 \\
0.0085 \\
0.0081\end{array}$ & $\begin{array}{l}0.0093 \\
0.0089 \\
0.0084 \\
0.0080 \\
0.0076\end{array}$ & $\begin{array}{l}0.0094 \\
0.0090 \\
0.0087 \\
0.0084 \\
0.0081\end{array}$ \\
\hline $\begin{array}{l}0 \cdot 0 \\
0 \cdot 0 \\
0 \cdot 0 \\
0 \cdot 0\end{array}$ & $\begin{array}{l}0.0078 \\
0.0075 \\
0.0073 \\
0.0070 \\
0.0068\end{array}$ & $\begin{array}{l}0.00 \\
0.00 \\
0.00 \\
0.00 \\
0.00\end{array}$ & $\begin{array}{l}0.0079 \\
0.0076 \\
0.0074 \\
0.0071 \\
0.0069\end{array}$ \\
\hline & $\begin{array}{l}0.0065 \\
0.0063 \\
0.0061 \\
0.0059 \\
0.0057\end{array}$ & $\begin{array}{l}0.0058 \\
0.0055 \\
0.0053 \\
0.0051 \\
0.0049\end{array}$ & $\begin{array}{l}0.0067 \\
0.0065 \\
0.0063 \\
0.0061 \\
0.0059\end{array}$ \\
\hline $\begin{array}{l}0.0 \\
0.0 \\
0.0 \\
0.0\end{array}$ & $\begin{array}{l}0.0055 \\
0.0054 \\
0.0052 \\
0.0050 \\
0.0049\end{array}$ & $\begin{array}{l}0.00 \\
0.00 \\
0.00 \\
0.00 \\
0.00\end{array}$ & $\begin{array}{l}0.0057 \\
0.0056 \\
0.0054 \\
0.0053 \\
0.0051\end{array}$ \\
\hline & $\begin{array}{l}0.0047 \\
0.0046 \\
0.0045 \\
0.0043 \\
0.0042\end{array}$ & $\begin{array}{l}0.0039 \\
0.0038 \\
0.0036 \\
0.0035 \\
0.0034\end{array}$ & $\begin{array}{l}0.0050 \\
0.0048 \\
0.0047 \\
0.0046 \\
0.0045\end{array}$ \\
\hline
\end{tabular}

0.1281 0.1123 0.0980 0.0852 0.0740

0.0643 0.0559 0.0488 0.0427 0.0376

0.0333 0.0296 0.0264 0.0237 0.0213

0.0193 0.0176 0.0161 0.0147 0.0135

0.0125

0.0116

0.0107

0.0100 0.0093

0.0087 0.0082 0.0077 0.0072 0.0068

0.0064

0.0061

0.0057

0.0054

0.0052

0.0049

0.0047

0.0044

0.0042

0.0040

0.0039

0.0037

0.0035

0.0034

0.0032

0.0031

0.0030

0.0029

0.0028

0.0027

$$
. .75
$$$$
.75
$$$$
-1.00
$$

1.00

0.0248 0.0236 0.0226 0.0215 0.0206

0.2440

0.0220

0.0211

0.2106

0.1917

0.0203

0.0195

0.1720

0.0187

0.1522

0.0197

0.0189

0.0181

0.0173

0.0166

0.1327

0.1142

0.0971

0.0816

0.0160

0.0153

0.0147

0.0142

0.0136

0.0679

0.0562

0.0463

0.0382

0.0315

0.0131

0.0126

0.0122

0.0117

0.0113

0.0262

0.0219

0.0186

0.0159

0.0137

0.0109

0.0105

0.0102

0.0098

0.0095

0.0120

0.0106

0.0094

0.0085

0.0077

0.0092

0.0089

0.0086

0.0084

0.0069

0.0063

0.0058

0.0054

0.0050

0.0078

0.0076

0.0074

0.0072

0.0046

0.0043

0.0040

0.0037

0.0069

0.0035

0.0068

0.0065

0.0064

0.0062

0.0033

0.0031

0.0029

0.0028

0.0180

0.0173

0.0166

0.0160

0.0154

0.0149

0.0143

0.0138

0.0133

0.0129

0.0124

0.0120

0.0116

0.0113

0.0109

0.0105

0.0102

0.0099

0.0096

0.0093

0.0060

0.0026

0.0090

0.0087

0.0085

0.0082

0.0080

0.0059

0.0057

0.00025

0.0055

0.0024

0.0022

0.0054

0.0021

0.0078

0.0076

0.0073

0.0071

0.0069

0.0053

0.0020

0.0068

0.0066

0.0064

0.0062

0.0061

0.0051

0.0050

0.0019

0.0059

0.0058

0.0056

0.0055

0.0049

0.0047

0.0018

0.0053

0.0046

0.0018

0.0052

0.0017

.005

0.0016

0.0040

0.0047

0.2772

0.2782

0.2770

0.2734

0.2674

0.2588

0.2476

0.2340

0.2182

0.2005

0.1813

0.1612

0.1407

0.1203

0.1007

0.0824

0.0657

0.0510

0.0385

0.0282

0.0200

0.0137

0.0090

0.0057

0.0035

0.0020

0.0011

0.0006 
ALPHA $=1.25$

$x$

BETA $=.00 \quad-.25$

$-.50$

.50

$-.75$

.75

$=1.00$

1.00

$x$

7.6

7.7

7.8

7.9

8.0

9.

10.

11.

12.

13.

14.

15.

16.

17.

18.

19.

20.

21.

22.

23.

24.

25.

26.

27.

28.

29.

30.

31.

38.

48.

$\begin{array}{lll}0.0038 & 0.0041 & 0.0033 \\ 0.0036 & 0.0040 & 0.0032 \\ 0.0035 & 0.0039 & 0.0031 \\ 0.0034 & 0.0038 & 0.0030 \\ 0.0033 & 0.0037 & 0.0029 \\ 0.0025 & 0.0028 & 0.0021 \\ 0.0020 & 0.0023 & 0.0016 \\ 0.0016 & 0.0018 & 0.0013 \\ 0.0013 & 0.0015 & 0.0010 \\ 0.0011 & 0.0013 & 0.0009 \\ 0.00009 & 0.0011 & 0.0007 \\ 0.0008 & 0.0009 & 0.0006 \\ 0.0007 & 0.0008 & 0.0005 \\ 0.0006 & 0.0007 & 0.0005 \\ 0.0005 & 0.0006 & 0.0004 \\ 0.00005 & 0.0005 & 0.0003 \\ 0.00004 & 0.0005 & 0.0003 \\ 0.0004 & 0.0004 & 0.0003 \\ 0.0003 & 0.0004 & 0.0002 \\ 0.0003 & 0.0003 & 0.0002 \\ 0.0003 & 0.0003 & 0.0002 \\ 0.0002 & 0.0003 & 0.0002 \\ 0.0002 & 0.0003 & 0.0002 \\ 0.0002 & 0.0002 & 0.0001 \\ 0.0002 & 0.0002 & \\ 0.0002 & 0.0002 & \\ 0.00002 & 0.0001 & \\ 0.0001 & & \\ & & \\ 0.0003 & \end{array}$

0.0043 0.0142

0.0041

0.0040

0.0039

0.0031

0.0025

0.0020

0.0017

0.0014

0.0012

0.0010

0.0009

0.0008

0.0007

0.0006

0.0006

0.0005

0.0005

0.0004

0.0004

0.0003

0.0003

0.0003

0.0003

0.0002

0.0002

0.0002

0.0001
0.0026 0.0025

0.0024

0.0023

0.0022

0.0016

0.001 ?

0.0009

0.0008

0.0006

0.0005

0.0004

0.0004

0.0003

0.0003

0.0002

0.0002

0.0002

0.0002

0.0001

0.0045

0.0044

0.0043

0.0042

0.0041

0.0032

0.0026

0.0022

0.0018

0.0015

0.0013

0.0011

0.0010

0.0009

0.0008

0.0007

0.0006

0.0006

0.0005

0.0005

0.0004

0.0004

0.0003

0.0003

0.0003

0.0003

0.0003

0.0002

0.0001
0.0015

0.0015

0.0014

0.0014

0.0013

0.00009

0.0007

0.0005

0.0004

0.0003

0.00003

0.0002

0.0002

0.0002

0.0001

0.0046

0.0045

0.0044

0.0043

0.0042

0.0034

0.0028

0.0023

0.0020

0.0017

0.0014

0.0012

0.0011

0.0010

0.0009

0.0008

0.0007

0.0006

0.0006

0.0005

0.0005

0.0004

0.0004

0.0004

0.0003

0.0003

0.0003

0.0003

0.0002

0.0001
7.6

7.7

7.8

7.9

8.0

9.

10 .

11.

12.

13.

14.

15.

16.

17.

18.

19.

20.

21.

22.

23.

24.

25.

26.

27.

28.

29.

30.

31.

38 .

48.

$A L P H A=1.50$

\begin{tabular}{|c|c|c|c|c|c|c|c|c|c|c|c|}
\hline$x$ & BETA & .00 &. .25 & .25 &. .50 & .50 & -.75 & .75 & -1.00 & 1.00 & $x$ \\
\hline $\begin{array}{l}0.0 \\
0.1 \\
0.2 \\
0.3 \\
0.4 \\
0.5\end{array}$ & - & $\begin{array}{l}0.2873 \\
0.2863 \\
0.2831 \\
0.2780 \\
0.2710 \\
0.2623\end{array}$ & $\begin{array}{l}0.2778 \\
0.2712 \\
0.2629 \\
0.2533 \\
0.2426 \\
0.2310\end{array}$ & $\begin{array}{l}0.2778 \\
0.2828 \\
0.2858 \\
0.2868 \\
0.2857 \\
0.2824\end{array}$ & $\begin{array}{l}0.2541 \\
0.2442 \\
0.2334 \\
0.2221 \\
0.2104 \\
0.1986\end{array}$ & $\begin{array}{l}0.2541 \\
0.2630 \\
0.2707 \\
0.2769 \\
0.2815 \\
0.2843\end{array}$ & $\begin{array}{l}0.2252 \\
0.2144 \\
0.2034 \\
0.1923 \\
0.1812 \\
0.11704\end{array}$ & $\begin{array}{l}0.2252 \\
0.2356 \\
0.2455 \\
0.2546 \\
0.2627 \\
0.2697\end{array}$ & $\begin{array}{l}0.1975 \\
0.1872 \\
0.1770 \\
0.1669 \\
0.1572 \\
0.1477\end{array}$ & $\begin{array}{l}0.1975 \\
0.2078 \\
0.2180 \\
0.2280 \\
0.2375 \\
0.2465\end{array}$ & $\begin{array}{l}0.0 \\
0.1 \\
0.2 \\
0.3 \\
0.4 \\
0.5\end{array}$ \\
\hline $\begin{array}{l}0.6 \\
0.7 \\
0.8 \\
0.9 \\
1.0\end{array}$ & & $\begin{array}{l}0.2521 \\
0.2408 \\
0.2285 \\
0.2155 \\
0.2020\end{array}$ & $\begin{array}{l}0.2189 \\
0.2063 \\
0.1936 \\
0.1808 \\
0.1683\end{array}$ & $\begin{array}{l}0.2772 \\
0.2700 \\
0.2610 \\
0.2505 \\
0.2386\end{array}$ & $\begin{array}{l}0.1867 \\
0.1749 \\
0.1634 \\
0.1522 \\
0.1415\end{array}$ & $\begin{array}{l}0.2851 \\
0.2839 \\
0.2806 \\
0.2753 \\
0.2680\end{array}$ & $\begin{array}{l}0.1598 \\
0.1495 \\
0.1397 \\
0.1303 \\
0.1214\end{array}$ & $\begin{array}{l}0.2754 \\
0.2795 \\
0.2819 \\
0.2825 \\
0.2811\end{array}$ & $\begin{array}{l}0.1386 \\
0.1299 \\
0.1216 \\
0.1137 \\
0.1062\end{array}$ & $\begin{array}{l}0.2548 \\
0.2621 \\
0.2683 \\
0.2733 \\
0.2769\end{array}$ & $\begin{array}{l}0.6 \\
0.7 \\
0.8 \\
0.9 \\
1.0\end{array}$ \\
\hline
\end{tabular}


ALPHA $=1.50$

\begin{tabular}{|c|c|c|c|c|c|c|c|c|c|c|c|}
\hline$x$ & BETA & .000 & -.25 & .25 &. .50 & .50 &. .75 & .75 & -1.00 & 1.00 & $x$ \\
\hline $\begin{array}{l}1.1 \\
1.2 \\
1.3 \\
1.4 \\
1.5\end{array}$ & & $\begin{array}{l}0.1884 \\
0.1748 \\
0.1615 \\
0.1486 \\
0.1361\end{array}$ & $\begin{array}{l}0.1561 \\
0.1443 \\
0.1331 \\
0.1224 \\
0.1124\end{array}$ & $\begin{array}{l}0.2257 \\
0.2119 \\
0.1977 \\
0.1832 \\
0.1688\end{array}$ & $\begin{array}{l}0.1313 \\
0.1216 \\
0.1124 \\
0.1038 \\
0.0958\end{array}$ & $\begin{array}{l}0.2589 \\
0.2481 \\
0.2359 \\
0.2225 \\
0.2082\end{array}$ & $\begin{array}{l}0.1129 \\
0.1050 \\
0.0975 \\
0.0905 \\
0.0840\end{array}$ & $\begin{array}{l}0.2777 \\
0.2724 \\
0.2650 \\
0.2559 \\
0.2450\end{array}$ & $\begin{array}{l}0.0992 \\
0.0926 \\
0.0865 \\
0.0807 \\
0.0753\end{array}$ & $\begin{array}{l}0.2788 \\
0.2790 \\
0.2774 \\
0.2738 \\
0.2684\end{array}$ & $\begin{array}{l}1.1 \\
1.2 \\
1.3 \\
1.4 \\
1.5\end{array}$ \\
\hline $\begin{array}{l}1.6 \\
1.7 \\
1.8 \\
1.9 \\
2.0\end{array}$ & & $\begin{array}{l}0.1243 \\
0.1133 \\
0.1029 \\
0.0933 \\
0.0845\end{array}$ & $\begin{array}{l}0.1031 \\
0.0944 \\
0.0863 \\
0.0789 \\
0.0721\end{array}$ & $\begin{array}{l}0.1546 \\
0.1409 \\
0.1278 \\
0.1154 \\
0.1038\end{array}$ & $\begin{array}{l}0.0884 \\
0.0815 \\
0.0751 \\
0.0692 \\
0.0638\end{array}$ & $\begin{array}{l}0.1933 \\
0.1781 \\
0.1628 \\
0.1478 \\
0.1333\end{array}$ & $\begin{array}{l}0.0780 \\
0.0723 \\
0.0671 \\
0.0623 \\
0.0579\end{array}$ & $\begin{array}{l}0.2325 \\
0.2188 \\
0.2041 \\
0.1887 \\
0.1729\end{array}$ & $\begin{array}{l}0.0702 \\
0.0655 \\
0.0612 \\
0.0571 \\
0.0534\end{array}$ & $\begin{array}{l}0.2610 \\
0.2518 \\
0.2408 \\
0.2283 \\
0.2145\end{array}$ & $\begin{array}{l}1.6 \\
1.7 \\
1.8 \\
1.9 \\
2.0\end{array}$ \\
\hline $\begin{array}{l}2.1 \\
2.2 \\
2.3 \\
2.4 \\
2.5\end{array}$ & & $\begin{array}{l}0.0765 \\
0.0692 \\
0.0625 \\
0.0565 \\
0.0511\end{array}$ & $\begin{array}{l}0.0660 \\
0.0603 \\
0.0551 \\
0.0505 \\
0.0462\end{array}$ & $\begin{array}{l}0.0931 \\
0.0833 \\
0.0743 \\
0.0663 \\
0.0590\end{array}$ & $\begin{array}{l}0.0589 \\
0.0543 \\
0.0501 \\
0.0463 \\
0.0428\end{array}$ & $\begin{array}{l}0.1194 \\
0.1064 \\
0.0942 \\
0.0831 \\
0.0729\end{array}$ & $\begin{array}{l}0.0538 \\
0.0500 \\
0.0465 \\
0.0433 \\
0.0403\end{array}$ & $\begin{array}{l}0.1569 \\
0.1412 \\
0.1259 \\
0.1112 \\
0.0974\end{array}$ & $\begin{array}{l}0.0499 \\
0.0467 \\
0.0437 \\
0.0409 \\
0.0383\end{array}$ & $\begin{array}{l}0.1995 \\
0.1838 \\
0.1675 \\
0.1510 \\
0.1346\end{array}$ & $\begin{array}{l}2.1 \\
2.2 \\
2.3 \\
2.4 \\
2.5\end{array}$ \\
\hline $\begin{array}{l}2.6 \\
2.7 \\
2.8 \\
2.9 \\
3.0\end{array}$ & & $\begin{array}{l}0.0463 \\
0.0420 \\
0.0381 \\
0.0346 \\
0.0315\end{array}$ & $\begin{array}{l}0.0424 \\
0.0389 \\
0.0358 \\
0.0329 \\
0.0303\end{array}$ & $\begin{array}{l}0.0526 \\
0.0468 \\
0.0418 \\
0.0373 \\
0.0333\end{array}$ & $\begin{array}{l}0.0396 \\
0.0367 \\
0.0341 \\
0.0316 \\
0.0294\end{array}$ & $\begin{array}{l}0.0639 \\
0.0558 \\
0.0486 \\
0.0423 \\
0.0369\end{array}$ & $\begin{array}{l}0.0376 \\
0.0351 \\
0.0328 \\
0.0306 \\
0.0287\end{array}$ & $\begin{array}{l}0.0847 \\
0.0730 \\
0.0625 \\
0.0531 \\
0.0450\end{array}$ & $\begin{array}{l}0.0359 \\
0.0337 \\
0.0317 \\
0.0298 \\
0.0280\end{array}$ & $\begin{array}{l}0.1186 \\
0.1033 \\
0.0888 \\
0.0753 \\
0.0631\end{array}$ & $\begin{array}{l}2.6 \\
2.7 \\
2.8 \\
2.9 \\
3.0\end{array}$ \\
\hline $\begin{array}{l}3.1 \\
3.2 \\
3.3 \\
3.4 \\
3.5\end{array}$ & & $\begin{array}{l}0.0 \overline{2} 287 \\
0.02262 \\
0.02240 \\
0.0220 \\
0.02203\end{array}$ & $\begin{array}{l}0.0280 \\
0.0258 \\
0.0239 \\
0.0222 \\
0.0206\end{array}$ & $\begin{array}{l}0.0299 \\
0.0268 \\
0.0242 \\
0.0218 \\
0.0197\end{array}$ & $\begin{array}{l}0.0274 \\
0.0255 \\
0.0238 \\
0.0222 \\
0.0208\end{array}$ & $\begin{array}{l}0.0322 \\
0.0281 \\
0.0246 \\
0.0216 \\
0.0190\end{array}$ & $\begin{array}{l}0.0268 \\
0.0252 \\
0.0236 \\
0.0222 \\
0.0209\end{array}$ & $\begin{array}{l}0.0378 \\
0.0318 \\
0.0266 \\
0.0223 \\
0.0186\end{array}$ & $\begin{array}{l}0.0264 \\
0.0248 \\
0.0234 \\
0.0221 \\
0.0209\end{array}$ & $\begin{array}{l}0.0521 \\
0.0424 \\
0.0340 \\
0.0269 \\
0.0209\end{array}$ & $\begin{array}{l}3.1 \\
3.2 \\
3.3 \\
3.4 \\
3.5\end{array}$ \\
\hline $\begin{array}{l}3.6 \\
3.7 \\
3.8 \\
3.9 \\
4.0\end{array}$ & & $\begin{array}{l}0.0186 \\
0.01172 \\
0.0159 \\
0.01147 \\
0.0137\end{array}$ & $\begin{array}{l}0.0191 \\
0.0178 \\
0.0166 \\
0.0155 \\
0.0145\end{array}$ & $\begin{array}{l}0.0179 \\
0.0163 \\
0.0149 \\
0.0136 \\
0.0125\end{array}$ & $\begin{array}{l}0.0194 \\
0.0182 \\
0.0171 \\
0.0161 \\
0.0151\end{array}$ & $\begin{array}{l}0.0168 \\
0.0149 \\
0.0133 \\
0.0120 \\
0.0107\end{array}$ & $\begin{array}{l}0.0196 \\
0.0185 \\
0.0174 \\
0.0165 \\
0.0156\end{array}$ & $\begin{array}{l}0.0157 \\
0.0132 \\
0.0112 \\
0.0095 \\
0.0082\end{array}$ & $\begin{array}{l}0.0197 \\
0.0187 \\
0.0177 \\
0.0167 \\
0.0159\end{array}$ & $\begin{array}{l}0.0160 \\
0.0121 \\
0.0089 \\
0.0065 \\
0.0047\end{array}$ & $\begin{array}{l}3.6 \\
3.7 \\
3.8 \\
3.9 \\
4.0\end{array}$ \\
\hline $\begin{array}{l}4.1 \\
4.2 \\
4.3 \\
4.4 \\
4.5\end{array}$ & & $\begin{array}{l}0.00127 \\
0.01118 \\
0.01110 \\
0.01103 \\
0.0097\end{array}$ & $\begin{array}{l}0.0136 \\
0.0128 \\
0.0120 \\
0.0113 \\
0.0106\end{array}$ & $\begin{array}{l}0.0115 \\
0.0106 \\
0.0098 \\
0.0091 \\
0.0084\end{array}$ & $\begin{array}{l}0.0142 \\
0.0134 \\
0.0127 \\
0.0120 \\
0.0113\end{array}$ & $\begin{array}{l}0.0097 \\
0.0088 \\
0.0080 \\
0.0073 \\
0.0067\end{array}$ & $\begin{array}{l}0.0147 \\
0.0139 \\
0.0132 \\
0.0125 \\
0.0119\end{array}$ & $\begin{array}{l}0.00071 \\
0.0062 \\
0.0055 \\
0.0048 \\
0.0043\end{array}$ & $\begin{array}{l}0.0151 \\
0.0143 \\
0.0136 \\
0.0130 \\
0.0123\end{array}$ & $\begin{array}{l}0.0033 \\
0.0023 \\
0.0015 \\
0.0010 \\
0.0007\end{array}$ & $\begin{array}{l}4.1 \\
4.2 \\
4.3 \\
4.4 \\
4.5\end{array}$ \\
\hline $\begin{array}{l}4.6 \\
4.7 \\
4.8 \\
4.9 \\
5.0\end{array}$ & & $\begin{array}{l}0.00091 \\
0.0085 \\
0.00880 \\
0.0075 \\
0.0071\end{array}$ & $\begin{array}{l}0.0100 \\
0.0094 \\
0.0089 \\
0.0084 \\
0.0080\end{array}$ & $\begin{array}{l}0.0078 \\
0.0073 \\
0.0068 \\
0.0064 \\
0.0060\end{array}$ & $\begin{array}{l}0.0107 \\
0.0102 \\
0.0096 \\
0.0092 \\
0.0087\end{array}$ & $\begin{array}{l}0.0062 \\
0.0057 \\
0.0053 \\
0.0049 \\
0.0046\end{array}$ & $\begin{array}{l}0.0113 \\
0.0107 \\
0.0102 \\
0.0097 \\
0.0093\end{array}$ & $\begin{array}{l}0.00039 \\
0.0035 \\
0.0032 \\
0.0029 \\
0.00027\end{array}$ & $\begin{array}{l}0.0118 \\
0.0112 \\
0.0107 \\
0.0102 \\
0.0098\end{array}$ & $\begin{array}{l}0.0004 \\
0.0003 \\
0.0002 \\
0.0001\end{array}$ & $\begin{array}{l}4.6 \\
4.7 \\
4.8 \\
4.9 \\
5.0\end{array}$ \\
\hline $\begin{array}{l}5.1 \\
5.2 \\
5.3 \\
5.4 \\
5.5\end{array}$ & & $\begin{array}{l}0.0007 \\
0.00063 \\
0.0060 \\
0.00557 \\
0.0054\end{array}$ & $\begin{array}{l}0.0076 \\
0.0072 \\
0.0068 \\
0.0065 \\
0.0062\end{array}$ & $\begin{array}{l}0.0056 \\
0.0053 \\
0.0050 \\
0.0047 \\
0.0045\end{array}$ & $\begin{array}{l}0.0083 \\
0.0079 \\
0.0075 \\
0.0072 \\
0.0768\end{array}$ & $\begin{array}{l}0.0043 \\
0.0040 \\
0.0037 \\
0.0035 \\
0.0033\end{array}$ & $\begin{array}{l}0.0088 \\
0.0085 \\
0.0081 \\
0.0077 \\
0.0074\end{array}$ & $\begin{array}{l}0.0025 \\
0.0023 \\
0.00021 \\
0.00020 \\
0.0018\end{array}$ & $\begin{array}{l}0.0093 \\
0.0089 \\
0.0086 \\
0.0082 \\
0.0078\end{array}$ & & $\begin{array}{l}5.1 \\
5.2 \\
5.3 \\
5.4 \\
5.5\end{array}$ \\
\hline $\begin{array}{l}5.6 \\
5.7 \\
5.8 \\
5.9 \\
6.0\end{array}$ & & $\begin{array}{l}0.0051 \\
0.0049 \\
0.0046 \\
0.0044 \\
0.0042\end{array}$ & $\begin{array}{l}0.0059 \\
0.0056 \\
0.0054 \\
0.0051 \\
0.0049\end{array}$ & $\begin{array}{l}0.0042 \\
0.0040 \\
0.0038 \\
0.0036 \\
0.0034\end{array}$ & $\begin{array}{l}0.0065 \\
0.0062 \\
0.0060 \\
0.0057 \\
0.0055\end{array}$ & $\begin{array}{l}0.0031 \\
0.0029 \\
0.0028 \\
0.0026 \\
0.0025\end{array}$ & $\begin{array}{l}0.0071 \\
0.0068 \\
0.0065 \\
0.0062 \\
0.0060\end{array}$ & $\begin{array}{l}0.0017 \\
0.0016 \\
0.0015 \\
0.0014 \\
0.0014\end{array}$ & $\begin{array}{l}0.0075 \\
0.0072 \\
0.0069 \\
0.0067 \\
0.0064\end{array}$ & & $\begin{array}{l}5.6 \\
5.7 \\
5.8 \\
5.9 \\
6.0\end{array}$ \\
\hline
\end{tabular}


ALPHA $=1.50$

\begin{tabular}{|c|c|c|c|c|c|c|c|c|c|c|}
\hline$x$ & BETA $=$ & .00 & -.25 & .25 & -.50 & .50 & -.75 & .75 & 1.00 & $x$ \\
\hline $\begin{array}{l}6.1 \\
6.2 \\
6.3 \\
6.4 \\
6.5\end{array}$ & & $\begin{array}{l}0.0040 \\
0.0038 \\
0.0037 \\
0.0035 \\
0.0034\end{array}$ & $\begin{array}{l}0.0047 \\
0.0045 \\
0.0043 \\
0.00041 \\
0.0040\end{array}$ & $\begin{array}{l}0.0033 \\
0.0031 \\
0.0030 \\
0.0028 \\
0.0027\end{array}$ & $\begin{array}{l}0.0053 \\
0.0050 \\
0.0 \hat{n} 48 \\
0.0046 \\
0.0045\end{array}$ & $\begin{array}{l}0.0024 \\
0.0022 \\
0.0021 \\
0.0020 \\
0.0019\end{array}$ & $\begin{array}{l}0.0057 \\
0.0055 \\
0.0053 \\
0.0051 \\
0.0049\end{array}$ & $\begin{array}{l}0.00013 \\
0.00012 \\
0.00011 \\
0.00011 \\
0.00010\end{array}$ & $\begin{array}{l}0.0062 \\
0.0059 \\
0.0057 \\
0.0055 \\
0.0053\end{array}$ & $\begin{array}{l}6.1 \\
6.2 \\
6.3 \\
6.4 \\
6.5\end{array}$ \\
\hline $\begin{array}{l}6.6 \\
6.7 \\
6.8 \\
6.9 \\
7.0\end{array}$ & & $\begin{array}{l}0.00032 \\
0.0031 \\
0.0030 \\
0.00029 \\
0.0027\end{array}$ & $\begin{array}{l}0.0038 \\
0.0036 \\
0.00035 \\
0.0034 \\
0.0032\end{array}$ & $\begin{array}{l}0.0026 \\
0.0025 \\
0.0024 \\
0.0023 \\
0.0022\end{array}$ & $\begin{array}{l}0.0043 \\
0.0041 \\
0.0040 \\
0.0038 \\
0.0037\end{array}$ & $\begin{array}{l}0.0018 \\
0.0018 \\
0.0017 \\
0.0016 \\
0.0015\end{array}$ & $\begin{array}{l}0.0047 \\
0.0046 \\
0.0044 \\
0.0042 \\
0.0041\end{array}$ & $\begin{array}{l}0.0010 \\
0.0009 \\
0.0009 \\
0.0009 \\
0.0008\end{array}$ & $\begin{array}{l}0.0051 \\
0.0049 \\
0.0048 \\
0.0046 \\
0.0045\end{array}$ & $\begin{array}{l}6.6 \\
6.7 \\
6.8 \\
6.9 \\
7.0\end{array}$ \\
\hline $\begin{array}{l}7.1 \\
7.2 \\
7.3 \\
7.4 \\
7.5\end{array}$ & & $\begin{array}{l}0.0026 \\
0.0025 \\
0.0024 \\
0.0023 \\
0.0023\end{array}$ & $\begin{array}{l}0.0031 \\
0.0030 \\
0.0029 \\
0.0028 \\
0.0027\end{array}$ & $\begin{array}{l}0.0021 \\
0.0020 \\
0.0019 \\
0.0019 \\
0.0018\end{array}$ & $\begin{array}{l}0.0036 \\
0.0034 \\
0.00333 \\
0.0032 \\
0.0031\end{array}$ & $\begin{array}{l}0.0015 \\
0.0014 \\
0.0014 \\
0.0013 \\
0.0012\end{array}$ & $\begin{array}{l}0.0040 \\
0.0038 \\
0.0037 \\
0.0036 \\
0.0034\end{array}$ & $\begin{array}{l}0.0008 \\
0.0007 \\
0.0007 \\
0.0007 \\
0.0007\end{array}$ & $\begin{array}{l}0.0043 \\
0.0042 \\
0.0040 \\
0.0039 \\
0.0038\end{array}$ & $\begin{array}{l}7.1 \\
7.2 \\
7.3 \\
7.4 \\
7.5\end{array}$ \\
\hline $\begin{array}{l}7.6 \\
7.7 \\
7.8 \\
7.9 \\
8.0 \\
9.0\end{array}$ & & $\begin{array}{l}0.0022 \\
0.0021 \\
0.0020 \\
0.0020 \\
0.0019 \\
0.0014\end{array}$ & $\begin{array}{l}0.0026 \\
0.0025 \\
0.0024 \\
0.0023 \\
0.0023 \\
0.0017\end{array}$ & $\begin{array}{l}0.0017 \\
0.0017 \\
0.0016 \\
0.0015 \\
0.0015 \\
0.0011\end{array}$ & $\begin{array}{l}0.0030 \\
0.0029 \\
0.0 ก 28 \\
0.0027 \\
0.0 ก 26 \\
0.0019\end{array}$ & $\begin{array}{l}0.00012 \\
0.0012 \\
0.0011 \\
0.0011 \\
0.0010 \\
0.0007\end{array}$ & $\begin{array}{l}0.0033 \\
0.0032 \\
0.0031 \\
0.0030 \\
0.0029 \\
0.0022\end{array}$ & $\begin{array}{l}0.0006 \\
0.0006 \\
0.0006 \\
0.0006 \\
0.0005 \\
0.0004\end{array}$ & $\begin{array}{l}0.0036 \\
0.0035 \\
0.0034 \\
0.0033 \\
0.0032 \\
0.0024\end{array}$ & $\begin{array}{l}7.6 \\
7.7 \\
7.8 \\
7.9 \\
8.0 \\
9.0\end{array}$ \\
\hline $\begin{array}{l}10 . \\
11 . \\
12 . \\
13 \\
14 .\end{array}$ & & $\begin{array}{l}0.00010 \\
0.0008 \\
0.0006 \\
0.0005 \\
0.0004\end{array}$ & $\begin{array}{l}0.0013 \\
0.0010 \\
0.0008 \\
0.0006 \\
0.0005\end{array}$ & $\begin{array}{l}0.0008 \\
0.0006 \\
0.0005 \\
0.0004 \\
0.0003\end{array}$ & $\begin{array}{l}0.0015 \\
0.0012 \\
0.0009 \\
0.0008 \\
0.0006\end{array}$ & $\begin{array}{l}0.0005 \\
0.0004 \\
0.0003 \\
0.0003 \\
0.0002\end{array}$ & $\begin{array}{l}0.0017 \\
0.0013 \\
0.0011 \\
0.0009 \\
0.0007\end{array}$ & $\begin{array}{l}0.00003 \\
0.00002 \\
0.00002 \\
0.00001\end{array}$ & $\begin{array}{l}0.0019 \\
0.0015 \\
0.0012 \\
0.0010 \\
0.0008\end{array}$ & $\begin{array}{l}10 . \\
110 \\
120 \\
13 . \\
14 .\end{array}$ \\
\hline $\begin{array}{l}15 . \\
16 . \\
170^{\circ} \\
18 . \\
19 .\end{array}$ & & $\begin{array}{l}0.00004 \\
0.00003 \\
0.00003 \\
0.00002 \\
0.00002\end{array}$ & $\begin{array}{l}0.0004 \\
0.0004 \\
0.0003 \\
0.0003 \\
0.0002\end{array}$ & $\begin{array}{l}0.0003 \\
0.0002 \\
0.0002 \\
0.0002 \\
0.0001\end{array}$ & $\begin{array}{l}0.0005 \\
0.0004 \\
0.0004 \\
0.0003 \\
0.0003\end{array}$ & $\begin{array}{l}0.0002 \\
0.0001\end{array}$ & $\begin{array}{l}0.0006 \\
0.0005 \\
0.0004 \\
0.0004 \\
0.0003\end{array}$ & & $\begin{array}{l}0.0007 \\
0.0006 \\
0.0005 \\
0.0004 \\
0.0004\end{array}$ & $\begin{array}{l}15 . \\
160^{\circ} \\
170^{\circ} \\
18^{\circ} \\
19 .\end{array}$ \\
\hline $\begin{array}{l}20 . \\
21 . \\
22 . \\
23 . \\
24 .\end{array}$ & & $\begin{array}{l}0.0 \overline{0} 002 \\
0.0 \overline{0} 01\end{array}$ & $\begin{array}{l}0.0002 \\
0.0002 \\
0.0002 \\
0.0001\end{array}$ & & $\begin{array}{l}0.0002 \\
0.0002 \\
0.0002 \\
0.0002 \\
0.0002\end{array}$ & & $\begin{array}{l}0.0003 \\
0.0003 \\
0.0002 \\
0.0002 \\
0.0002\end{array}$ & & $\begin{array}{l}0.0003 \\
0.0003 \\
0.0003 \\
0.0002 \\
0.0002\end{array}$ & $\begin{array}{l}20 . \\
21 . \\
22 . \\
23 . \\
24 .\end{array}$ \\
\hline $\begin{array}{l}25 . \\
26 . \\
27 .\end{array}$ & & & & & 0.0001 & & $\begin{array}{l}0.0002 \\
0.0001\end{array}$ & & $\begin{array}{l}0.0002 \\
0.0002 \\
0.0001\end{array}$ & $\begin{array}{l}25 . \\
26 . \\
27 .\end{array}$ \\
\hline
\end{tabular}


ALPHA $=1.75$

\begin{tabular}{|c|c|c|c|c|c|c|c|c|c|c|c|}
\hline$x$ & BETA & .00 & -.25 & .25 &. .50 & .50 & -.75 & .75 & -1.00 & 1.00 & $x$ \\
\hline $\begin{array}{l}0.0 \\
0.1 \\
0.2 \\
0.3 \\
0.4 \\
0.5\end{array}$ & & $\begin{array}{l}0.2835 \\
0.2824 \\
0.2800 \\
0.2761 \\
0.2706 \\
0.2636\end{array}$ & $\begin{array}{l}0.2821 \\
0.2793 \\
0.2750 \\
0.2692 \\
0.2621 \\
0.2537\end{array}$ & $\begin{array}{l}0.2821 \\
0.2833 \\
0.2828 \\
0.2807 \\
0.2770 \\
0.2717\end{array}$ & $\begin{array}{l}0.2782 \\
0.2736 \\
0.2677 \\
0.2604 \\
0.2520 \\
0.2427\end{array}$ & $\begin{array}{l}0.2782 \\
0.2813 \\
0.2828 \\
0.2827 \\
0.2809 \\
0.2775\end{array}$ & $\begin{array}{l}0.2720 \\
0.2660 \\
0.2587 \\
0.2503 \\
0.2410 \\
0.2310\end{array}$ & $\begin{array}{l}0.2720 \\
0.2768 \\
0.2801 \\
0.2819 \\
0.2821 \\
0.2807\end{array}$ & $\begin{array}{l}0.2642 \\
0.2569 \\
0.2486 \\
0.2395 \\
0.2297 \\
0.2193\end{array}$ & $\begin{array}{l}0.2642 \\
0.2703 \\
0.2752 \\
0.2787 \\
0.2808 \\
0.2813\end{array}$ & $\begin{array}{l}0.0 \\
0.1 \\
0.2 \\
0.3 \\
0.4 \\
0.5\end{array}$ \\
\hline $\begin{array}{l}1.1 \\
1.2 \\
1.3 \\
1.4 \\
1.5\end{array}$ & & $\begin{array}{l}0.2003 \\
0.1878 \\
0.1752 \\
0.1626 \\
0.1502\end{array}$ & $\begin{array}{l}0.1872 \\
0.1750 \\
0.1628 \\
0.1508 \\
0.1392\end{array}$ & $\begin{array}{l}0.2138 \\
0.2013 \\
0.1885 \\
0.1755 \\
0.1626\end{array}$ & $\begin{array}{l}0.1750 \\
0.1632 \\
0.1516 \\
0.1404 \\
0.1295\end{array}$ & $\begin{array}{l}0.2272 \\
0.2152 \\
0.2025 \\
0.1894 \\
0.1761\end{array}$ & $\begin{array}{l}0.1637 \\
0.1526 \\
0.1417 \\
0.1312 \\
0.1212\end{array}$ & $\begin{array}{l}0.2399 \\
0.2286 \\
0.2165 \\
0.2037 \\
0.1904\end{array}$ & $\begin{array}{l}0.1536 \\
0.1431 \\
0.1330 \\
0.1232 \\
0.1139\end{array}$ & $\begin{array}{l}0.2511 \\
0.2411 \\
0.2299 \\
0.2178 \\
0.2050\end{array}$ & $\begin{array}{l}1.1 \\
1.2 \\
1.3 \\
1.4 \\
1.5\end{array}$ \\
\hline $\begin{array}{l}1.6 \\
1.7 \\
1.8 \\
1.9 \\
2.0\end{array}$ & & $\begin{array}{l}0.1381 \\
0.1265 \\
0.1153 \\
0.1047 \\
0.15948\end{array}$ & $\begin{array}{l}0.1279 \\
0.1172 \\
0.1070 \\
0.0973 \\
0.0883\end{array}$ & $\begin{array}{l}0.1498 \\
0.1373 \\
0.1252 \\
0.1136 \\
0.1026\end{array}$ & $\begin{array}{l}0.1191 \\
0.1092 \\
0.0999 \\
0.0911 \\
0.0830\end{array}$ & $\begin{array}{l}0.1628 \\
0.1495 \\
0.1366 \\
0.1241 \\
0.1121\end{array}$ & $\begin{array}{l}0.1116 \\
0.1025 \\
0.0940 \\
0.0860 \\
0.0785\end{array}$ & $\begin{array}{l}0.1768 \\
0.1632 \\
0.1495 \\
0.1362 \\
0.1232\end{array}$ & $\begin{array}{l}0.1051 \\
0.0968 \\
0.0890 \\
0.0817 \\
0.0749\end{array}$ & $\begin{array}{l}0.1915 \\
0.1777 \\
0.1637 \\
0.1498 \\
0.1360\end{array}$ & $\begin{array}{l}1.6 \\
1.7 \\
1.8 \\
1.9 \\
2.0\end{array}$ \\
\hline $\begin{array}{l}2.1 \\
2.2 \\
2.3 \\
2.4 \\
2.5\end{array}$ & & $\begin{array}{l}0.08855 \\
0.0768 \\
0.0689 \\
0.00616 \\
0.0549\end{array}$ & $\begin{array}{l}0.0799 \\
0.0721 \\
0.0650 \\
0.0585 \\
0.0525\end{array}$ & $\begin{array}{l}0.0923 \\
0.0827 \\
0.0738 \\
0.0656 \\
0.0581\end{array}$ & $\begin{array}{l}0.0754 \\
0.0683 \\
0.0619 \\
0.0560 \\
0.0506\end{array}$ & $\begin{array}{l}0.1007 \\
0.0899 \\
0.0800 \\
0.0707 \\
0.0623\end{array}$ & $\begin{array}{l}0.0716 \\
0.0653 \\
0.0594 \\
0.0540 \\
0.0491\end{array}$ & $\begin{array}{l}0.1107 \\
0.0989 \\
0.0877 \\
0.0773 \\
0.0678\end{array}$ & $\begin{array}{l}0.0685 \\
0.0627 \\
0.0573 \\
0.0524 \\
0.0478\end{array}$ & $\begin{array}{l}0.1225 \\
0.1096 \\
0.0973 \\
0.0857 \\
0.0749\end{array}$ & $\begin{array}{l}2.1 \\
2.2 \\
2.3 \\
2.4 \\
2.5\end{array}$ \\
\hline $\begin{array}{l}2.6 \\
2.7 \\
2.8 \\
2.9 \\
3.0\end{array}$ & & $\begin{array}{l}0.0489 \\
0.0435 \\
0.0386 \\
0.0343 \\
0.0304\end{array}$ & $\begin{array}{l}0.0471 \\
0.0422 \\
0.0378 \\
0.0339 \\
0.0303\end{array}$ & $\begin{array}{l}0.0514 \\
0.0453 \\
0.0398 \\
0.0350 \\
0.0307\end{array}$ & $\begin{array}{l}0.0457 \\
0.0413 \\
0.0372 \\
0.0336 \\
0.0303\end{array}$ & $\begin{array}{l}0.0546 \\
0.0477 \\
0.0415 \\
0.0360 \\
0.0312\end{array}$ & $\begin{array}{l}0.0446 \\
0.0405 \\
0.0368 \\
0.0334 \\
0.0304\end{array}$ & $\begin{array}{l}0.0590 \\
0.0511 \\
0.0440 \\
0.0377 \\
0.0321\end{array}$ & $\begin{array}{l}0.0437 \\
0.0399 \\
0.0364 \\
0.0333 \\
0.0305\end{array}$ & $\begin{array}{l}0.0649 \\
0.0558 \\
0.0477 \\
0.0403 \\
0.0338\end{array}$ & $\begin{array}{l}2.6 \\
2.7 \\
2.8 \\
2.9 \\
3.0\end{array}$ \\
\hline $\begin{array}{l}3.6 \\
3.7 \\
3.8 \\
3.9 \\
4.0\end{array}$ & & $\begin{array}{l}0.0150 \\
0.01134 \\
0.01120 \\
0.01108 \\
0.00097\end{array}$ & $\begin{array}{l}0.0159 \\
0.0114 \\
0.01130 \\
0.0118 \\
0.01107\end{array}$ & $\begin{array}{l}0.0139 \\
0.0123 \\
0.0108 \\
0.0096 \\
0.0085\end{array}$ & $\begin{array}{l}0.0168 \\
0.0153 \\
0.0139 \\
0.0127 \\
0.0116\end{array}$ & $\begin{array}{l}0.0127 \\
0.0110 \\
0.0095 \\
0.0082 \\
0.0071\end{array}$ & $\begin{array}{l}0.0175 \\
0.0160 \\
0.01147 \\
0.0135 \\
0.0124\end{array}$ & $\begin{array}{l}0.0113 \\
0.0095 \\
0.0079 \\
0.0066 \\
0.0055\end{array}$ & $\begin{array}{l}0.0181 \\
0.0167 \\
0.0154 \\
0.0142 \\
0.0131\end{array}$ & $\begin{array}{l}0.0099 \\
0.0078 \\
0.0061 \\
0.0047 \\
0.0036\end{array}$ & $\begin{array}{l}3.6 \\
3.7 \\
3.8 \\
3.9 \\
4.0\end{array}$ \\
\hline $\begin{array}{l}4.1 \\
4.2 \\
4.3 \\
4.4 \\
4.5\end{array}$ & & $\begin{array}{l}0.0 \overline{0} 87 \\
0.00079 \\
0.0072 \\
0.00065 \\
0.0060\end{array}$ & $\begin{array}{l}0.0098 \\
0.0089 \\
0.0081 \\
0.0075 \\
0.0069\end{array}$ & $\begin{array}{l}0.0076 \\
0.0068 \\
0.0061 \\
0.0055 \\
0.0049\end{array}$ & $\begin{array}{l}0.0106 \\
0.0098 \\
0.0090 \\
0.0083 \\
0.0077\end{array}$ & $\begin{array}{l}0.0062 \\
0.0055 \\
0.0048 \\
0.0042 \\
0.0038\end{array}$ & $\begin{array}{l}0.0114 \\
0.0106 \\
0.0098 \\
0.0090 \\
0.0084\end{array}$ & $\begin{array}{l}0.00046 \\
0.00039 \\
0.0033 \\
0.00028 \\
0.00024\end{array}$ & $\begin{array}{l}0.0121 \\
0.0113 \\
0.0104 \\
0.0097 \\
0.0090\end{array}$ & $\begin{array}{l}0.0028 \\
0.0021 \\
0.0016 \\
0.0012 \\
0.0008\end{array}$ & $\begin{array}{l}4.1 \\
4.2 \\
4.3 \\
4.4 \\
4.5\end{array}$ \\
\hline $\begin{array}{l}4.6 \\
4.7 \\
4.8 \\
4.9 \\
5.0\end{array}$ & & $\begin{array}{l}0.00054 \\
0.0050 \\
0.0046 \\
0.00042 \\
0.0039\end{array}$ & $\begin{array}{l}0.0063 \\
0.0058 \\
0.0054 \\
0.0050 \\
0.0046\end{array}$ & $\begin{array}{l}0.0045 \\
0.0041 \\
0.0037 \\
0.0034 \\
0.0031\end{array}$ & $\begin{array}{l}0.0071 \\
0.0066 \\
0.0061 \\
0.0057 \\
0.0053\end{array}$ & $\begin{array}{l}0.0034 \\
0.0030 \\
0.0027 \\
0.0025 \\
0.0023\end{array}$ & $\begin{array}{l}0.0078 \\
0.0072 \\
0.0068 \\
0.0063 \\
0.0059\end{array}$ & $\begin{array}{l}0.00021 \\
0.0018 \\
0.0016 \\
0.0014 \\
0.0013\end{array}$ & $\begin{array}{l}0.0084 \\
0.0079 \\
0.0073 \\
0.0069 \\
0.0064\end{array}$ & $\begin{array}{l}0.0006 \\
0.0004 \\
0.0003 \\
0.0002 \\
0.0001\end{array}$ & $\begin{array}{l}4.6 \\
4.7 \\
4.8 \\
4.9 \\
5.0\end{array}$ \\
\hline
\end{tabular}


ALPHA $=1.75$

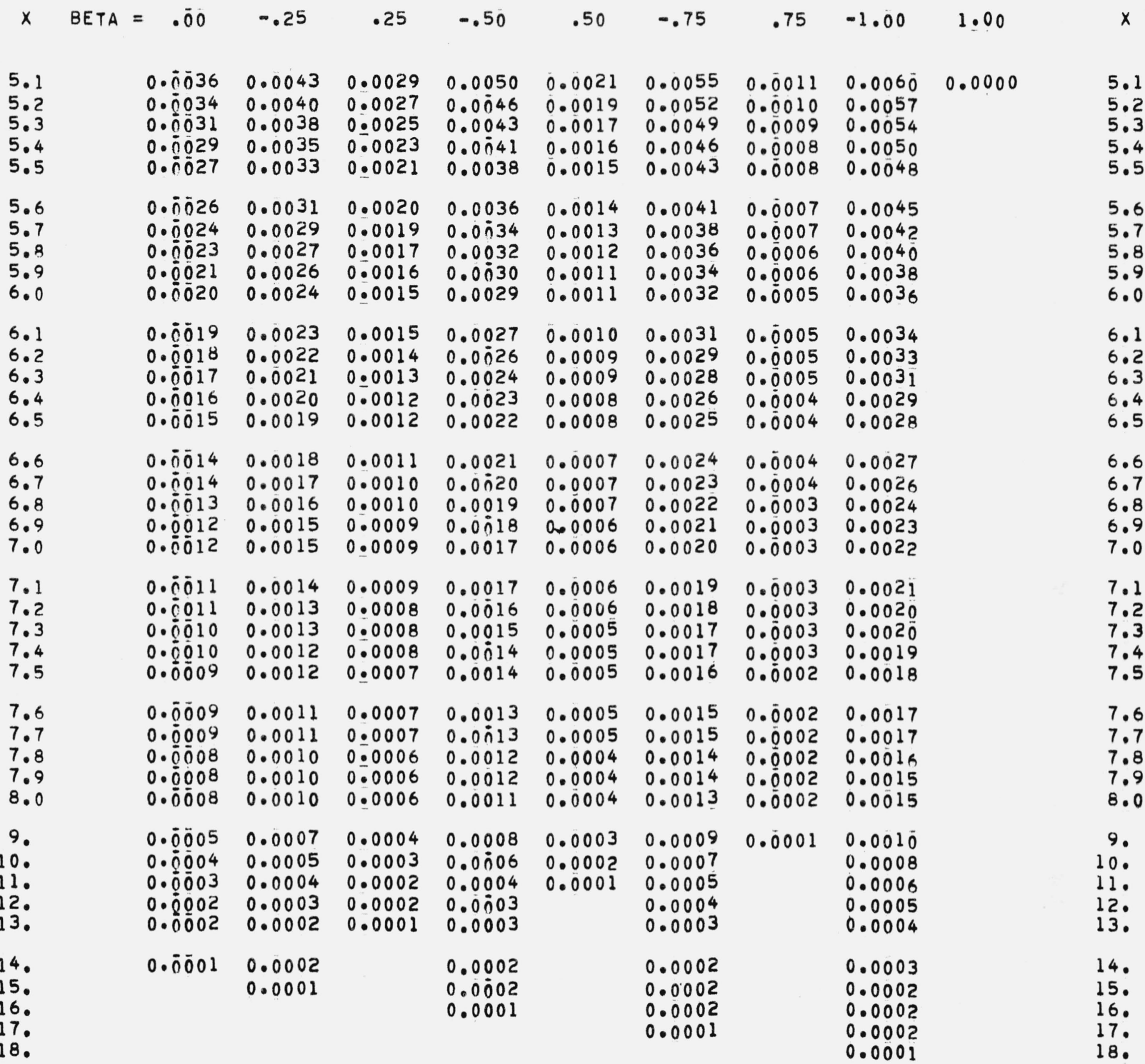




\section{$P(X ; 2, B E T A)$}
. ว.

.

.1

.3

.4

.5

.5

.7

.8

.9

$\begin{array}{lr}0 . & 02829 \\ 1 . & .21970 \\ 2 . & .10378 \\ 3 . & .02973 \\ \text { 4. } & .00517 \\ 5 . & .00054 \\ 6 . & 0.00003\end{array}$

0.20139
0.2046
0.9367
0.2503
$0.042 ?$
$0.0404 ?$
0.00003

0.27929 0.19601 0.08412 0.02141 0.000343 0.00033 0.00002

\subsection{2} 0.18489 v. 7517 .. 1854 0.00277 0.00025 0.00001

\subsection{3} 0.17282 0.06684

(.).ก1568

0.00223

0.00019 0.00001

\subsection{0} 0.16073 0.05913 0. 01319 0.00179 0.00015

\subsection{2} 0.14875 0.05275 0.01105 0.00142 0.00011

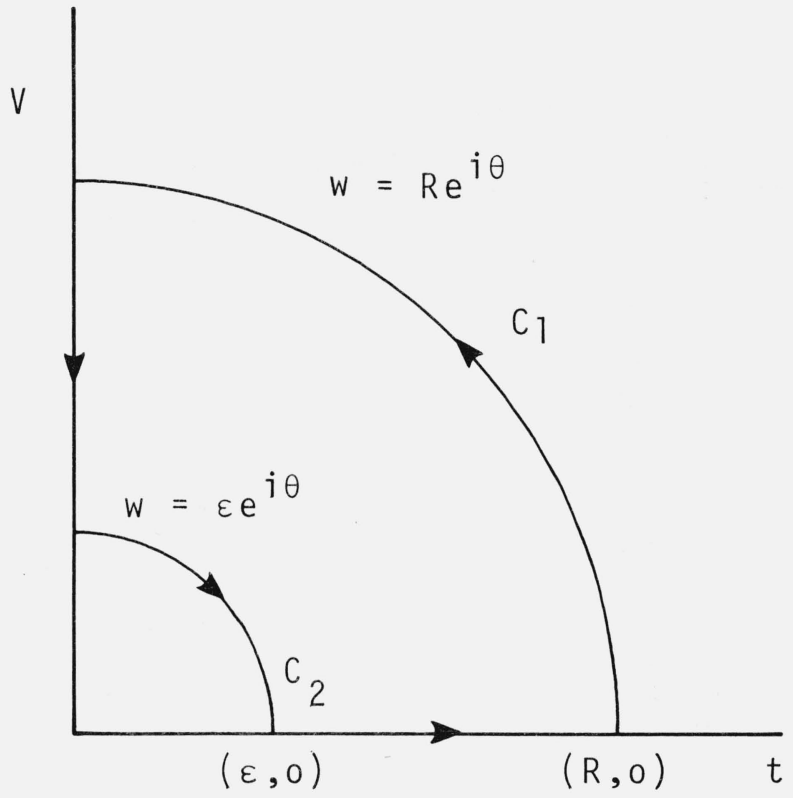

Figure 1. Contour for $\mathrm{p}_{2}(\mathrm{x} ; \alpha, \beta)$. 


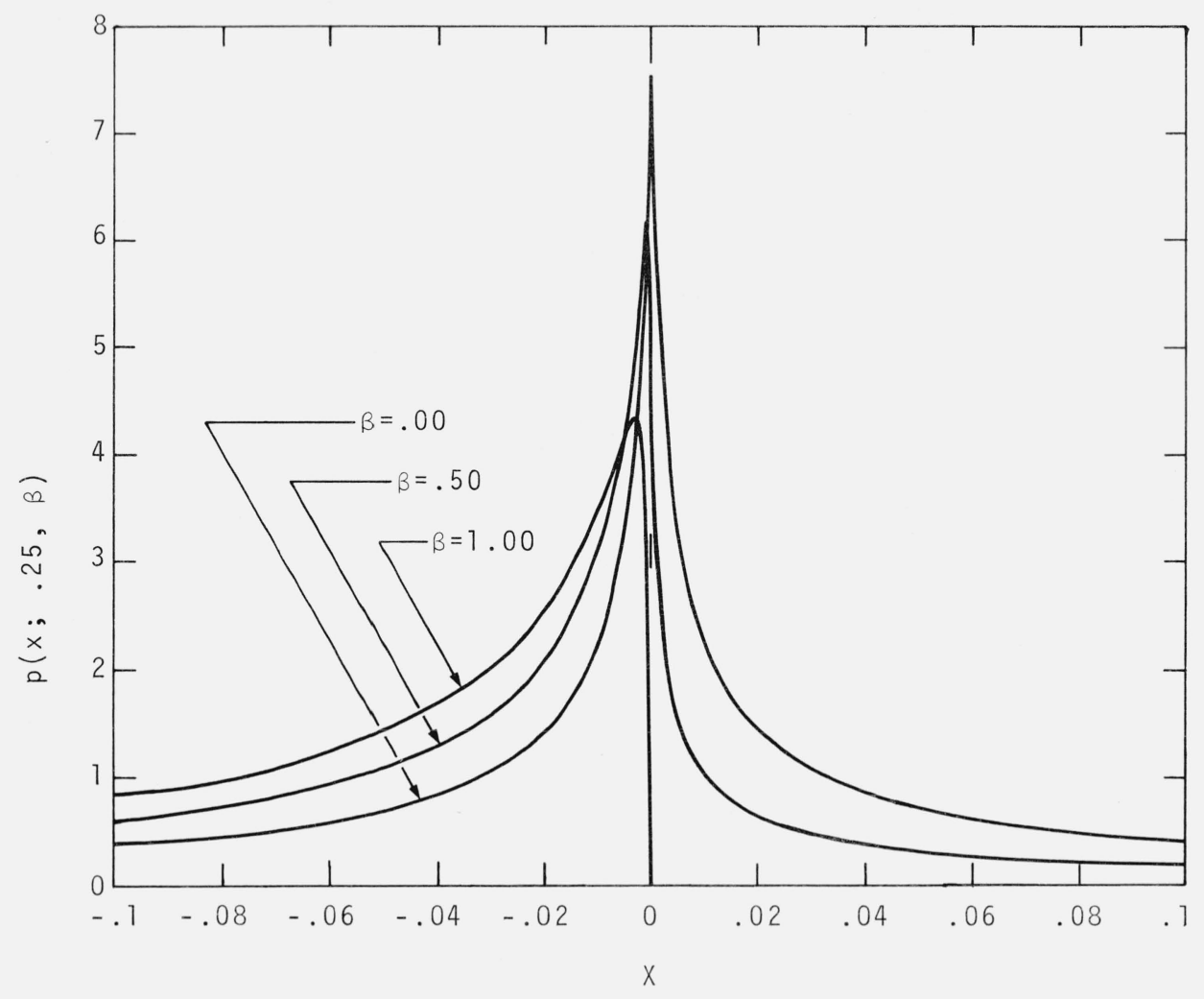

FigURE 2. Stable probability density functions $\mathrm{p}(\mathrm{x} ; \alpha, \beta)$ for $\alpha=0.25$.

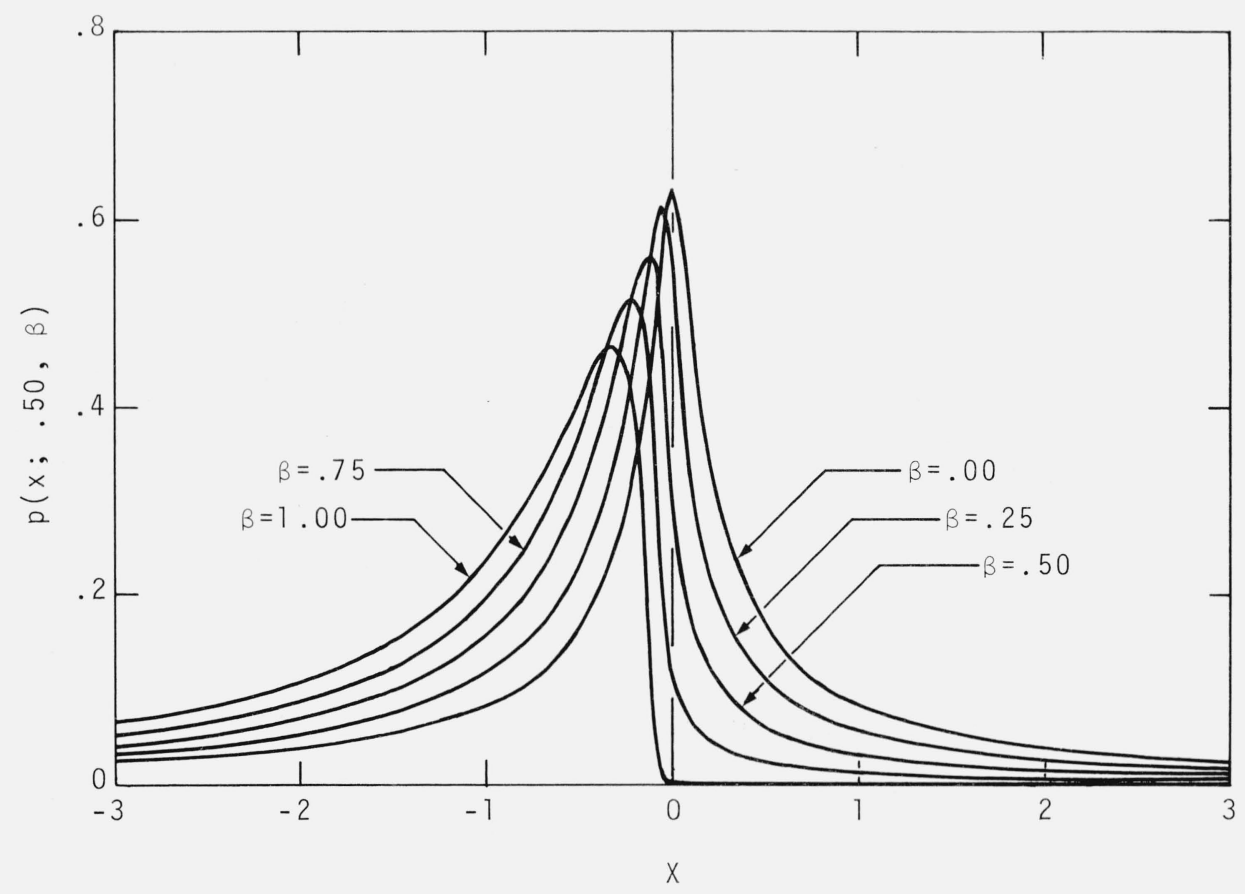

FigURE 3. Stable probability density functions $\mathrm{p}(\mathrm{x} ; \alpha, \beta)$ for $\alpha=0.50$. 


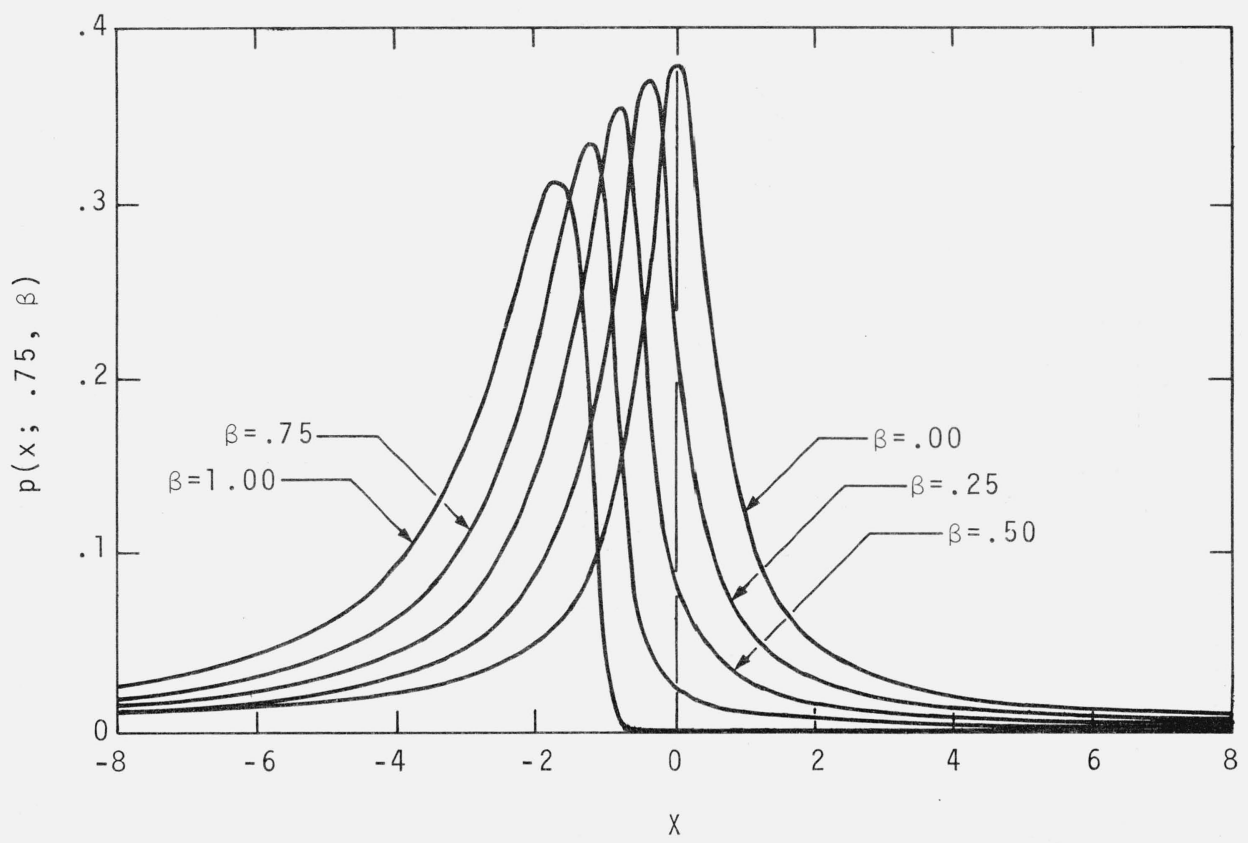

Figure 4. Stable probability density functions $\mathrm{p}(\mathrm{x} ; \alpha, \beta)$ for $\alpha=0.75$.

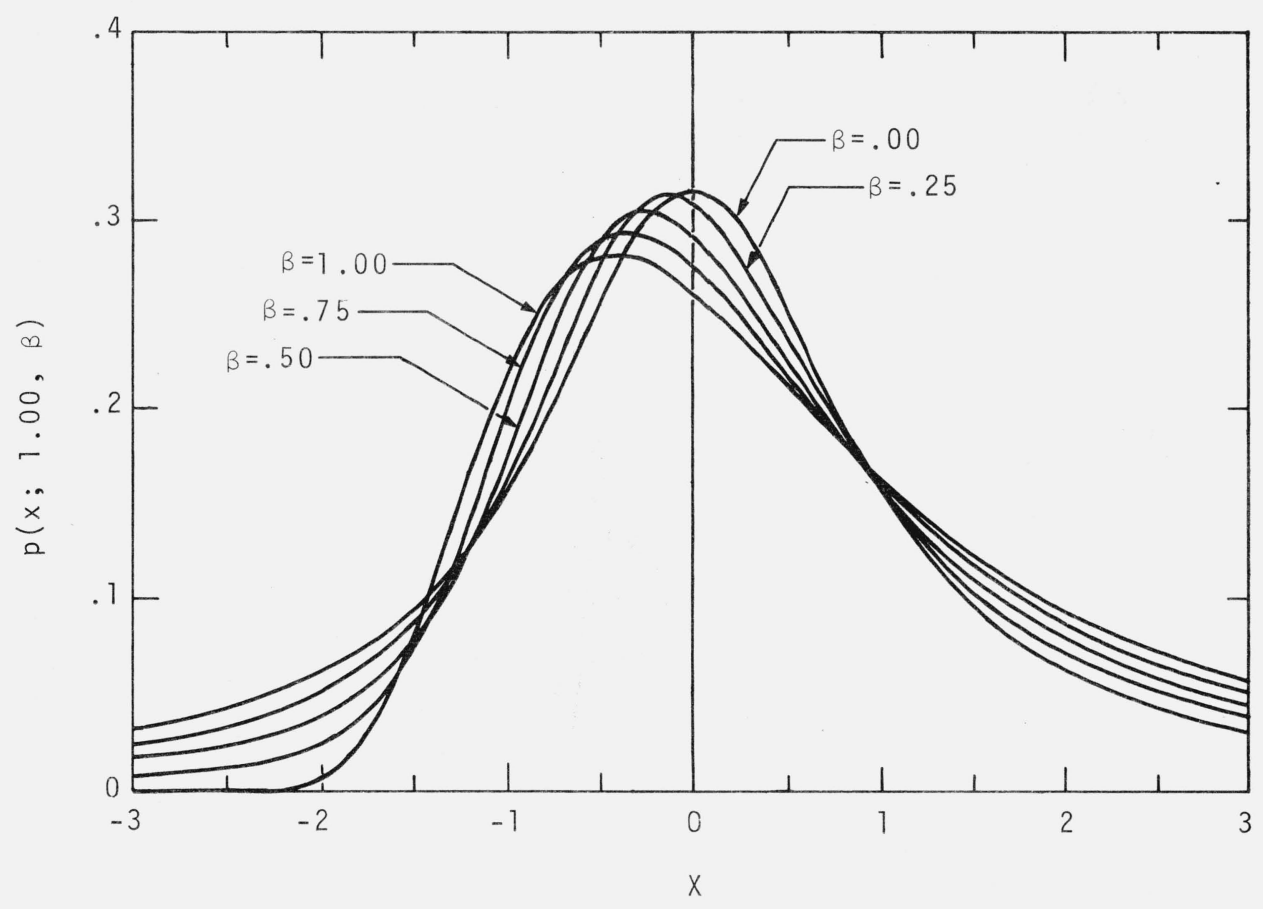

Figure 5. Stable probability density functions $\mathrm{p}(\mathrm{x} ; \alpha, \beta)$ for $\alpha=1.00$.

Note reversal of location of heavier tail from that for $\alpha \neq 1$. 


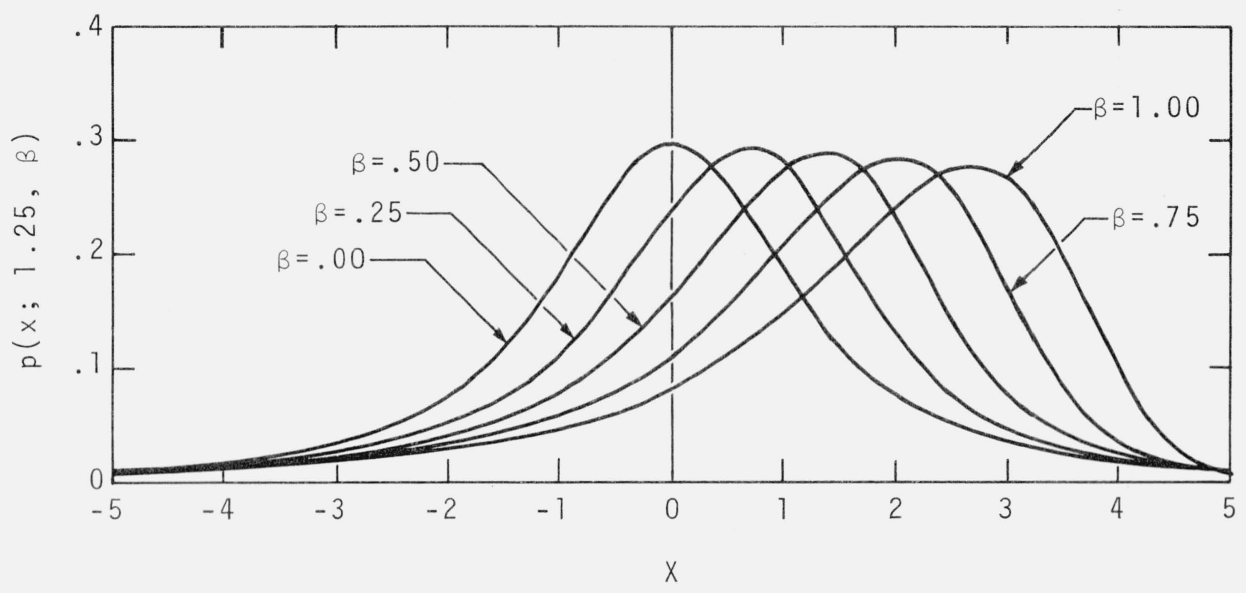

Figure 6. Stable probability density functions $\mathrm{p}(\mathbf{x} ; \alpha, \beta)$ for $\alpha=1.25$.

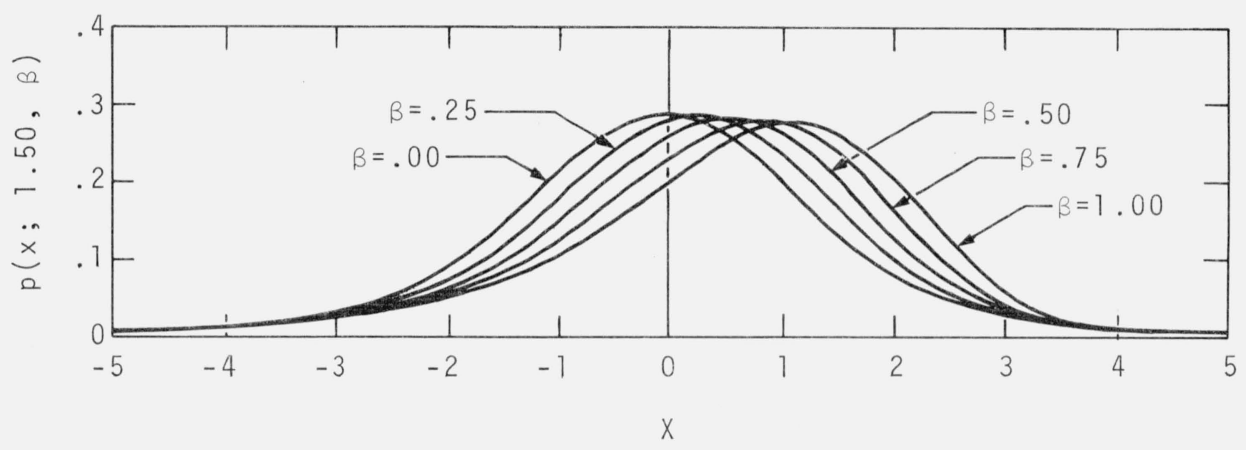

FIGURE 7. Stable probability density functions $\mathrm{p}(\mathbf{x} ; \alpha, \beta)$ for $\alpha=1.50$.

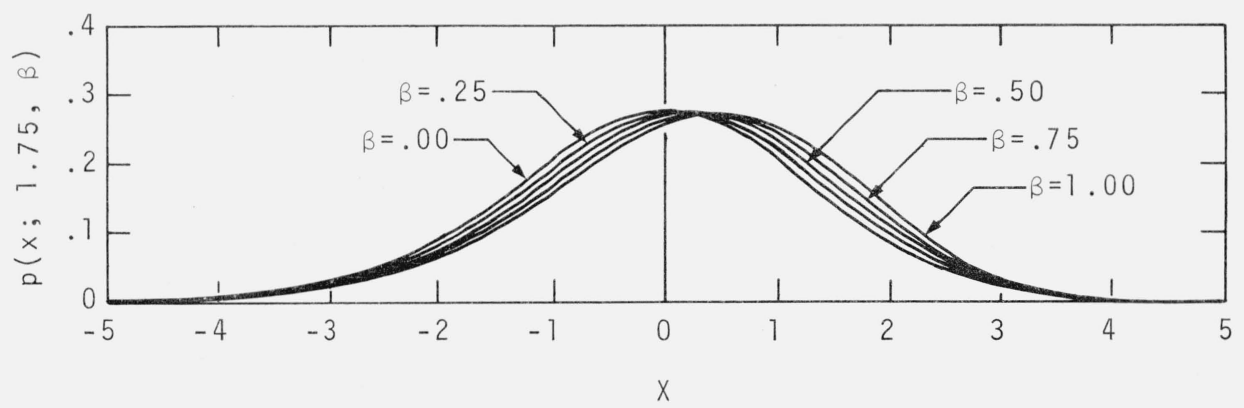

Figure 8. Stable probability density functions $\mathrm{p}(\mathrm{x} ; \alpha, \beta)$ for $\alpha=1.75$. 


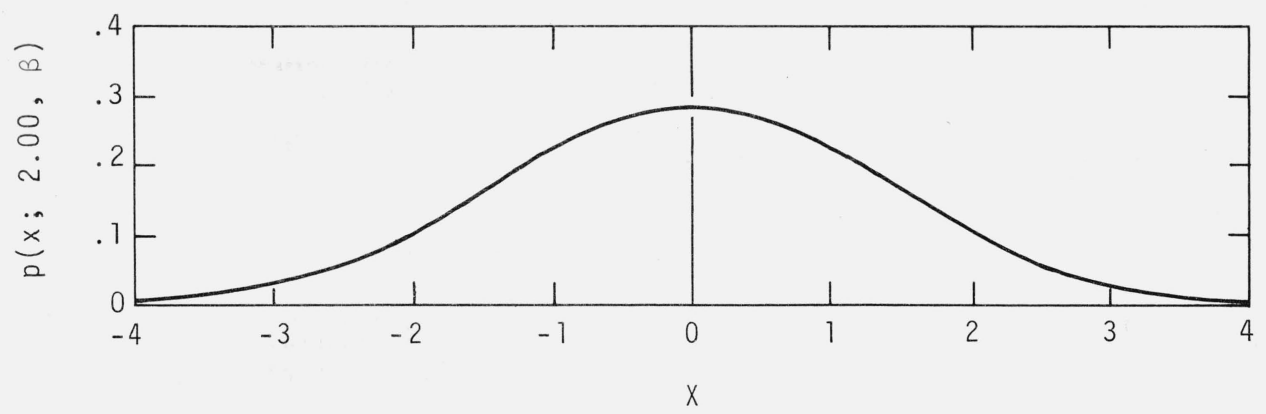

FiguRE 9. Stable probability density function $\mathrm{p}(\mathrm{x} ; \alpha, \beta)$ for $\alpha=2$ (the normal pdf).

(Paper 77B3\&4-390) 